\title{
Feeding the Critically III Obese Patient
}

\author{
Dr Paul Secombe \\ Master of Clinical Science \\ Joanna Briggs Institute \\ Faculty of Health and Medical Sciences \\ The University of Adelaide \\ Australia
}

2017 


\section{Contents}

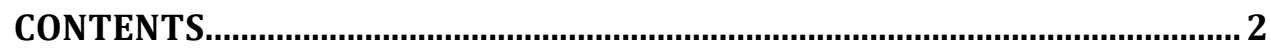

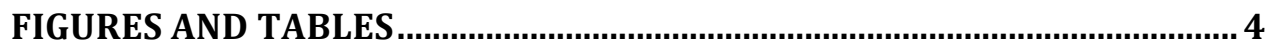

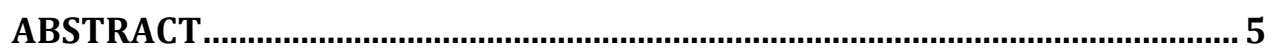

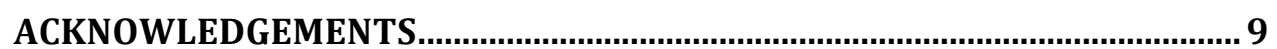

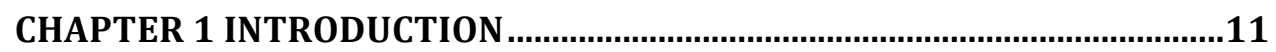

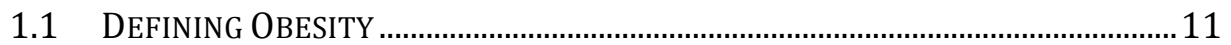

1.1.1 Defining 'Obesity' - The Historical Context..........................................12

1.1.2 The Build and Blood Pressure Study - a Shaky Foundation.............13

1.1.3 Ideal Body Weight and Body Mass index - the Flaws ........................16

1.1.4 Obesity - A Flawed but Pragmatic Definition.......................................21

1.2 OBESITY EPIDEMIOLOGY ..................................................................................... 22

1.2.1 Prevalence of Obesity and its Effect on Health Care Costs ................22

1.2.2 Prevalence of Obesity in the Intensive Care Unit.................................23

1.3 NUTRITION IN THE INTENSIVE CARE UNIT .......................................................26

1.3.1 Determining Energy Expenditure …………….....................................30

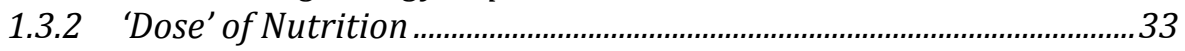

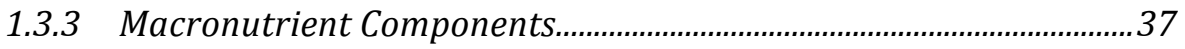

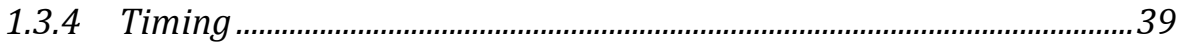

1.3.5 Non-Nutritional Benefits of Enteral Feeding ......................................40

1.4 NUTRITIONAL THERAPY FOR THE CRITICALLY ILL OBESE PATIENT .................. 42

1.5 SOURCES OF VARIABILITY IDENTIFIED IN THE LITERATURE ……………….......5 50

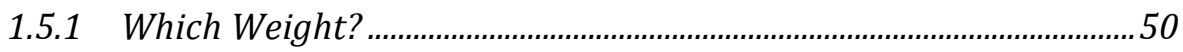

1.5.2 The Obesity Paradox ………….................................................................5

1.5.3 Dedicated Nutritional Support Services................................................55

1.5.4 Supplemental Parenteral Nutrition .......................................................56

1.5.5 Assessment of Nutritional Reserves/Risk of Malnutrition .................57

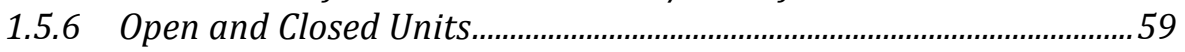

1.6 SIGNIFICANCE OF THE REVIEW...........................................................................6 60

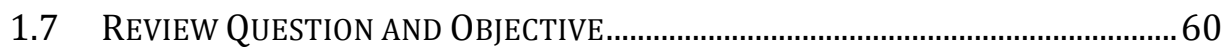

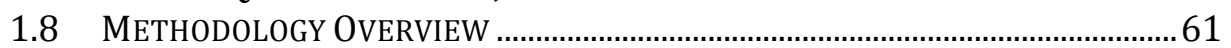

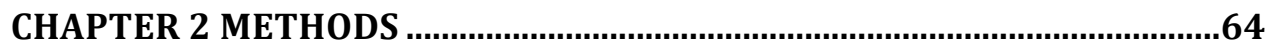

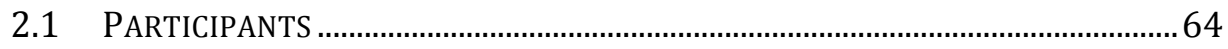

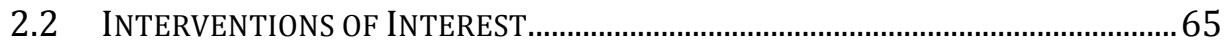

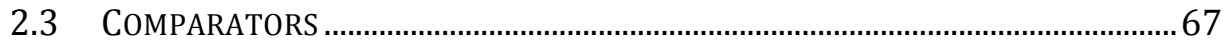

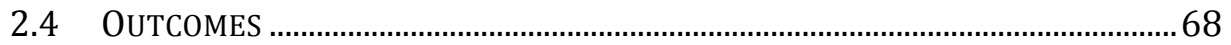

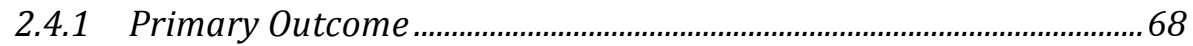

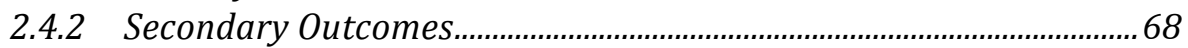

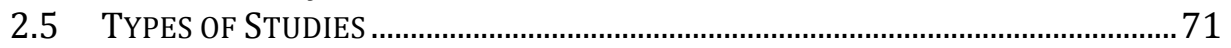

2.6 REVIEW METHOD ……………………………………………………....... 71

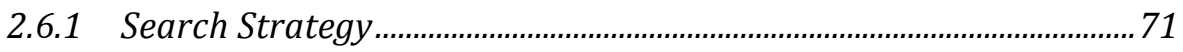

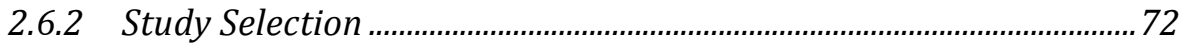

2.6.3 Assessment of Methodological Quality ………...................................... 72

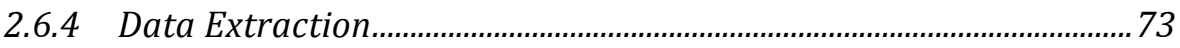

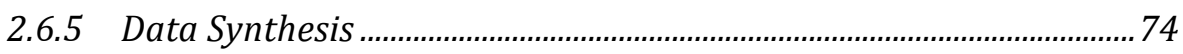

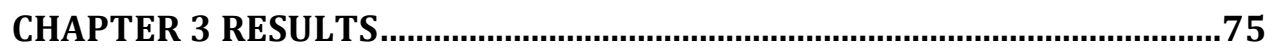

3.1 SEARCHING AND STUDY SELECTION................................................................ 75 
3.2 METHODOLOGICAL QUALITY OF THE INCLUDED STUDIES ..................................79

3.3 CHARACTERISTICS OF THE INCLUDED STUDIES....................................................80

3.3.1 Geographical Location of the Included Studies.................................. 80

3.3.2 Study Populations of the Included Studies .......................................... 84

3.3.3 Study Design and Interventions of the Included Studies................... 87

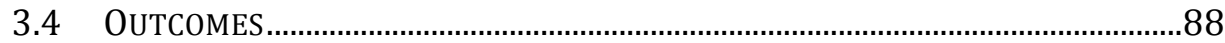

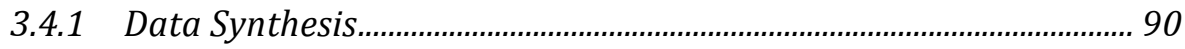

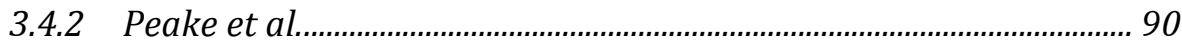

3.4.3 Petros et al.................................................................................... 97

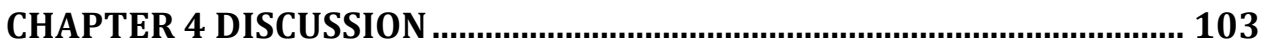

4.1 RESULTS IN CONTEXT ...............................................................................103

4.2 LiMITATIONS OF RESEARCH IN THE FIELD .....................................................108

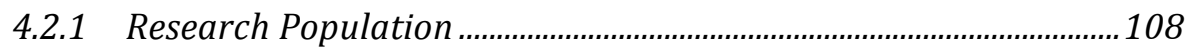

4.2.2 Use of Observational Data ……...........................................................109

4.2.3 Uncounted calories ................................................................................110

4.2.4 The Assumption of Constant Metabolic Demand...............................111

4.2.5 The Use of Ideal Body Weight ...........................................................112

4.3 LimitaTIONS OF THE SYSTEMATIC REVIEW ………………………………......112

4.4 IMPLICATIONS FOR PRACTICE ..........................................................................116

4.5 IMPLICATIONS FOR FUTURE RESEARCH........................................................117

4.6 CONCLUSIONS.........................................................................................120

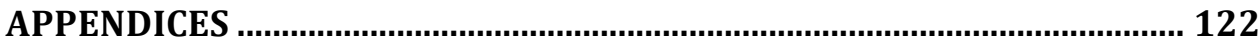

APPENDIX 1 SYSTEMATIC REVIEW PROTOCOL ……………………………………....122

APPENDIX 2 SEARCH STRATEGY ...............................................................................136

APPENDIX 3 MASTARI CRITICAL APPRAISAL TOOL ……………………..................141

3.1 Randomised Control / Pseudo-randomised Trial ...................................141

3.2 Cohort (with control)/Case-Controlled Series ..........................................152

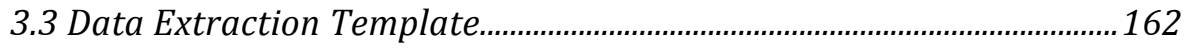

APPENDIX 4 CORRESPONDENCE ………………………….......................................164

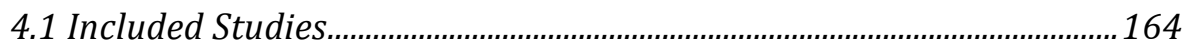

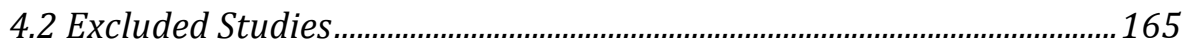

APPENDIX 5 EXCLUDED STUDIES................................................................................170

5.1 Following Review of Full Text..................................................................170

5.2 Following Correspondence with Author ................................................171

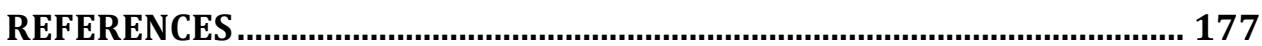




\section{Figures and Tables}

FIGURE 1: RELATIONSHIP BETWEEN BODY MASS INDEX AND MEASURED PERCENTAGE BODY FAT.

FIGURE 2: ALL CAUSE MORTALITY VERSUS BODU MASS INDEX FOR MALES AND FEMALES

FIGURE 3: HAZARD RATIOS FOR ALL CAUSE MORTALITY VERSUS BODY MASS INDEX

FiguRE 4: PUBMED PUBLICATIONS BY YEAR.................................................42

FIGURE 5: IDEAL BODY WEIGHT BY COMMONLY USED FORMULAE AGAINST HEIGHT .53

FIGURE 6: BODY MASS INDEX AGAINST HEIGHT FOR IDEAL BODY WEIGHT BY COMMON FORMULAE .

FIGURE 7: PRISMA FLOW DIAGRAM

FIGURE 8: MORTALITY ENDPOINTS FROM DATA PROVIDED BY PEAKE...........94

FiguRE 9: SECONDARY ENDPOINTS FROM DATA PROVIDED BY PEAKE...........95

FIGURE 10: FURTHER SECONDARY ENDPOINTS FROM DATA PROVIDED BY

$$
\text { PEAKE. }
$$

FIGURE 11: MORTALITY FROM DATA PROVIDED BY PETROS 100

FigURE 12: SECONDARY ENDPOINTS PROVIDED BY PETROS 101

FIGURE 13: POWER CALCULATION

TABLE 1: CLINICAL QUESTIONS ADDRESSED IN ASPEN GUIDELINES ............................47

TABLE 2: CRITICAL APPRAISAL USING THE JBI-MASTARI TOOL .................................80

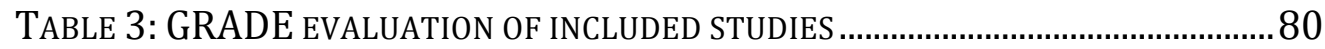

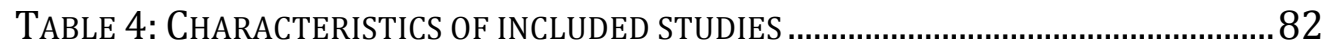

TABLE 5: OBESE GROUP DEMOGRAPHIC DATA FROM DATA PROVIDED BY

PEAKE. .85

TABLE 6: OBESE GROUP DEMOGRAPHIC DATA FROM DATA PROVIDED BY

PETROS.

TABLE 7: REVIEW ENDPOINTS THAT COULD BE ASCERTAINED

TABle 8: ObESE GROUP OUTCOME DATA FROM DATA PROVIDED BY PEAKE. 92

TABle 9: OBESE GROUP OUTCOME DATA FROM DATA PROVIDED BY PETROS 


\begin{abstract}
Obesity is increasing in prevalence. Supporting the critically ill obese patient will become an increasingly important skill in the intensivist's armamentarium, and enteral nutritional therapy forms a cornerstone of this support. Despite this, neither an optimal total caloric goal nor the macronutrient components of a nutritional strategy for the critically ill obese patient has been established. The objective of the research described in this thesis was to systematically review the best available evidence describing nutritional strategies that target energy and protein delivery to reduce morbidity and mortality in the obese patient who is critically ill.
\end{abstract}

A search for published and grey literature was conducted across a range of electronic databases including PubMed, Embase, CINAHL, ProQuest Dissertations and Theses and Conference Papers Index, Cochrane Central Trials Register, and the WHO Clinical Trials Register, and was supplemented by a hand search of the reference lists of study publications retrieved. Studies were selected for inclusion and subsequent assessment of methodological quality if they evaluated the clinical effect of targeting calorie and protein delivery in critically ill obese adult patients. In order to identify studies representative of critically ill patients, only studies conducted in intensive care units and in which $\geq 50 \%$ of recruited patients were receiving mechanical ventilation for $\geq 24$ hours were eligible, while 
the World Health Organization definition (body mass Index $\geq 30 \mathrm{~kg} / \mathrm{m}^{2}$ ) was used to classify obese patients.

The search yielded 1000 unique records that were screened for eligibility. After removal of duplicates and screening of titles and abstracts, 18 studies were retrieved in full and underwent full text screening, of which six were excluded. Of the remaining 12 studies, only one recruited an obese population (albeit with an alternative definition of obesity). The remaining 11 studies identified recruited ICU patients without stratifying for, or targeting a particular weight, and therefore a proportion of whom would be expected to be obese. Contact was attempted with all corresponding authors to request access to the obese subgroup data for each study identified. Replies were received from eight authors representing 10 studies. Only two were able to provide raw data regarding the obese patients recruited to their studies; however, heterogeneity in research design of these two studies precluded meaningful data synthesis.

The augmented versus routine approach to giving energy (TARGET) study compared two different enteral formulae with different caloric density, but with an identical protein component, the difference in caloric density being made up of fat and carbohydrate. The control arm targeted 19.9 $\mathrm{kcal} / \mathrm{kg} /$ day, while the intervention arm targeted $29.3 \mathrm{kcal} / \mathrm{kg} /$ day. In the second study for which raw data were available, patients were randomised to either a eucaloric arm in which $100 \%$ of their estimated daily energy requirements were targeted ( $13 \mathrm{kcal} / \mathrm{kg} / \mathrm{day})$, or to a hypo- 
caloric arm in which $50 \%$ of their estimated daily energy requirements were targeted $(8.8 \mathrm{kcal} / \mathrm{kg} / \mathrm{day})$. There was neither a signal for benefit nor for harm in the primary outcome of interest (mortality), nor in any of the secondary outcomes for which data were available (length of stay, nosocomial infection, duration of mechanical ventilation, gastro-intestinal intolerance or insulin requirement).

In conclusion, there is a paucity of data supporting any approach to nutritional therapy for the critically ill obese patient. The optimal calorie and protein target remains elusive and further robust primary research is urgently required. 


\section{Declaration}

I, Dr Paul Secombe, certify that this work contains no material that has been accepted for the award of any other degree or diploma in any university of any other tertiary institution, and, to the best of my knowledge and belief, contains no material previously published or written by any other person, except where due reference has been made in the text. In addition, I certify that no part of this work will, in the future be used in a submission for any other degree or diploma in any university or other tertiary institution without the prior approval of the University of Adelaide and where applicable, any partner institution responsible for the joint award of this degree.

I acknowledge the support I have received for my research through the provision of an Australian Government Research Training Program Scholarship.

I give consent to this copy of my thesis, when deposited in the University Library, being available for loan and photocopying, subject to the provisions of the Copyright Act, 1968.

I also give permission for the digital version of my thesis to be made available on the web, via the University's digital research repository, the Library catalogue and also through web search engines, unless permission has been granted by the University to restrict access for a period of time

Dr Paul Secombe

28 February 2017 


\section{Acknowledgements}

Completion of this thesis would not have been possible with the support of a number of people to whom I am indebted and would like to acknowledge and thank.

Firstly, my supervisors, Associate Professor Edoardo Aromataris and Professor Marianne Chapman, for their advice and guidance. Their patience and attention to detail have been exemplary, often re-directing my attention back to the topic when it threatened to follow other interesting pathways in the story.

The academic and support staff of the Joanna Briggs Institute (JBI) who nourished the intellectual and academic rigour required to successfully complete this thesis. To Ms Siang Tay who undertook professional copyediting of the thesis in accordance with the Australian Standards for Editing Practice (specifically sections $\mathrm{D}$ and $\mathrm{E}$ ) in a timely manner. Also, my fellow JBI students who were a source of inspiration, in particular, Dr Simon Harley who kindly undertook the secondary appraisals necessary for the systematic review.

To my partner, Rebekah, my son, Henry, and our as yet unborn second child, thank you for allowing me to spend time writing this thesis when I could have been spending time with you, my family. 
Finally, to my intensivist colleagues who spend their days and nights caring for the critically ill. In particular, Dr Penny Stewart who has been a persistent and constant mentor, and Associate Professor Adam Deane who both inspired an interest in research and provided important early advice. 


\section{Chapter 1 Introduction}

This chapter briefly introduces the historical context from which the definition of obesity evolved and from which obesity epidemiology is now described. The burgeoning obesity epidemic is explored within the context of critical illness. The literature informing the delivery of nutrition to the critically ill patient is summarised before exploring the role of nutrition in the critically ill obese patient specifically, providing the framework for the introduction of the research question.

\subsection{Defining Obesity}

For most of human history, corpulence has been considered a sign of good health and affluence, and adipose reserves probably conferred a survival advantage during feast-famine cycles. ${ }^{(1)}$ At a simple physiological level the deposition of fat occurs due to an imbalance between caloric intake and expenditure. This process is confounded by complex interactions between genetics, epigenetic influences, the environment, economics, market forces and individual behaviours. ${ }^{(2-6)}$ During the late $19^{\text {th }}$ and early $20^{\text {th }}$ centuries, however, it was recognised that the excessive deposition of fat reserves, a phenomenon subsequently labelled "obesity", predisposes one to both excess morbidity and mortality.

The recognition that excessive adipose tissue deposition predisposes one to excess early mortality highlighted the importance of developing a universally accepted definition of obesity and increased the impetus to 
derive an index of relative body weight. ${ }^{(7,8)}$ It was argued that such an index would be useful since the proportion of body weight and height should indicate something about "... 'build' or shape and about obesity and fatness" ${ }^{\prime 9) p .329}$ The underlying assumption upon which this supposition is based is that an "ideal body weight" (IBW) exists for people of a particular height. The need for an index that linked an easily measurable variable (such as height) with body build had long been recognised in the anthropometric sciences and was vigorously pursued by the insurance industry after actuaries reported increased mortality in their overweight policyholders. ${ }^{(1,7,8)}$ An appreciation of the historical context from which the definitions of obesity have evolved is necessary to understand the existing flaws in these definitions.

\subsubsection{Defining 'Obesity' - The Historical Context}

Adolphe Quètelet, a $19^{\text {th }}$ century statistician, was the first to recognise a relationship between height and weight. ${ }^{(10)} \mathrm{His}$ observations led to the Quètelet Index, recognising that, apart from growth spurts soon after birth and during puberty, weight increased as the square of height. ${ }^{(1)}$ Following his observations, a range of metrics based around the ratio of weight to height have been suggested, all which assume that an IBW for a particular height exists. Some of these included the use of $130 \%$ of IBW, the "ponderal index", and the Rohrer index. ${ }^{(9,11)}$ A seminal 1972 article concluded, however, on the basis of empirical measurements carried out on 7424 healthy (almost exclusively white) men in 12 cohorts across five countries (most of which were Anglicised), that the ratio of weight in 
kilograms $(\mathrm{kg})$ to height in metres $(\mathrm{m})$ squared $\left(\mathrm{kg} / \mathrm{m}^{2}\right)$, termed the body mass index (BMI), gave the best index of relative weight. ${ }^{(9)}$ Much of the data on which this conclusion was based was drawn from the standard height-weight tables that give the weight at which mortality is lowest (subsequently generally taken to be the IBW) published by the life insurance industry on the basis of the "Build and Blood Pressure Study". ${ }^{(7-9)}$ Given the importance of this study in deriving IBW, and subsequently in the justification of BMI, it is worthy of critical analysis.

\subsubsection{The Build and Blood Pressure Study - a Shaky Foundation}

The "Build and Blood Pressure Study", published in 1959 by the Society of Actuaries, represents 25 years of mortality data collected by US insurance companies and undertaken for underwriting purposes. ${ }^{(8)}$ This large epidemiological study built on an earlier intra-company investigation of mortality among insured lives according to build (or body size) that covered the years $1885-1927 .{ }^{(7,8)}$ The introduction to the study notes that "(d)uring this time mortality from the infectious diseases... has declined sharply... In sharp contrast the mortality from heart and other circulatory diseases - conditions associated with overweight and hypertension - has shown very little change" ${ }^{\prime(8) p .1} \mathrm{~A}$ number of individual insurance companies had already identified an association between overweight policyholders and mortality, and as a result "the committee on Mortality of the Society of Actuaries invited all United States and Canadian companies ... to contribute their experience to an investigation of mortality according to build and blood pressure" ${ }^{(8) p .1}$ 
The details of nearly five million policyholders were included in the build study, of whom 133000 had died during the study period $1935-1953$, a mortality rate of $2.7 \%$. However, included amongst the exclusion criteria listed on page 3 of the publication was "(p)olicies issued on the lives of persons resident outside the United States or Canada". ${ }^{(8) p .3}$ As a result, policyholders from whom these data were collected were almost exclusively white middle and upper class American and Canadians. ${ }^{(8)}$ Furthermore, the detailed analysis was undertaken on a subset of policyholders (290 000 men and 70000 women). Height was measured while policyholders were in their shoes, and weight measured while in their "indoor clothing", the assumption being that the extra height due to shoes would be offset by the extra weight from "indoor clothing". Adding further to the potential confounders is that a proportion of policyholders had their weight and height estimated, rather than measured approximately $20 \%$ on the basis of a post hoc audit of $2 \%$ of the sample. ${ }^{(8)}$ This post hoc audit also revealed that the weight of policyholders who were actually weighed was, on average, greater than that of policyholders who had estimated their weight, leading the authors to conclude that it was likely that policyholders systematically underestimated their own weight. ${ }^{(8)}$ From these data, standard weight-height tables were produced. These standard weight-height tables purport to demonstrate the weight for the height at which the mortality rate is lowest at each octile of age in this demographic, and which has been subsequently generalised to be an IBW. Finally, these tables were used to justify the use of the metric 
"weight on height squared" $\left(\mathrm{kg} / \mathrm{m}^{2}\right)$ as the best measure of relative weight. ${ }^{(8,9)}$

A number of formulae, based loosely on data from the Build and Blood Pressure Study ${ }^{(8)}$ and which as a result bear uncanny similarities, have been devised to calculate IBW, despite the lack of clarity around what this term actually means. The most commonly used is a formula devised by Devine to describe gentamicin pharmacokinetics. ${ }^{(12)}$ However, it later became apparent that Devine's formula was based on estimates provided by his mentor, presumably from the Build and Blood Pressure Study and not on empirical measures. ${ }^{(13)}$ Another common formula is the Hamwi equation, which works on the assumption that a woman five feet tall weighs exactly 100 pounds and that a man who is five feet tall weighs exactly 106 pounds, also relying on data from the Build and Blood Pressure Study. ${ }^{(8,14)}$

There are a number of potential flaws in using data from the Build and Blood Pressure Study as the basis for both IBW and defining a "normal" BMI. Firstly, the population from which the data was derived were almost exclusively white middle and upper class North Americans. Secondly, there was a real risk of systematic bias since those with extremes of "build" (or blood pressure) were likely to be offered policies with higher premiums leading to a reduced uptake of life insurance. Thirdly, it is plausible that policyholders may have had multiple policies across a number of insurance companies. There was insufficient data to substantiate or refute this and neither was there any attempt to control 
for this possible confounding influence. Fourthly, there was a large disparity between the number of males and females who held life insurance during the study period. The authors themselves noted that the mortality tables generated from their data provided "an approximate measure of the mortality of men who are standard life insurance risks and overstates greatly the mortality of women who qualify for standard life insurance" ${ }^{(8) p .44}$ Finally, the goal of the study was not to define an IBW but to identify the weight for height that had the lowest mortality stratified by age octiles, a subtle but important distinction. Despite this, BMI has become the standard nomenclature for defining obesity, and IBW the standardised variable for use in a number of physiological formulae used in daily critical care practice, including ideal tidal volume and predictors of energy expenditure. ${ }^{(15)}$

\subsubsection{Ideal Body Weight and Body Mass index - the Flaws}

The use of BMI in defining obesity has further limitations, in addition to being potentially based on flawed processes from the Build and Blood Pressure Study. ${ }^{(8)}$ These are worth exploring in some depth given that the definition of obesity is largely built around IBW and BMI. Firstly, BMI fails to account for non-fat mass, which may include muscle, water or other non-adipose tissue (such as a foetus). This becomes startlingly obvious when the BMI of elite professional athletes is calculated. For example, Stephen Moore, the current captain of the Australian Rugby Union team (the Wallabies), has a BMI of $32.4 \mathrm{~kg} / \mathrm{m}^{2}$ on the basis of his $186 \mathrm{~cm} 112 \mathrm{~kg}$ frame. There is increasing interest in separating the "fat but fit" individual 
from the obese individual, since being "obese" but physically active may offset the detrimental health impacts of obesity. ${ }^{(16)}$ Body mass index fails to account for this, albeit that the concept of the "fat but fit" individual, like much of obesity literature, is controversial. ${ }^{(17)}$

Secondly, BMI suffers from a failure of scalability. This is to say that tall people are not scaled up little people. Quètelet himself recognised this, postulating that "(i)f man increased equally in all his dimensions, his weight at different ages would be as the cube of his height" and that the transverse growth of man is less than the vertical. ${ }^{(10) p .85}$ In short, mass increases to the third power of linear dimensions. The absence of a linear relationship was eloquently demonstrated by Jackson and colleagues in the Heritage Family Study (Figure 1). ${ }^{(18)}$

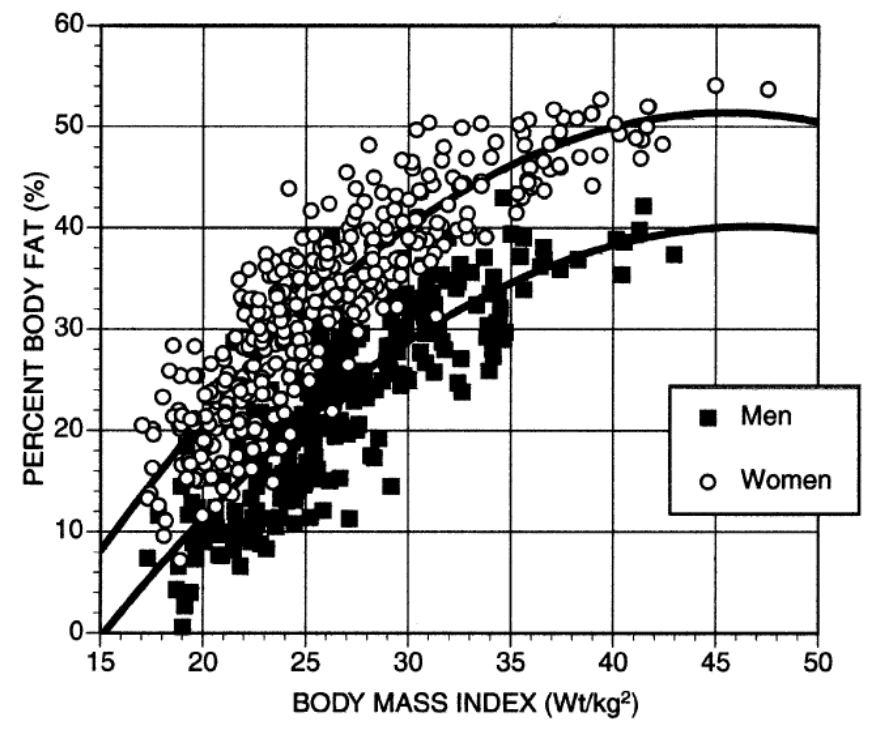

Figure 1: Relationship between BMI and measured percentage body fat for males and females demonstrating the non-linear relationship between percentage body fat and BMI Source: Jackson et al. (with permission) ${ }^{(18)}$ 
Thirdly, BMI does not distinguish adipose type and distribution. ${ }^{(19)}$ While total body fat is important, there is evidence that central adiposity (reflecting visceral fat) is more important as a risk factor for both cardiovascular disease and mortality. ${ }^{(20)}$

Fourthly, the "Quetelet Index" upon which BMI is based was derived from population data and application of this data to the individual may not be appropriate. As a result, the use of BMI for population based assessments examining broad trends in large groups of people and as a screening tool can be justified, but it lacks the sensitivity and specificity to be used as a diagnostic tool at the individual level. ${ }^{(18,21)}$

In addition, there is an assumption that an "optimal weight" exists, and that this is stable across the age range as well as over time. As discussed in Section 1.1.2, the basis of an "optimal weight" (or presumably the weight at which mortality is lowest) is based on epidemiological evidence that is both old and biased. There has been mixed evidence on the association between BMI and mortality. The Prospective Studies Collaboration undertook an analysis of 57 prospective studies (predominantly from Western Europe and North America) examining the relationship between $\mathrm{BMI}$ and all cause mortality. ${ }^{(22)}$ The results of combining nearly 90000 study participants recruited between 1975 and 1985 showed that BMI was associated with increased total mortality in all age strata from 35 to 89 years, but that this increased mortality was due to specific causes (ischaemic heart disease, stroke, diabetes and liver disease), suggesting that BMI was a good screening tool for other disease 
processes that ultimately resulted in death. ${ }^{(22)}$ It also highlighted the J shaped relationship that exists between BMI and mortality in which individuals with a low BMI $\left(<18 \mathrm{~kg} / \mathrm{m}^{2}\right)$ have a higher mortality risk than those with a BMI of $25-30 \mathrm{~kg} / \mathrm{m}^{2}$ (Figure 2).

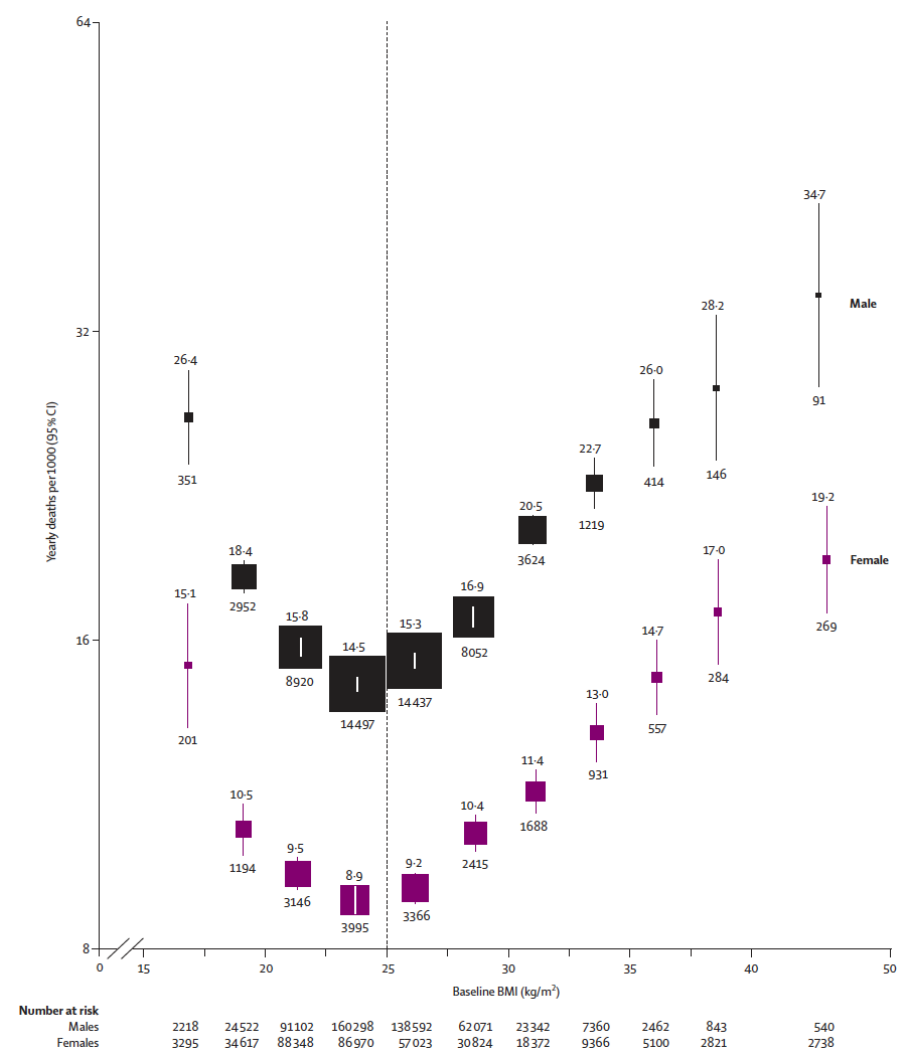

Figure 2: All cause mortality versus BMI for males and females demonstrating the increased mortality rate associated with both high and low BMI Source: The Prospective Studies Collaboration (with permission) ${ }^{(22)}$

In contrast, Flicker and colleagues combined two longitudinal studies (the Health in Men Study and the Australian Longitudinal Study of Women's Health) to specifically examine the association between BMI and all cause mortality in older individuals, finding that the BMI at which mortality was lowest was in the $25-29.9 \mathrm{~kg} / \mathrm{m}^{2}$ range, and that the mortality risk in individuals with class I obesity (BMI $30-34.9 \mathrm{~kg} / \mathrm{m}^{2}$ ) was similar to those in the normal range or those who had an "ideal" body weight. ${ }^{(23)}$ Again, the J- 
shaped relationship between $\mathrm{BMI}$ and mortality was evident, but the "IBW" had shifted to the right (Figure 3).

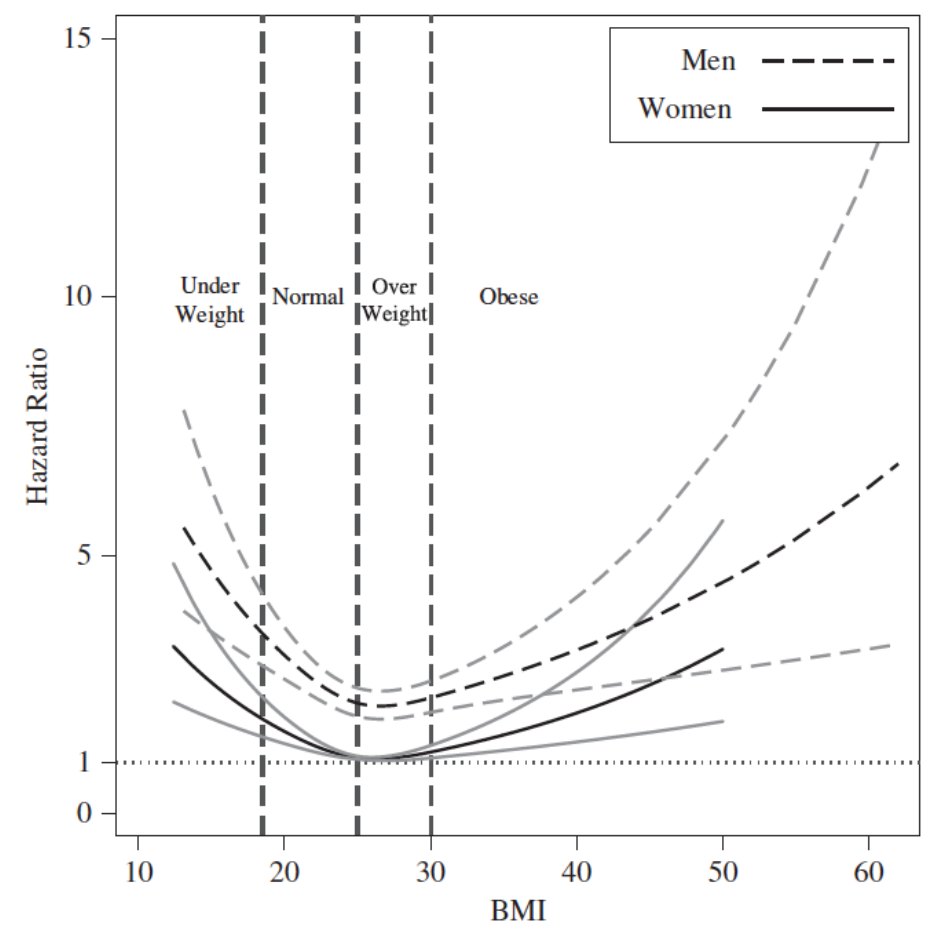

Figure 3: Hazard ratios for all cause mortality versus BMI for males and females 70

- 75 years of age demonstrating the right shift in the BMI at which mortality is lowest in an older cohort

Source: Flicker et al. (with permission) $)^{(23)}$

Furthermore, there is more recent evidence emerging that the association between $\mathrm{BMI}$ and mortality is not stable across time. A large Danish epidemiological study examined three cohorts spanning 30 years. ${ }^{(24)}$ The BMI associated with the lowest all cause mortality increased by $3.3 \mathrm{~kg} / \mathrm{m}^{2}$ over this period while the hazard ratio for all cause mortality associated with a BMI of greater than $30 \mathrm{~kg} / \mathrm{m}^{2}$ compared to a BMI of $18.5-24.9$ $\mathrm{kg} / \mathrm{m}^{2}$ decreased to 1.0 over the same period. ${ }^{(24)}$ This finding was robust and remained after controlling for a range of confounders, including age, sex, smoking status, alcohol consumption and income. Adding further to 
the evidence that BMI is not stable across time or age is the recent study by Thomson and colleagues who undertook a prospective cohort analysis within the Women's Health Initiative examining the relationship between $\mathrm{BMI}$ and mortality in 77000 woman. ${ }^{(25)}$ After adjustment for ethnicity, education, alcohol consumption and smoking, the hazard ratio for BMI of $25-30$ was less than 1 , while the hazard ratio for a BMI of $30-35$ was $1.01 .^{(25)}$

An interpretation of these data is that there has been an improvement in chronic disease management of those conditions that are associated with obesity, or that these data could throw further doubt on the veracity of $\mathrm{BMI}$ and IBW. Which of these two possibilities explains the outcomes observed in these observational studies cannot be determined; however, there is mounting evidence from other small observational studies of improved mortality, functional capacity, and slowed physical and cognitive decline in older adults at a BMI above the normal range. ${ }^{(26,27)}$ Finally, BMI is not universal across all ethnicities. ${ }^{(28,29)}$

\subsubsection{Obesity - A Flawed but Pragmatic Definition}

Despite these flaws, the American Medical Association, in recognising obesity as a disease in 2013 , defines obesity as a BMI $\geq 30 \mathrm{~kg} / \mathrm{m}^{2}$, despite a recommendation against this from the association's own Council on Science and Public Health. ${ }^{(30)}$ There has been a call from the (Australian) Committee of Presidents of Medical Colleges for Australia to follow the same path. ${ }^{(31)}$ The American Society of Parenteral and Enteral Nutrition 
(ASPEN) also recommend the use of BMI in defining obesity. ${ }^{(32)}$ Yet defining obesity in this way may be too simplistic, and, as evidenced by the controversy surrounding the American Medical Association's decision, a simple working definition of obesity remains elusive..$^{(9,19)}$

The World Health Organisation (WHO) offers an alternative definition in addition to using a BMI $\geq 30 \mathrm{~kg} / \mathrm{m}^{2}$ - the abnormal or excessive fat accumulation that may impair health. ${ }^{(33)}$ Although widely cited as a definition, this is difficult to interpret and apply without an associated empirical measure. ${ }^{(34)}$ As a result, and despite the limitations of using BMI, it has become the standard nomenclature and is widely used in the literature.

\subsection{Obesity Epidemiology}

\subsubsection{Prevalence of Obesity and its Effect on Health Care Costs}

International epidemiological studies demonstrate that the prevalence of obesity, as defined by a $\mathrm{BMI} \geq 30 \mathrm{~kg} / \mathrm{m}^{2}$, has risen over the last three decades. ${ }^{(33)}$ Current estimates are that there are nearly 2.1 billion people worldwide who are either overweight (BMI $\geq 25$ and $<30 \mathrm{~kg} / \mathrm{m}^{2}$ ) or obese $\left(\mathrm{BMI} \geq 30 \mathrm{~kg} / \mathrm{m}^{2}\right) .{ }^{(6,35)}$ Epidemiological studies demonstrate that this phenomenon is not exclusive to developed countries, although the rate appears to have plateaued in these countries, with prevalence increasing substantially in developing countries. ${ }^{(35)}$ Obesity is associated with a range of co-morbidities including cardiovascular disease, hypertension, diabetes mellitus, gallbladder disease, osteoarthritis, sleep apnoea and stroke. ${ }^{(6,36-}$ 39) 
In the United States, $35 \%$ of adults are obese, and obesity ranks as the $5^{\text {th }}$ leading cause of death, contributing to 3.4 million deaths in $2010 .{ }^{(36-38)}$ The cost of managing both obesity and the co-morbid diseases associated with and exacerbated by obesity is rising. The stimated annual expenditure in 2005 for obesity and obesity related complications was US\$190 million. ${ }^{(40)}$ Supporting this is observational data indicating that obese patients have $46 \%$ higher inpatient costs, $27 \%$ more outpatient visits and $80 \%$ higher pharmaceutical expenditure compared to their lean counterparts. ${ }^{(41)}$ Australian data from the 2011 census suggest that $28 \%$ of the population is obese. In some rural areas, the prevalence rises to $44 \%$, with indications that it is continuing to rise. ${ }^{(42-44)}$ Obesity is the second highest contributor to the burden of disease, behind dietary risks and ahead of smoking. ${ }^{(45)}$ While there are no comparable Australian data, it would be reasonable to assume that the health related costs of managing obesity, while lower than the US, are also higher than the health costs of lean individuals.

\subsubsection{Prevalence of Obesity in the Intensive Care Unit}

Managing the critically ill obese patient is more complex than managing their lean counterparts. There are few, if any, aspects of critical care that are not impacted by obesity. It alters the pattern of co-morbidities, impacts on functional status, increases the technical difficulties of management (vascular access, performing tracheostomy, pressure area care, and access to and the interpretation of radiological imaging), and modifies drug pharmacokinetics. ${ }^{(34)}$ 
Obesity is associated with a number of chronic medical conditions that involve most organ systems. There are increased cardiovascular risks, including concomitant hypertension, biventricular dysfunction or failure and death. ${ }^{(39,46)}$ Cardiac output increases by approximately $0.1 \mathrm{~L} / \mathrm{min} / \mathrm{kg}$ of fat to account for both the increased baseline oxygen requirement and to perfuse the additional mass, which in turn requires its own vascular supply, estimated to be 1.96 miles of neovascularisation for each $1 \mathrm{~kg}$ of adipose tissue. ${ }^{(46-50)}$ There is an increased risk of respiratory compromise due to concomitant obstructive sleep apnoea, restrictive lung disease, reduced functional residual capacity, and a need for higher mean airway pressures when using positive pressure ventilation. ${ }^{(46)}$ There is often hepatomegaly, usually as a result of fatty infiltration and altered fuel mobilisation in response to systemic inflammation. ${ }^{(32,51)}$

While it seems intuitive that the obese patient, with their increased risk of concomitant co-morbid disease states, may be at higher risk of requiring an intensive care unit (ICU) admission for critical illness, the evidence for this is mixed and probably confounded by inclusion, exclusion criteria and study population. For example, two recent nutritional studies conducted in a mixed ICU in Columbia recruited no patient with a $\mathrm{BMI} \geq 30 \mathrm{~kg} / \mathrm{m}^{2}{ }^{2} .52$, ${ }^{53)}$ In contrast, a large multi-national (Saudi Arabia and Canada), multicentre nutritional trial recruited a heterogeneous cohort in which the prevalence of obesity approached $50 \% .{ }^{(54)}$ Australian data are lacking, but Dennis and colleagues reporting the results of a single centre retrospective observational study found $33 \%$ of ICU admissions had a BMI $\geq 30 \mathrm{mg} / \mathrm{m}^{2}$, 
more than the Australian baseline prevalence of $28 \% .{ }^{(55,56)}$ Other trials conducted in the ICU have recruited samples in which the prevalence of obesity in the intensive care largely mirrors that of the general population. ${ }^{(57-60)}$

It may also seem intuitively plausible that mortality in the obese population requiring ICU admission for critical illness should be higher, given the range of associated co-morbidities, the associated pathophysiological features outlined above and the increased logistical difficulties involved in both diagnostic and therapeutic interventions. ${ }^{(34)}$ However, these data are also inconsistent. Some studies have suggested increased mortality. ${ }^{(61-64)}$ Others, however, show no effect or suggest a possible survival benefit. ${ }^{(58,65-68)}$ This phenomenon, where obesity seems to confer a survival benefit has been called the obesity paradox (Section 4.2.2).

Despite the conflicting results around mortality in the critically ill obese patent, the literature does indicate increased morbidity associated with obesity including increased infective complications, prolonged duration of mechanical ventilation, increased ICU and hospital length of stay (LoS), and increased risk of organ failure, resulting in greater resource allocation to this group of patients..$^{(32,55,61-63,69,70)}$ Given this, any intervention(s) that reduce the mortality and morbidity associated with a critical illness would be beneficial. 


\subsection{Nutrition in the Intensive Care Unit}

Providing nutrition to the critically ill patient is an accepted standard of care. ${ }^{(71,72)}$ This recognition is underpinned by a number of studies that have associated caloric deficit with morbidity and mortality in critically ill patients, as well as mechanistic data derived from normal physiology. ${ }^{(57,73-}$

${ }^{81)}$ There is universal acceptance that the enteral route is the preferred route of delivery for a number of reasons, including cost as well as the non-nutritional benefits that derive from delivery of substrate to the gut (Section 1.3.5). ${ }^{(32,82-84)}$ For this reason, this thesis focuses on regimens that preferentially utilise the enteral route of nutritional delivery. In doing so, it is accepted that tolerance for enteral nutrition may be a marker of illness severity rather than a mediator of complications and poor outcomes. $^{(85)}$

It has long been recognised that the early phases of critical illness are characterised by a complex neuroendocrine and inflammatory/immune response associated with an increase in energy expenditure and a catabolic state driven by the stress response. ${ }^{(86-89)}$ The stress response involves up-regulation of the sympathetic nervous system and the release of pituitary hormones resulting in altered cortisol metabolism and elevated levels of endogenous catecholamines. ${ }^{(90-92)}$ These produce a range of metabolic disturbances, including stress hyperglycaemia and proteolysis. Hyperglycaemia arises from both acquired peripheral resistance to the effects of anabolic factors (predominantly insulin) and increased hepatic gluconeogenesis. ${ }^{(91-93)}$ Furthermore, there is altered 
mobilisation of fuel stores, futile cycling and evidence of altered lipoprotein metabolism. ${ }^{(92-96)}$ Proteolysis is accelerated releasing amino acids that are thought to be important in supporting gluconeogenesis, tissue repair, immune defence and the synthesis of acute phase reactants, resulting in net protein losses of $1-2 \mathrm{~kg}$ of protein over a ten-day ICU admission. ${ }^{(97-100)}$ In the short term, this is likely to be an adaptive response, but with time and ongoing inflammation this becomes maladaptive with a concomitant risk of protein-calorie malnutrition, immunosuppression and wasting of functional muscle tissue, further compounded by disuse atrophy. ${ }^{(57,92,93,95,101,102)}$ While muscle atrophy and ICU acquired weakness are complex and poorly understood, it is postulated that the provision of calories and sufficient protein to offset the negative nitrogen balance that results from uncontrolled proteolysis may mitigate this process. ${ }^{(99)}$

While the association between calorie deficit with morbidity and mortality is largely derived from either observational studies or small randomised controlled trials, it has nevertheless been used as justification for matching energy expenditure in the prescription of nutrition for the critically ill patient. ${ }^{(57,71,73-79)}$ The combination of these data and the plausible physiological rationale has resulted in a near universal acceptance that the provision of full caloric requirements to the critically ill patient is essential. Some authors, however, argue that there is a teleological advantage to the starvation response that occurs in the early phases of critical illness, and that preservation of autophagy, which is said to be suppressed with the provision of nutrition, has a physiological advantage. ${ }^{(92,103)}$ 
Autophagy is a normal physiologic process that serves a "housekeeping" role for the cell. ${ }^{(104)}$ It allows cells to eliminate large protein aggregates, microorganisms and excessive fat or carbohydrate stores, providing a survival mechanism in starvation through energy generation and promoting protein synthesis. ${ }^{(80,104)}$ Interference with autophagy has been postulated as one mechanism behind the mixed results that have been generated in research studies examining the role of nutrition in critical illness. ${ }^{(104)}$ Early full dose nutrition theoretically reduces mitochondrial function and tolerance to oxidative stress, and increases the risk of multiple organ failure with cell death and increased mortality through autophagy inhibition. ${ }^{(80,104)}$ The interaction between autophagy and feeding, however, appears more complex than currently appreciated and identifying autophagy inhibition as the sole mechanism for adverse events and accelerated cellular death is simplistic. ${ }^{(80,104)}$ There is a complex interplay between autophagy and the inflammatory response, with each inducing and suppressing the other. ${ }^{(105)}$ As such, in the well nourished critically ill patient at least, the preservation of autophagy at the expense of starvation is not thought to be of significance in the prescription of nutrition. $^{(104)}$

Indeed, there is increasing evidence that appropriate and early nutritional intervention can attenuate the hyper-dynamic systemic response and depressed immune reaction that accompany critical illness. ${ }^{(82,92)}$ This evolving body of evidence around the non-nutritional benefits of providing nutrition has resulted in nutritional "support" moving beyond simply the provision of exogenous fuels. ${ }^{(32)}$ Feeding the critically ill patient, 
particularly via the enteral route, is thought to help attenuate the metabolic response to stress, prevent and/or reduce oxidative cellular injury, and modulate the immune response. ${ }^{(32,74,82)}$ Early delivery of nutrition is seen as a pro-active therapeutic intervention designed to favourably impact patient outcomes through reduced disease severity, diminished complications, and a reduction in ICU length of stay. Nutrition is not, however, prescribed in isolation from a range of other interventions in the management of the critically ill patient, reflecting the involvement of multiple physiologic pathways. The type and extent of such interventions is dependent on the type and degree of physiological stressor and the type and degree of inflammatory insult. As such, the prescription of nutrition to the critically ill patient cannot be examined in isolation, and must be viewed in the context of a range of interventions, none of which are independent of the other.

The underlying assumption is that the provision of an exogenous source of energy for those who are unable to feed themselves (by definition the critically ill) and minimisation of the protein-calorie deficit that occurs, particularly during the first week of illness, will result in improved outcomes for critically ill patients. ${ }^{(74,82)}$ However, nutritional therapy in the ICU is complex, and the literature is rife with conflicting data, reflected by a lack of concordance in international guidelines. ${ }^{(71,83,106)}$ Areas of ongoing controversy include predicting who will best benefit from early nutritional intervention, the components of an "optimal" nutritional prescription, as well as how much and how best to feed the morbidly obese population. ${ }^{(82,}$ $107,108)$ 
In attempting to untangle the complexities and conflicting data observed in the nutritional literature, it is useful to consider nutritional therapy in the same way as any other drug therapy, with consideration given to the dose (including components), timing of initiation, and route of delivery of the therapy. It is plausible that some of the variability in outcomes arises due to the differences in these variables, compounded by the complex biological, metabolic and physiological changes observed in critical illness, the heterogenous nature of ICU cohorts, and the observational nature of much of the published data. As a result, debate continues in the critical care literature regarding the optimal route of delivery, target dose, and macronutrient components of nutritional support, leading some authors to ponder where the "sweet" spot between the provision of too little and too much nutrition lies. ${ }^{(71)}$

\subsubsection{Determining Energy Expenditure}

The ability to estimate energy expenditure underpins the basis for determining the nutritional targets of the critically ill patient. Two approaches to this have predominated, and, given the importance that this has in determining nutritional requirements, they are worth describing in some detail.

Simple weight based equations or more complex predictive equations have been the mainstay for nutritional prescription, and a number of prescriptions are in common use, including the Harris Benedict, Schofield, 
Penn State and Ireton-Jones equations, often modified by the use of "correction factors" that purport to adjust for the increased catabolic state associated with critical illness. ${ }^{(109,110)}$ There are, however, fundamental problems with the use of an equation based estimate of energy expenditure; these include whether ideal, actual or adjusted body weight is used, and the heterogeneity of patients in the intensive care who may have varying degrees of inflammatory response and at varying stages of their critical illness depending on the nature of the pathophysiology that prompted admission. It has been long recognised that the metabolic response to critical illness changes over time, and this is partly recognised in the European Society of Parenteral and Enteral Nutrition (ESPEN) guidelines. ${ }^{(87-89,92,93)}$ Finally, these formulae have not been validated in those at higher risk of complications, including the malnourished, the elderly and the obese. ${ }^{(72)}$

Indirect calorimetry (IC), a non-invasive technique that uses gas exchange measurements (oxygen consumption and carbon dioxide production) to estimate energy metabolism, has been advocated by some authors as an alternative to predictive equations. Although showing some promise, the use of IC has not been widely accepted in clinical practice. There are a number of reasons for this, not the least of which is that evidence of a mortality benefit is lacking, while there is the suggestion of increased morbidity through a longer duration of mechanical ventilation. ${ }^{(111,112)}$ The tight calorie control study (TICACOS), a phase II prospective randomised study, sought to determine whether nutritional support guided by repeated measures of resting energy requirement using IC had an impact 
on patient outcomes. ${ }^{(111)}$ The study group received more energy (2086 $\mathrm{kcal} /$ day versus $1480 \mathrm{kcal} /$ day) despite the fact that the difference between mean resting energy expenditure between the two groups was not statistically different. Most of the difference between the two groups was in the form of supplemental parenteral nutrition $(571 \mathrm{kcal} /$ day versus $164 \mathrm{kcal} / \mathrm{day})$, and the mean protein delivered to the study group was significantly higher ( $76 \mathrm{~g} /$ day versus $53 \mathrm{~g} /$ day), potentially confounding the results. Duration of ventilation, ICU LOS and rates of infectious complications were all statistically higher in the study group but the authors reported a statistically non-significant mortality benefit at 50 days in the study group. A further phase III trial is underway (TICACOS International) ${ }^{(113)}$ that may provide a definitive answer about the role of IC in estimating energy expenditure; however, other logistical reasons are likely to contribute to the poor uptake of IC in clinical intensive care. These include equipment costs, the variability of a critically ill patient's underlying metabolic rate (likely to vary from day to day, and even hour to hour, determined by body temperature, level of sedation and other metabolic processes), its limited utility in moderate to severe respiratory disease (it cannot be used when the fraction of inspired oxygen exceeds 0.6 or where the positive end expiratory pressure exceeds $10 \mathrm{cmH}_{2} \mathrm{O}$ ), interference from the humidification of circuits and when renal replacement therapy is required. ${ }^{(72,114)}$ Furthermore, there is evidence that the accuracy of IC is affected at the extremes of height and weight. ${ }^{(82)}$ Therefore, if the goal of nutritional therapy is to match resting energy expenditure, or some fraction of it, with exogenous nutritional support, 
there should be some confidence in how the "target" is derived. However, this remains contentious, reflected by the different recommendations from major societies. ${ }^{(32,83,112)}$ The American Society of Parenteral and Enteral Nutrition recommend that "in the absence of IC, ... a published predictive equation or simplistic weight based equation (25 - 30 $\mathrm{kcal} / \mathrm{kg} / \mathrm{day}$ ) be used to determine energy requirement", noting that the nutritional prescription for the critically ill obese patient differs. ${ }^{(32) p .163}$ In contrast, ESPEN recommend $20-25 \mathrm{kcal} / \mathrm{kg} /$ day during the early "ebb" phase of the metabolic response, increasing to $25-30 \mathrm{kcal} / \mathrm{kg}$ as the metabolic phase shifts to the flow anabolic recovery phase. ${ }^{(83,86-89)}$ The Canadian Critical Care Trials Group (CCCTG) have refrained from a recommendation on how a nutritional target is derived, citing insufficient evidence but note that, in addition to the high costs associated with IC, there is a signal for harm associated with its use, including an increased LoS and increased rates of infective complications. ${ }^{(112)}$ Furthermore, although suggesting predictive formulae, there is no explicit mention of which formula is best suited to the critically ill patient.

\subsection{2 'Dose' of Nutrition}

Notwithstanding the difficulties with determining energy expenditure and the lack of consensus on how best to measure this, the consequences of providing both too few and too many calories have an impact on both morbidity and mortality. ${ }^{(71)}$ Mechanistically, too few calories to meet energy expenditure over a prolonged period results in increased catabolism with concomitant muscle wasting, contributes to morbidity and 
is ultimately lethal if left uncorrected. ${ }^{(71)}$ Too many calories results in deposition of adipose tissue, a response that had teleological advantages when the species ate to live, but in the critically ill patient is thought to contribute to increased carbon dioxide production which potentially slows liberation from mechanical ventilation. ${ }^{(71,115-117)}$ On the basis of these observations, prescribing the appropriate "dose" of nutrition with regard to calories appears important, yet evidence on energy delivery and clinical outcomes is conflicting.

A number of observational studies have associated caloric deficit with morbidity and mortality, and it seems to intuitively follow from these observations that the prescription of sufficient calories to match energy expenditure will reduce morbidity and mortality, yet this approach remains unproven. ${ }^{(57,71,73-81)}$ Furthermore, there are animal data demonstrating that caloric restriction may prolong life span and promote cell survival. ${ }^{(118-121)}$ This has led to a school of thought that the target calorie prescription should represent a fraction of the energy expenditure that is less than one, so called hypo-caloric feeding regimens, in which $40-$ $60 \%$ of estimated energy requirement is prescribed. The initial versus full enteral feeding in patients with acute lung injury EDEN study randomised well-nourished patients with acute respiratory distress syndrome (ARDS) to either six days of "trophic" feeds ( $20 \mathrm{ml} / \mathrm{hr}$ of a $1 \mathrm{kcal} / \mathrm{ml}$ formula) or to full enteral feeds. ${ }^{(122)}$ Full feeding was defined by applying a simplistic weight based rate of $25-30 \mathrm{kcal} / \mathrm{kg}$ using IBW as the variable, although how IBW was derived was not specified. ${ }^{(122)}$ There was no difference in the primary outcome (ventilator free days). Of the secondary outcomes only 
daily gastro-intestinal intolerance at days 2 and 3 were statistically significant (favouring trophic feeds). Generalisation of this result beyond patients with ARDS is problematic, but the study was nevertheless hypothesis generating. Subsequently, several other small studies as well as a meta-analysis suggested that a hypo-caloric feeding regimen might confer clinical benefit. ${ }^{(123-125)}$ This was tested in the permissive underfeeding or standard enteral feeding in critically ill adults (PermiT) trial, a large multi-centre international trial enrolling a heterogenous ICU population. Despite finding a mortality benefit in an earlier single centre pilot trial using the same regimen, the PermiT investigators were unable to demonstrate any difference in either their primary outcome (90-day mortality) or any of a range of secondary outcomes when patients were randomised to either a hypo-caloric feeding regimen ( $40-60 \%$ of estimated energy requirements) or standard care (70 - 100\% of estimated energy requirements). ${ }^{(54,123)}$ Estimated requirements in the PermiT trial were equation based (Penn-State formula for those with a BMI $<30 \mathrm{~kg} / \mathrm{m}^{2}$ and the 1992 Ireton-Jones formula for those with a BMI > $30 \mathrm{~kg} / \mathrm{m}^{2}$ using actual body weight as the variable). ${ }^{(54)} \mathrm{A}$ subsequent meta-analysis which included the Permit trial also found no difference in the risk of acquired infections, hospital mortality, ICU LoS or ventilator free days between patients receiving intentional hypo-caloric feeding regimens compared to eucaloric regimens, suggesting no benefit from hypo-caloric regimens but also no significant harm. ${ }^{(107)}$

Clouding the landscape further are the results of a phase II trial comparing an energy dense formula with a standard formula. ${ }^{(126)}$ The TARGET 
investigators substituted a $1.5 \mathrm{kcal} / \mathrm{ml}$ formula for a standard $1.0 \mathrm{kcal} / \mathrm{ml}$ formula in a double blinded, randomised parallel group trial. The goal feeding rate was $1 \mathrm{ml} / \mathrm{kg} \mathrm{IBW} / \mathrm{hr}$ up to a maximum of $100 \mathrm{ml} / \mathrm{hr}$, where IBW was derived from a minor variation of Devine's IBW formula. ${ }^{(12,126)}$ Devine's IBW formula was also used in the the Acute Respiratory Distress Syndrome Network's Ventilation with Lower Tidal Volumes as Compared with Traditional Tidal Volumes for Acute Lung Injury and the Acute Respiratory Distress Syndrome (ARMA) trial comparing high and low tidal volumes, and probably the EDEN trial. ${ }^{(15,122)}$ The primary outcome in this phase II feasibility study was the daily calorie delivery from study enteral nutrition while secondary outcomes were addressed at clinically important outcomes such as LoS, duration of mechanical ventilation and mortality. ${ }^{(126)}$ Patients randomised to the $1.5 \mathrm{kcal} / \mathrm{ml}$ formula received nearly $50 \%$ more calories (but the same amount of protein) than the patients in the standard formula group. There were no differences reported for any of the secondary outcomes. The authors did, however, report a "signal for improved survival" at 90 days for the patients receiving the energy dense formula. ${ }^{(126) p .8}$ In a phase II trial, a signal for improved survival such as this is sufficient support to justify the conduct of a phase III trial which is currently underway. ${ }^{(126,127)}$ The evidence base surrounding which caloric target is optimal for the critically ill patient therefore remains obscure.

Finally, the assumption that delivery of nutrients to the small bowel is synonymous with absorption may be an oversimplification. There is evidence suggesting that the delivery of both carbohydrates and lipids to 
the small bowel does not necessarily ensure that there is systemic uptake. $^{(128,129)}$

The lack of conclusive evidence regarding caloric prescription for enteral nutrition in critically ill patients has resulted in the optimal feeding goal being identified as one of the most controversial aspects of care. ${ }^{(71)}$ The evidence base relies extensively on observational studies, while the randomised controlled trials that have been undertaken are either conducted on specific patients groups (for example, ARDS) or are inconclusive. This has resulted in international guidelines that are either contradictory or completely silent on important aspects of nutritional therapy.

\subsubsection{Macronutrient Components}

In considering the prescription of nutritional therapy for the critically ill patient, it is not sufficient to consider the caloric prescription in isolation from the macro-nutrient components - lipid (fat), carbohydrate and protein - and the ratio of each in the total calorie target. Of particular importance is the ratio of non-protein and protein calories because of the different ways in which these are metabolised, and the altered metabolic profile in critical illness. ${ }^{(51,91,128)}$

The metabolic changes that occur during the stress response are complex and include impaired fat mobilisation. ${ }^{(91)}$ Due to this, it has long been believed that carbohydrates are the preferred energy source during the early catabolic phase of critical illness, although even this long held belief 
is being questioned with an emerging opinion that protein may be more beneficial in the first 48 hours. ${ }^{(57,106,130-135)}$ Notwithstanding this ongoing controversy, the optimal amount of carbohydrate provision in critical illness has not been elucidated but is thought to be limited by the maximal glucose oxidation rate which is $4-7 \mathrm{mg} / \mathrm{kg} /$ minute. ${ }^{(136,137)}$ Providing carbohydrates in excess of this rate inevitably results in hyperglycaemia, adipose tissue deposition and possibly excess carbon dioxide production, slowing liberation from mechanical ventilation. ${ }^{(115-117)}$ Conversely, the minimum exogenous glucose requirement is, in theory, zero. ${ }^{(138)}$ However, glucose is a universal fuel for all cells, and the complete absence of an exogenous supply of glucose results in the breakdown of fat and protein to supply the substrate for glucoenogenesis. Therefore, while there is little evidence around the minimal carbohydrate requirement in critical illness, in practice $50-66 \%$ of the total caloric target, not exceeding $2000 \mathrm{kcal} / \mathrm{day}$, is delivered as carbohydrate. ${ }^{(137,139,140)}$

Activation of the stress response leads to insulin resistance, which in turn results in up-regulated gluconeogenesis. Gluconeogenesis is a metabolic process occurring predominantly in the liver that results in the generation of glucose from non-carbohydrate substrates, including glucogenic amino acids. The amino acid substrates are generated predominantly by the breakdown of skeletal muscle. ${ }^{(85)}$ Provision of adequate protein is, at least in part, directed at providing an alternative substrate for gluconeogenesis and reducing the need for the breakdown of lean muscle mass to provide this amino acid pool for gluconeogenesis. ${ }^{(131)}$ There is empirical evidence, albeit in a small sample, of substantially increased protein turnover in 
critically ill patients compared to healthy volunteers. ${ }^{(133)}$ Furthermore, the provision of exogenous protein may provide substrates to complement the inflammatory response and critical physiological processes. ${ }^{(106)}$ Despite this, there are conflicting results in studies examining protein intake and outcome. ${ }^{(98,141)}$ Although the evidence base is not strong and the most effective protein-to-energy ratio for critically ill patients remains elusive, international guidelines based on little more than expert opinion suggest that $1.2-2.0 \mathrm{~g} / \mathrm{kg} /$ day of protein should be targeted in the critically ill. ${ }^{(32,}$ ${ }^{83)}$ Despite this recommendation, there is evidence that current feeding regimens are not providing this "dose" of protein to critically ill patients. $^{(106)}$

\subsubsection{Timing}

Enteral feeding is successful and usually well tolerated in all ICU patients that have been fully resuscitated and are haemodynamically stable. ${ }^{(32,82,}$ ${ }^{142,143)}$ Historically, enteral feeding has been delayed for fear of inducing gut ischaemia or non-occlusive bowel necrosis due to the increased blood supply in the splanchnic circulation associated with provision of enteral nutrition. ${ }^{(80)}$ It has been evident in the last decade, however, that early commencement of enteral nutrition (within 72 hours) compared to delayed commencement (after 72 hours) has benefits for both morbidity and mortality. ${ }^{(143,144)}$ Indeed a more recent trial suggests that the very early (within the first six hours of ICU admission) initiation of enteral nutrition may be safe. ${ }^{(145)}$ 
complex. Numerous observational studies demonstrate that critically ill patients who receive enteral nutrition frequently receive only $60 \%$ of calories prescribed..$^{(57,146,147)}$ Reasons that have been identified for the disparity between the prescribed caloric dose and that delivered include delays in the initiation of therapy for fear of gut ischaemia, delayed placement of enteric feeding tubes or replacement following dislodgement, prolonged fasting for therapeutic or diagnostic procedures, and gut dysmotility. ${ }^{(72,82,92,126,148)}$ This results in both a high incidence of unintentional underfeeding, and further complicates the question of protein and calorie delivery to the critically ill patient discussed in Sections 1.3.2 and $1.3 .3 . .^{(72,142,147,149)}$

\subsubsection{Non-Nutritional Benefits of Enteral Feeding}

Notwithstanding the debate regarding the dose, components and timing of nutritional therapy, there is consensus that it should be provided, initiated early, and preferably via the enteral route. In addition to the obvious delivery of exogenous macro-nutrients to the patient who is unable to source their own nutritional support, and providing protein and energy substrates with the view to maintaining amino acid substrate and lean muscle mass, there are a number of non-nutritional benefits. These can be broadly divided into gastro-intestinal benefits, immunological benefits and metabolic benefits. ${ }^{(82)}$

Gut dysfunction in the critically ill patient is multi-factorial and involves segmental or diffuse dysmotility, reduced villous height, loss of the absorptive surface at the villus tips, as well as alterations in gut 
microbiota. ${ }^{(82,150)}$ Proposed gastro-intestinal benefits of enteral nutrition include the maintenance of gut epithelial integrity, reduced bacterial translocation (in animal models at least), reduced bacterial overgrowth and a reduction in the incidence of gastric and duodenal stress ulcers. ${ }^{145,}$ ${ }^{151-154)}$ Provision of enteral nutrition assists with the restoration of gut integrity, enhances contractility, increases the height and density of the brush border, and assists with the restoration of commensal bacteria. ${ }^{(150,}$ ${ }^{155)}$ Furthermore, there are animal data suggesting that providing nutrition via the enteral route may attenuate the systemic inflammatory response in response to an ischaemic insult. ${ }^{(156,157)}$

Immunological effects include maintenance of humoral (antibody mediated) immune function, modulation of key regulatory cells to enhance cellular immunity, and maintenance of mucosa-associated Iymphoid tissue in a number of epithelial surfaces. ${ }^{(155,158-161)}$ Metabolic benefits (over and above the provision of an exogenous energy source and anti-oxidants) include the promotion of insulin release and sensitivity through the incretin effect, and possibly attenuation of stress metabolism to reduce futile cycling and physiological fuel utilisation. ${ }^{(162,163)}$

The increasing emphasis on enteral nutrition is demonstrated by the fourfold increase in citations that occurred over the years 2006 to 2015 (Figure 4). Despite, or perhaps because of, the increased interest in the therapeutic effect of nutritional interventions on the morbidity and mortality of critically ill patients, the results reported in the literature are frequently conflicting. ${ }^{(71)}$ 


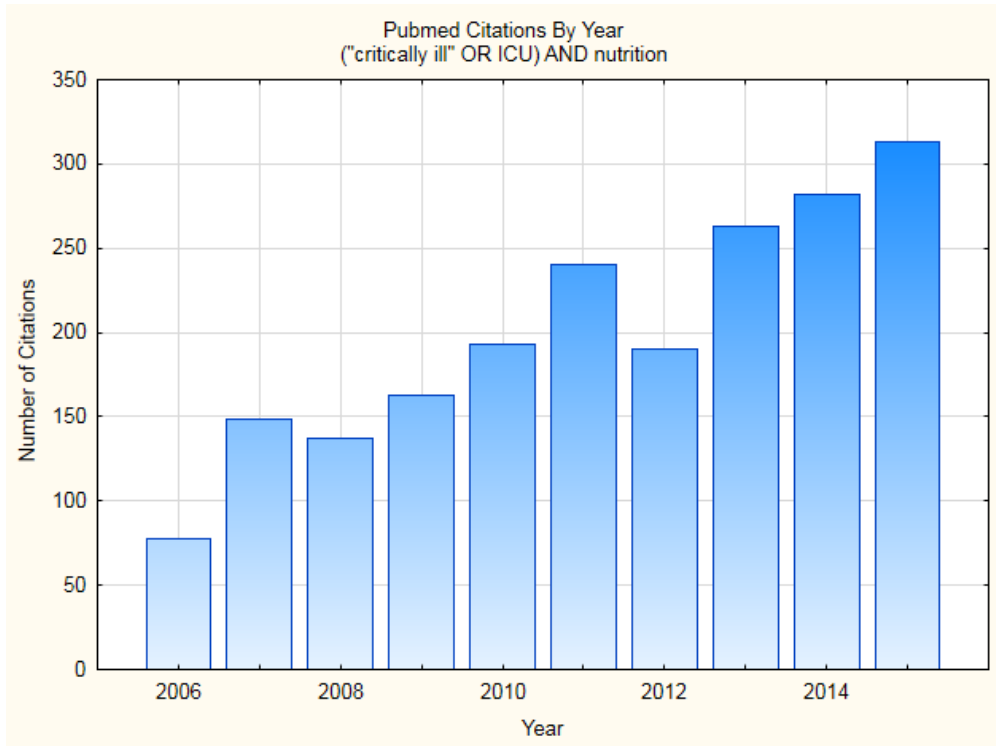

Figure 4: PubMed publications by year demonstrating the increasing number of publications focussing on nutrition in the critically ill

\subsection{Nutritional Therapy for the Critically III Obese Patient}

Nutrition for the critically ill obese patient may need to differ from that provided for their lean counterparts. Metabolic processes differ, particularly in those with underlying insulin resistance, itself a marker of the metabolic syndrome, which may predispose to futile cycling, altered fuel utilisation and protein catabolism..$^{(34,94,95,164-168)}$ A study recruiting from a trauma ICU found that obese patients derived $39 \%$ of their resting energy requirement from fat metabolism, compared to $61 \%$ in their lean counterparts. ${ }^{(169)}$ The shortfall in energy was compensated by increased protein metabolism, suggesting a greater potential for loss of lean muscle mass. ${ }^{(169)}$ In the short term, this is likely to be an adaptive response but with time and ongoing inflammation, this becomes maladaptive with a concomitant risk of protein-calorie malnutrition, immunosuppression and 
wasting of functional muscle tissue resulting from protein catabolism over lipolysis and is further compounded by disuse atrophy..$^{(92,95,102)}$

There is, in addition, evolving evidence that hormones derived from both the gut and adipose tissue are also involved in the response to stress and critical illness, and that adipose tissue in particular is not a benign tissue bed but rather could be considered an endocrine organ. ${ }^{(166,170-172)}$ Some of these hormones are thought to be pro-inflammatory and some antiinflammatory, but both the net result and clinical significance of these is yet to be fully elucidated. ${ }^{(92,166,170)}$

It is plausible therefore that the metabolic derangements seen in the critically ill lean patient are amplified and compounded in the critically ill obese patient, particularly in the area of accelerated proteolysis and loss of lean muscle mass. It could be argued that preservation of lean muscle in the critically ill obese patient has substantial implications, given the larger mass that is required to be mobilised during the rehabilitation phase of their critical illness.

Assessing the critically ill obese patient for nutrition risk is difficult. Current ASPEN guidelines suggest using biomarkers of metabolic syndrome (serum glucose, triglycerides and cholesterol) as a measure of potential futile cycling, co-morbidities, and determination/estimation of the level of inflammatory response. ${ }^{(32)}$ In recognising that obesity is not protective against malnutrition and in particular protein malnutrition, early initiation of enteral nutrition is recommended but there is evidence 
that this is substantially delayed in practice. ${ }^{(173)}$ The reasons for this delay have not been elucidated but may be related to the false assumption that every obese patient has nutritional reserves due to the presence of excessive adipose tissue. ${ }^{(173)}$ There is evidence that malnutrition occurs at both ends of the BMI spectrum, supported by observational data that reports that up to $57 \%$ of overweight or obese hospitalised patients show signs of malnutrition. A French observational study found that obese patients have an odds ratio of 1.5 of malnutrition relative to patients within the normal weight range..$^{(32,174)}$

Despite the importance given to the early initiation of nutrition, the frequency of enteral nutrition (virtually universal), the cost (approximately $\$ 23 /$ day), the biologic rationale, the high mortality in critically ill patients, the frequency of muscle wasting and the reduced functional outcomes in survivors, there is a surprising paucity of evidence guiding the prescription of nutritional therapy in the critically ill obese patient. This is reflected in International guidelines. ${ }^{(175)}$ The European Society of Parenteral and Enteral Nutrition and the Canadian Critical Care Trials Group (CCTG) are silent on the issue of nutritional regimens for the critically ill obese patient. ${ }^{(83,112)}$ The American Society of Parenteral and Enteral Nutrition, in contrast, advocate a hypo-caloric (12 - $14 \mathrm{kcal} / \mathrm{kg} /$ day actual body weight), high protein ( $>2 \mathrm{~g} / \mathrm{kg} /$ day $\mathrm{IBW}$ ) regimen, acknowledging that the evidence justifying this approach is of low quality. ${ }^{(32)}$ The lack of evidence in the area of nutritional therapy for the critically ill obese patient is highlighted in ASPEN's most recent guidelines. ${ }^{(32)}$ Of the eight clinical questions posed around the nutritional management of the critically ill obese patient (Table 
1), all eight recommendations are based on expert consensus and none could be justified on the quality of evidence alone. ${ }^{(32)}$ Question 4 is the clinical question of relevance to this thesis (Table 1).

The physiological basis for a high-protein hypo-caloric regimen is two-fold. Firstly the intentional underfeeding of calories encourages weight loss while high protein maintains lean muscle mass. The argument is that weight loss may increase insulin sensitivity, improve glycaemic control, facilitate nursing care and reduce the risk of co-morbidities. ${ }^{(11,32)}$ There is no evidence to support this supposition, and whether sufficient weight loss can occur across the duration of an ICU admission is questionable. The median ICU LoS in a recent large nutritional study was 13 days, with an inter quartile range (IQR) of eight to 21 days, while an Australian study exploring the role of caloric augmentation in ICU patients reported a median ICU LoS of 9.6 and 11.8 days in the intervention and control arms respectively (IQR $6.9-22.8$ and $5.9-22.6$ days). ${ }^{(54,126)}$ The second is provision of a high protein load. A retrospective study indicated that a dose of protein of $2.0 \mathrm{~g} / \mathrm{kg} \mathrm{IBW} /$ day was insufficient to achieve a neutral nitrogen balance when $\mathrm{BMI}>40 \mathrm{~kg} / \mathrm{m}^{2}$, albeit that this was in a population receiving enteral nutrition. ${ }^{(176)}$ From this it has been assumed that providing $2-2.5 \mathrm{~g} / \mathrm{kg} \mathrm{IBW/day} \mathrm{should} \mathrm{approximate} \mathrm{protein} \mathrm{requirements,}$ preserve nitrogen balance and allow for adequate wound healing. The American Society of Parental and Enteral Nutrition recommend the use of nitrogen balance studies to titrate the dose of protein to achieve neutral nitrogen balance, although it was not clear how often this occurs in practice. ${ }^{(32)}$ Furthermore, it is not clear that any dose of protein will 
completely eliminate the nitrogen deficit that occurs during the early phases of critical illness which may be a result of the normal stress response discussed in Section 1.3.3.

A search of the literature and a review of the International consensus statements published by the major nutritional peak bodies revealed no other widely used or advocated nutritional approach targeting the critically ill obese patient. ${ }^{(32,83,112)}$ Despite the rising prevalence of obesity in the general population as well as the ICU, there is a paucity of empirical data to guide an approach to enteral nutrition that targets energy and protein delivery with the goal of reducing morbidity and mortality for the critically ill obese patient. 
Table 1: Clinical questions addressed in the 2016 ASPEN Guidelines ${ }^{(32)}$

\begin{tabular}{|c|c|c|c|}
\hline \multicolumn{2}{|c|}{ Question } & $\begin{array}{l}\text { Recommendation } \\
\text { Commencement of enteral nutrition within } 24-48 \text { hours of } \\
\text { admissions for obese patients who cannot sustain volitional } \\
\text { intake. }\end{array}$ & $\begin{array}{l}\text { Level of } \\
\text { Evidence } \\
\text { Expert opinion }\end{array}$ \\
\hline Q2 & $\begin{array}{l}\text { What additional parameters should be addressed with } \\
\text { a nutrition assessment in critical illness when the } \\
\text { patient is obese? }\end{array}$ & $\begin{array}{l}\text { Assessment should focus on biomarkers of metabolic } \\
\text { syndrome, evaluation of co-morbidities, and a } \\
\text { determination of level of inflammation, in addition to those } \\
\text { parameters described for all ICU patients. }\end{array}$ & Expert opinion \\
\hline Q3 & $\begin{array}{l}\text { What factors on assessment identify obese patients in } \\
\text { the ICU to be at high risk? }\end{array}$ & $\begin{array}{l}\text { Assessment focus on evidence of central adiposity, } \\
\text { metabolic syndrome, sarcopaenia, BMI > 40, systemic }\end{array}$ & Expert opinion \\
\hline
\end{tabular}




\begin{tabular}{|c|c|c|c|}
\hline & & $\begin{array}{l}\text { inflammatory response, or other co-mobibidities that } \\
\text { correlate with higher obesity-related risk for cardiovascular } \\
\text { disease and mortality. }\end{array}$ & \\
\hline Q4 & $\begin{array}{l}\text { Does the use of high-protein hypo-caloric feeding } \\
\text { improve clinical outcomes compared with high- } \\
\text { protein eucaloric feeding? }\end{array}$ & $\begin{array}{l}\text { High-protein hypo-caloric feeding be implemented in the } \\
\text { care of obese ICU patients to preserve lean body mass, } \\
\text { mobilise adipose stores, and minimise the metabolic } \\
\text { complications of overfeeding. }\end{array}$ & Expert opinion \\
\hline Q5 & $\begin{array}{l}\text { What are the appropriate targets for energy and } \\
\text { protein intake? }\end{array}$ & $\begin{array}{l}65-70 \% \text { of target energy requirements as measured by IC. } \\
\text { Where IC is not available then } 11-14 \mathrm{kcal} / \mathrm{kg} \text { actual body } \\
\text { weight. Protein should be provided in a range from } 2.0 \mathrm{~g} / \mathrm{kg} \\
\text { IBW. }\end{array}$ & Expert opinion \\
\hline Q6 & $\begin{array}{l}\text { What indications, if any, exist for the use of specialty } \\
\text { enteral formulations? }\end{array}$ & $\begin{array}{l}\text { If available a low caloric density with a reduced non-protein } \\
\text { calories: nitrogen ratio be used. }\end{array}$ & Expert opinion \\
\hline
\end{tabular}




\begin{tabular}{|l|l|l|l|}
\hline Q7 & What are appropriate monitors to follow? & Hyperglycaemia, hyperlipidaemia, hypercapnia, fluid \\
\hline Q8 & $\begin{array}{l}\text { Does the obese ICU patient with a history of bariatric } \\
\text { surgery or other malabsorptive condition require any } \\
\text { additional supplementation? }\end{array}$ & Supplemental thiamine should be administered prior to \\
& initiating dextrose containing intravenous fluids or nutrition & Expert opinion \\
\end{tabular}

$\mathrm{BMI}$ - body mass index

ICU - intensive care unit

IC - Indirect Calorimetry 


\subsection{Sources of Variability Identified in the Literature}

In reviewing the literature around both nutritional therapy for the critically ill patient and the literature pertaining to obesity, a number of issues that potentially confound outcomes were identified. These may contribute to the conflicting results that make the evidence base confusing and are worth exploring.

\subsubsection{Which Weight?}

As discussed in Section 1.1, weight forms the basis of nutritional prescription for all equation based methods. Yet there is inconsistency within the literature regarding which weight is used as the variable. Actual body weight has been used in some studies, with some making a further adjustment for the obese (for example, IBW plus $25 \%$ of the difference between ideal and actual body weights). In other studies, an IBW is used as the variable which has a number of advantages including obviating the need for a recent weight.

Figure 5 plots the most commonly used IBW formulae across a range of heights for both men (Panel A) and women (Panel B), respectively. Although there are marked similarities between the results, for males there is at least a $10 \mathrm{~kg}$ difference (approximately 13\%) between the most conservative and most liberal formulae in the middle of the height range, increasing to approximately $15 \mathrm{~kg}$ in the extremes. For females this difference is more marked, producing a $15 \mathrm{~kg}$ difference in the middle of 
the height range and up to $20 \mathrm{~kg}$ in the extremes of height. It can be seen then that the choice of IBW formula could potentially result in significant differences in both calorie and protein delivery. Figure 6 converts the heights to BMI using IBW for males (Panel A) and females (Panel B). Acknowledging the inherent problems with BMI (Section 1.1), with the exception of short people, the formulae mostly produce BMIs that fall within the "normal range". The inherent flaws of using BMI, including the lack of stability with both age and over time, have been discussed (Section 1.1.3).

An alternative proposed weight is the "adjusted body weight", which has been defined variously as anything between $125-138 \%$ of IBW. ${ }^{(177)}$ It is derived from two calculations - a calculation to derive IBW and a subsequent ratio of the actual body weight to IBW. As it uses two calculations, it necessarily introduces further error. The most recent guideline published by ASPEN recommends against the use of adjusted body weight due to the variability in its definition. ${ }^{(32)}$ For weight-based interventions, ASPEN's recommendation is to use actual, usual or IBW, but they make no recommendation about which IBW formula to use. Figure 5 demonstrates the degree of error that the use of different formulae for IBW may introduce.

Given the problems of generalising about IBW from insurance data (Section 1.1), there is an argument that much of what has subsequently transpired with regard to IBW and BMI should be considered with a degree of caution. It also follows that the choice of which weight to use 
(actual, ideal or adjusted) as the variable can have significant impacts on the calorie and protein prescription, while it remains intuitively obvious that prescribing nutrition to a severely underweight $\left(\mathrm{BMI}<18 \mathrm{~kg} / \mathrm{m}^{2}\right)$ patient on the basis of IBW may result in significant overfeeding. It is important therefore to be specific about which weight is being used in calculating a nutritional goal, to acknowledge the limitations of the method, as well as to consider what is actually delivered to the gut of a critically ill patient (rather than prescribed). 

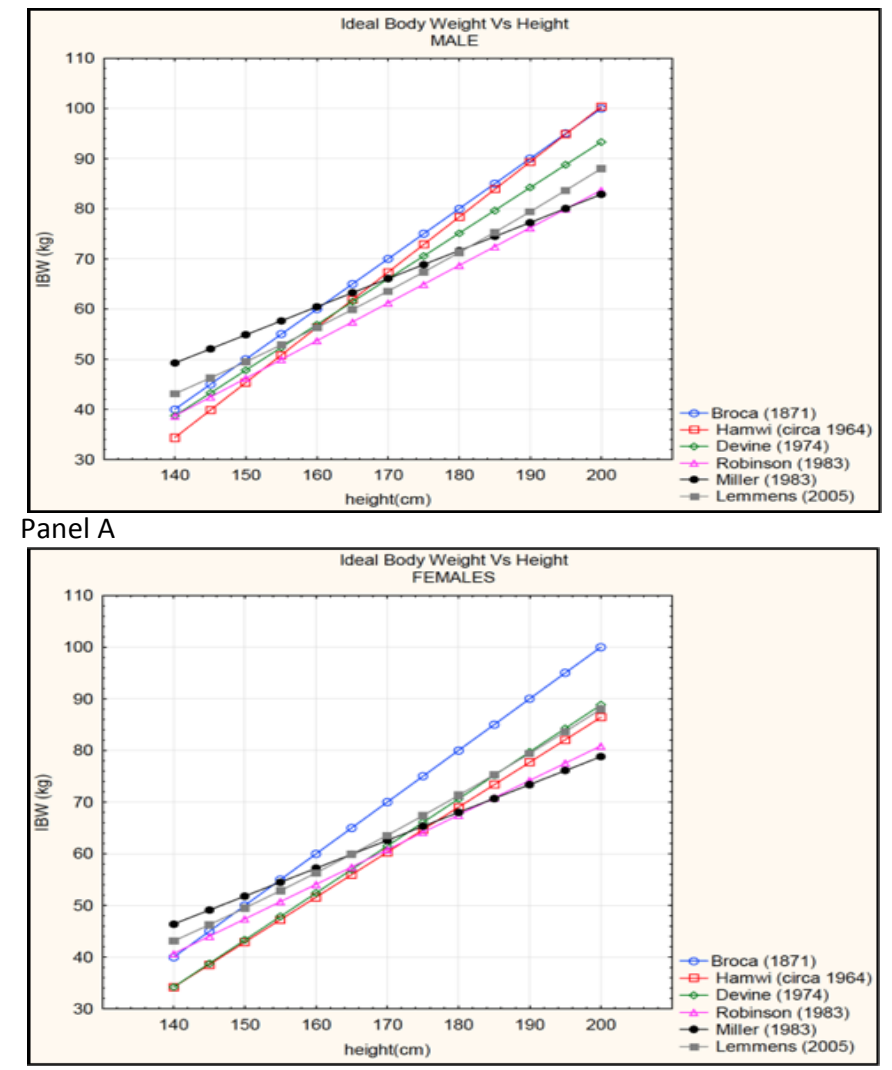

Panel B

Figure 5: Ideal body weight (IBW) by commonly used IBW

formulae against height

Panel A - Males; Panel B - Females

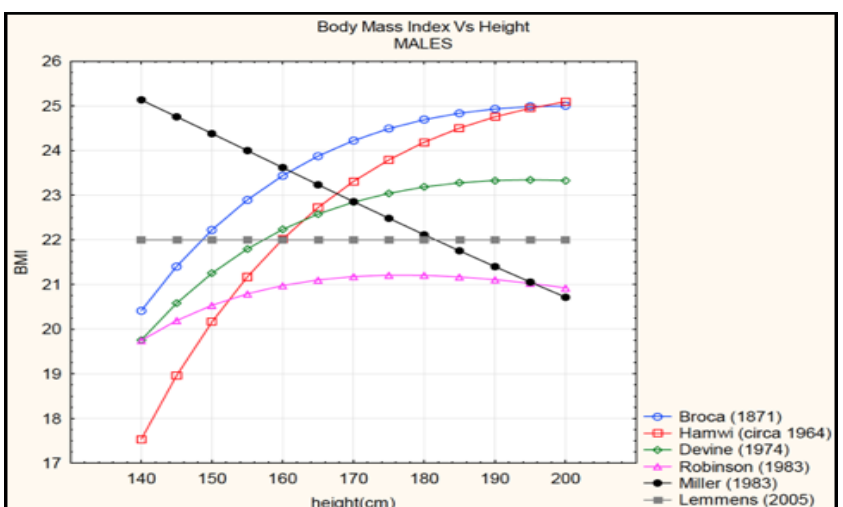

Panel A

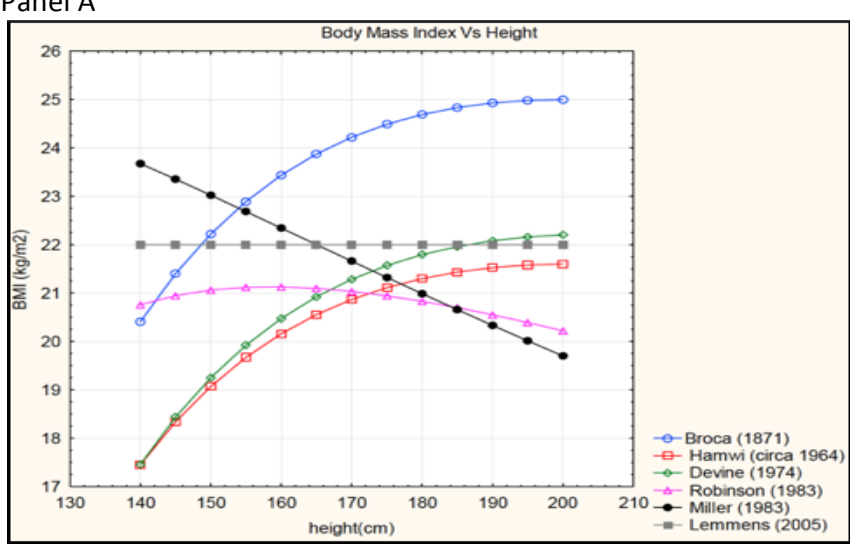

Figure 6: Body mass index (BMI) against height for IBW by

common IBW formulae

Panel A - Males; Panel B - Females 


\subsubsection{The Obesity Paradox}

The obesity paradox refers to a phenomenon in which being overweight or having class I obesity (BMI $30-34.9 \mathrm{~kg} / \mathrm{m}^{2}$ ) appears to confer a survival benefit compared to patients with a normal BMI. ${ }^{(70)}$ The phenomenon may extend to class II obesity (BMI $35-39.9 \mathrm{~kg} / \mathrm{m}^{2}$ ) but patients with class III obesity $\left(\mathrm{BMI} \geq 40 \mathrm{~kg} / \mathrm{m}^{2}\right)$ have a worse outcome. ${ }^{(178)}$ This phenomenon has been observed in both prospective and retrospective series across a range of medical conditions including cardiovascular disease and stroke survivors. ${ }^{(179-183)}$ Intensive care populations in which the "obesity paradox" has been observed include patients with sepsis, survivors of cardiac arrest, community acquired pneumonia, surgical ICU patients as well as heterogenous ICU populations. ${ }^{(58,61,184-191)}$ The finding of a protective effect, however, is by no means universal. ${ }^{(192-194)}$

The conflicting results of studies examining the obesity paradox may not simply be the result of using $\mathrm{BMI}$ as the variable. Other issues that have been identified include study design and the introduction of confounding factors, including selection bias, treatment bias, time-varying exposure or other confounders such as hip circumference, concurrent cardiopulmonary dysfunction, physical fitness/physical activity levels (the fat but fit patient) or socio-economic status. ${ }^{(70,195-200)}$ There is, in addition, evolving and increasingly compelling evidence that "optimal" weight may increase with age. ${ }^{(25,201)}$ Other potential explanations include using BMI, which has a number of failings as discussed in Section 1.1, and failing to account for underlying malnutrition. Body mass index does not describe the distribution of adipose tissue and is a poor marker of adiposity itself in p. 54 of 216 
the older adult. ${ }^{(60,70,172)}$ Finally, many studies have failed to control for underlying malnutrition. Robinson et al., in a prospective study, failed to find a protective effect from obesity once malnutrition was assessed and controlled for. ${ }^{(60)}$

Contributing further to scepticism about the existence of the obesity paradox is the absence of a physiological mechanistic model that explains how mild obesity could be protective. A number of theories have been postulated including adipose tissue acting as a reservoir for inflammatory cytokines, lipid "sinks" mopping up endotoxins and the endocrine functions of adipose tissue synthesising anti-inflammatory hormone. ${ }^{(34,172)}$ Although these postulate possible adaptive protective effects that may contribute to the observed phenomenon, there is little firm evidence currently.

Nevertheless, any review considering an endpoint of mortality in an obese population must include the possibility that a mortality benefit could be due to the "obesity paradox" and not necessarily the intervention. In an area where much of the data is derived from observational studies, and in a review in which it is likely that data will be derived from subgroup data that will have not been stratified for obesity, the presence of the obesity paradox should be considered as a potential confounding influence.

\subsubsection{Dedicated Nutritional Support Services}

It is common practice in Australasian ICUs to have a dedicated dietician within the unit who guides but does not dictate nutritional prescription. In 
the United States, a pharmacist is often involved - generally identified as pharmacy nutrition support therapists. These therapists may be responsible for "prescribing enteral and/or parenteral nutrition, laboratory analysis, and pharmacotherapy integrated with nutrition therapy (e.g. fluid and electrolytes, pro-kinetic drugs, insulin, antidiarrhoeal and laxative therapy)". (202)p.718 In Europe the model is more closely aligned with the Australasian model.

It is not clear what differences may arise from having non-medically trained therapists prescribing nutritional and supportive therapy, and this has not been investigated. However, there is evidence that admission to a closed ICU under the management of a treating intensivist improves patient outcomes. ${ }^{(203,204)}$

This review will consider studies for inclusion from a variety of countries, many of which will have vastly different approaches to who prescribes nutritional therapy and who takes ultimate clinical responsibility for the decisions around this. What impact this has on clinical outcomes is uncertain.

\subsubsection{Supplemental Parenteral Nutrition}

The practice of using supplemental parenteral nutrition when caloric goals are not being met with nutrition suppled via the enteral route within the first 72 hours varies considerably within the international critical care community. While there are a number of reasons why a trial of the enteral route may fail to meet caloric goals at 72 hours, the subsequent 
management has been controversial. The European Society of Parenteral and Enteral Nutrition currently recommend the early use of supplemental PN to minimise the cumulative energy deficit, while ASPEN recommend withholding any form of parenteral nutrition until days $5-7$ in a previously well-nourished patient. ${ }^{(32,83)}$ The CCCTG have withheld any recommendation on the timing of supplemental PN, citing a lack of evidence. $^{(205)}$

Nevertheless, combining studies from different continents with different approaches to supplemental PN necessarily introduces a potential confounding influence. For the purpose of the systematic review undertaken, this potential confounder was avoided by focussing on studies that preferentially utilise the enteral route.

\subsubsection{Assessment of Nutritional Reserves/Risk of Malnutrition}

The issue of patient heterogeneity is further complicated by the heterogeneity in nutritional risk, particularly in any intervention that examines nutrition. The importance of providing an exogenous source of energy (including protein) during the early phases of critical illness where there is a period of increased energy expenditure and negative nitrogen balance is heightened by the observation that a number of patients in the intensive care may be malnourished (or at "nutritional risk"). ${ }^{(72,78,111,206)}$ Identifying patients for whom the early delivery of nutrition is likely to benefit most has proven difficult in the intensive care setting but intuitively it is those who are malnourished who will benefit most. ${ }^{(207,208)}$ 
Identifying this group in the ICU, however, is recognised as problematic due to difficulties taking an accurate nutritional history and where fluid redistribution makes interpretation of physical findings difficult. Traditional means of assessing for "nutritional risk", such as the subjective global assessment (SGA) or the malnutrition universal screening tool (MUST), have been validated inambulatory settings. These methods rely on being able to obtain a nutritional history and an accurate weight, perform a physical examination and utilise biochemical markers such as serum protein, albumin, pre-albumin and transferrin. In the critically ill patient, these traditional means of assessing for risk are of little use in the critically ill patient. ${ }^{\left({ }^{(2)}\right)}$ The critically ill patient is frequently sedated, making it impossible to obtain an accurate nutritional history. Weight cannot be measured, unless scales are installed in the bed, , and even when obtained may be inaccurate due to the accumulation of excess fluid, particularly in the interstitial tissues. This accumulation and redistribution of fluid also makes physical examination difficult, while many of the protein biomarkers of malnutrition are also acute phase reactants and are altered in critical illness. Paradoxically, despite their adipose tissue reserves, obese patients may be at risk of malnutrition. ${ }^{(60)}$

Furthermore, it is now being recognised that not all ICU patients respond to artificial nutrition in the same manner. As a result, studies that include heterogeneous ICU populations with a wide spectrum of nutritional risk are more likely to yield negative or unreliable results. ${ }^{(76)}$ 
Although this has led to the formation of scores that purport to better identify the critically ill patient who is more likely to benefit from early aggressive provision of nutrition, considering studies that do not stratify by nutritional risk may introduce a degree of confounding. It has been shown, for example, that for patients who remain in ICU for more than three days, those at higher risk of malnutrition (as determined by the Nutrition Risk in Critically III (NUTRIC) score) had a better outcome with aggressive nutritional intervention comprising more calories and protein. $(76,209,210)$

\subsubsection{Open and Closed Units}

The model of intensive care delivery varies between countries. In the United States a model of "open ICUs" predominates. Under this model, the ICU has unlimited access to multiple doctors who are free to admit and manage their own patients. ${ }^{(211)}$ Full time directors and directors with qualifications in intensive care medicine are less common in countries practicing under this model, as are the requirements for a dedicated doctor around the clock. In Australasia "closed ICUs" predominate. A closed ICU has admission, discharge and referral policies under the control of intensivists, and ultimate responsibility for patient care, including all management decisions, are made by the treating intensivist. In addition, the 24-hour per day presence of a doctor dedicated to patients in the ICU is mandated. Cost effectiveness and patient outcomes are improved in closed units, hence introducing a degree of confounding in the interpretation of international studies. ${ }^{(203,204)}$ 
Although the differences between outcomes across countries is likely to be nullified through the use of treatment and control arms from either within the same ICU or at least within the same country, differences in culture, unit design and management intervention will necessarily introduce a degree of confounding.

\subsection{Significance of the Review}

Supporting the critically ill obese patient will become an increasingly important skill in the intensivist's armamentarium, and enteral nutritional therapy forms a cornerstone of this support. Despite this, neither the optimal total caloric goal nor the macronutrient components of a feeding regimen for the critically ill obese patient is evident. Although suggestions to alter the macronutrient goals for this vulnerable group of patients appear to have a sound physiological basis, the level of evidence is low, and the clinical approach to supporting the critically ill obese patient is based on expert opinion. The aim of this review is therefore to evaluate the literature to determine the best available evidence describing a nutritional strategy that targets energy and protein delivery to reduce morbidity and mortality in the obese patient who is critically ill.

\subsection{Review Question and Objective}

The objective of the review was to identify, critically appraise and synthesise the best available evidence on the effectiveness of enteral 
nutritional strategies targeting protein and calorie delivery for the critically ill obese patient on morbidity and mortality.

More specifically, the review question guiding the review was:

In the critically ill obese patient, what is the optimal enteral protein and calorie target that improves mortality and morbidity?

\subsection{Methodology Overview}

A systematic review is the systematic location, appraisal and synthesis of evidence from scientific studies in an attempt to evaluate and interpret all available research evidence pertinent to a particular clinical question. A systematic review provides an exhaustive and unbiased presentation of the available evidence by synthesising the results of multiple studies. ${ }^{(212,}$ ${ }^{213)}$ The findings and conclusions from systematic reviews are considered to hold greater validity than those arising from either single studies or traditional literature reviews as they are based on rigorous methods that aim to minimise the risk of error and bias throughout the review process. $^{(214)}$

Scientific rigour is maintained through the explicit and comprehensive reporting of the methods that are predefined and reproducible. ${ }^{(215)}$ This process includes the a priori development of a study protocol which includes: an explicit statement of the research question(s) to be answered by the review; clear delineation of the inclusion and exclusion criteria used to select studies; details of the search strategy used to locate both 
published and unpublished literature; a clear explanation of how studies are selected and critically appraised; and how the primary data is extracted and synthesised from the studies chosen for inclusion in the review. ${ }^{(214-216)}$ The study protocol for the review presented in this thesis was published in November, 2015 (Appendix 1)..$^{(217)}$

There are at least four major advantages of a systematic review of effects over clinical trials. Firstly, by combining data it offers increased statistical power over individual smaller clinical trials, that is, it increases the probability of identifying an effect when an effect is present. ${ }^{(213)}$ Secondly, by demonstrating similar effects across a wide variety of clinical settings, designs and populations, a systematic review of effects can provide evidence of the robustness and generalisability of the intervention under investigation. ${ }^{(213)}$ This heterogeneity could be seen either as a weakness of the systematic review process or an advantage because of its ability to enhance the generalisability and transferability of data. Thirdly, the transparent appraisal and systematic assessment of quality allows for a solid basis on which recommendations about the clinical management of patients can be made. In areas such as that explored in this thesis - how best to nutritionally support a critically ill obese patient - a systematic review of effects offers the advantage of the ability to draw a conclusion on the basis of the best available evidence about the course of clinical management from disparate sources. Finally, by focussing on a systematic review of effects, the utilisation of potentially expensive but ineffective interventions or, of even more concern, interventions that result in harm, 
can be identified. Ultimately, it is about improving the clinical management of patients and optimising outcomes. 


\section{Chapter 2 Methods}

This chapter describes the methods that were used in the conduct of the systematic review. The eligibility criteria, search strategy, and processes utilised for critical appraisal, data extraction and data synthesis are detailed.

The systematic review was undertaken in accordance with an a priori protocol (Appendix 1). ${ }^{(217)}$ The protocol pre-specified the methods to identify, appraise and synthesise the best available evidence on the effectiveness of enteral nutrition targeting calorie or protein targets to improve mortality or morbidity in the critically ill obese patient.

\subsection{Participants}

The systematic review considered studies that included critically ill obese adult patients receiving enteral nutrition at any stage during their ICU admission for longer than 72 hours. It was expected that this would primarily include studies that recruited patients during the early phase of their critical illness when volitional nutrition was not possible.

To ensure that included studies were representative of critically ill patients, only studies conducted in ICUs and in which $\geq 50 \%$ of recruited patients had been receiving mechanical ventilation for $\geq 24$ hours were eligible. This criteria has been used previously in systematic reviews examining nutritional outcomes in critically ill patients. ${ }^{(108)}$ In limiting the 
search to studies involving critically ill patients in this way, it was recognised that the criteria that determine ICU admission differs between jurisdictions. These criteria are determined in part by resources, in part by cultural differences and in part by the model of intensive care that predominates in that jurisdiction (closed versus open ICUs), and often give rise to diverse populations characterised by heterogeneity in admission diagnosis, severity of disease, metabolic derangement and therapeutic intervention(s). This conundrum has been recognised in other publications describing nutrition in critically ill patients. ${ }^{(83)}$

Critically ill populations composed of both elective and emergency ICU admissions were included, as were critically ill populations with a medical or surgical admission diagnosis.

The WHO definition of obesity, having a BMI $\geq 30 \mathrm{~kg} / \mathrm{m}^{2}$, was used. Where studies published prior to this time were identified that used an alternative definition of obesity (such as $125 \%$ of IBW), contact with the primary author was attempted to clarify baseline data.

Studies examining a paediatric population or in which the parenteral route of administration predominated were excluded.

\subsection{Interventions of Interest}

The systematic review considered all studies that compared any enteral feeding/nutrition that specified a goal calorie and/or protein target per 
kilogram weight. Despite ASPEN recommendations that IBW be used for calculating energy requirements in obese patients, wide variation exists in the use of which weight is used to calculate nutritional requirements (actual, adjusted, ideal)..$^{(32)}$ For the purposes of standardising the "dose" of nutrition as much as possible, IBW was reported where it could be determined from the primary source.

Nutritional therapy was defined by both the targeted caloric goal, and/or the targeted protein goal. With regard to total targeted calories, these were likely to fall into categories that were defined as hypo-caloric $1<20$ $\mathrm{kcal} / \mathrm{kg} / \mathrm{day})$, eu-caloric (20 - $30 \mathrm{kcal} / \mathrm{kg} / \mathrm{day})$ and hyper-caloric (> 30 $\mathrm{kcal} / \mathrm{kg} / \mathrm{day}$ ), while targeted protein delivery was categorised as low protein $(<1 \mathrm{~g} / \mathrm{kg} /$ day $)$, moderate protein $(1-2 \mathrm{~g} / \mathrm{kg} /$ day $)$ and high protein (> $2 \mathrm{~g} / \mathrm{kg} /$ day).

Alternatively, the "dose" of nutrition could be defined by the calories and/or protein actually delivered to the patient since there is a welldocumented disparity between the targeted dose and the dose delivered to patients. ${ }^{(72,92,147,149)}$ Despite this, the former method (namely the targeted goal) was used since this is the clinically important component clinicians prescribe the target dose, not the dose delivered to the small bowel. To tease out the effects of this, the "dose" actually delivered to the patient was also summarised where sufficient detail could be ascertained from the primary data. 


\subsection{Comparators}

A single a priori comparator was deliberately not specified in the protocol (Appendix 1) for a number of reasons. ${ }^{(217)}$ Firstly, there remains controversy within the critical care literature about the optimal caloric "dose" and the proportion of non-protein calories of nutritional therapy for the critically ill non-obese patient, let alone before the additional metabolic complications of the critically ill obese are introduced (Section 1.4)..$^{(71,72,107,108,126)}$ The paucity of high quality evidence guiding the optimal caloric "dose" is reflected in the disparities seen in international guidelines which are vague and often inconsistent, while two recent systematic reviews and meta-analyses, one addressing the question of eucaloric versus hypo-caloric targets ${ }^{(107)}$ and the second examining the effect of caloric delivery on hospital mortality, ${ }^{(108)}$ concluded that the optimal strategy for providing calories and protein in critically ill patients has yet to be determined. ${ }^{(32,71,83)}$ Secondly, and probably reflecting the absence of high quality evidence, there is a wide variety of approaches to nutritional therapy reported in the literature. This in part reflects a shift in the standard of care as the provision of nutrition is increasingly viewed as an active therapeutic intervention rather than merely the provision of support. ${ }^{(32,74,82,92)}$ Thirdly, there is a well-documented disparity between the "dose" prescribed and that actually delivered. ${ }^{(72,142,147,149)}$

For these reasons, any study that compared two (or more) different nutritional prescriptions targeting a calorie or protein goal was considered for inclusion in the review. 


\subsection{Outcomes}

Outcomes of interest in this review were chosen primarily for their importance as patient centred outcomes. In addition, secondary outcomes were selected for their ability to act as surrogate markers of morbidity.

\subsubsection{Primary Outcome}

Mortality at any time point was the a priori primary outcome. Survival is invariably central to the definition of successful treatment for both clinicians and patients. Mortality as a primary outcome has a number of advantages, most notably, that it is less susceptible to bias and confounders than other surrogate endpoints.

\subsubsection{Secondary Outcomes}

Although all cause mortality at any time point was chosen as the primary endpoint, the use of pre-specified, time dependent, mortality endpoints has become prevalent in critical care literature. These endpoints are often designed to extend beyond the ICU or hospital admission, and as such were identified as important secondary outcomes for the systematic review. The Brussels roundtable consensus statement emphasised the importance of moving beyond short term ICU or hospital mortality in considering the success of an admission for critical illness. ${ }^{(218)}$ For this 
reason, alternative time dependent mortality endpoints were sought in the studies selected, specifically ICU, 30-day, 60-day and 90-day mortality.

Furthermore, given that the likelihood of identifying large multi-centre trials was a priori considered low, other important patient centred outcomes that focussed on markers of morbidity were selected. These included ICU and hospital LoS, as well as duration of mechanical ventilation or its corollary ventilator free days. In selecting these endpoints, it was recognised that they are not hard endpoints and that there are potential confounders in interpreting the results. While ICU and hospital LoS are important measures for patients, clinicians and hospital managers, since LoS can also have significant economic implications, they have limitations since both can be influenced by extraneous factors such as bed block (the inability to discharge to a ward bed when the patient is ward ready). ${ }^{(219)}$ Duration of mechanical ventilation (or ventilator free days) as an endpoint has similar failings, with different facilities or indeed different clinicians within facilities adopting a different approach to ventilator weaning and extubation criteria. Despite these considerations, it was anticipated that similar issues would affect all arms (whether treatment or control) within each study reducing the effect of confounding.

Additional secondary outcomes included nitrogen balance, azotaemia (blood urea nitrogen), acute kidney injury, the incidence of nosocomial infection, weight loss or change in BMI, gastro-intestinal intolerance (high gastric residual volume, vomiting or diarrhoea) and insulin requirement. 
Nitrogen balance was chosen as a surrogate marker of the adequacy of protein supplementation and is calculated using formulae allowing for protein intake and 24-hour urinary protein excretion. ${ }^{(220)}$ Azotaemia (serum urea) and renal injury using the Acute Dialysis Quality Initiative (ADQI) definition (RIFLE) were chosen as markers of potential harm related to the inability to clear protein metabolites, and the implication that the presence of acute kidney injury (AKI) may limit protein delivery. ${ }^{(221)}$ The incidence of nosocomial infection is important since an association between nutritional status and nosocomial infection incidence was identified in a number of studies. ${ }^{(73,222,223)}$ Since weight loss is one proposed benefit of the ASPEN recommended prescription of a hypocaloric high-protein regimen, change in weight or a change in BMI was included, while gastro-intestinal intolerance is a common adverse event with nutritional interventions, particularly those that are calorie dense. ${ }^{(11,}$ ${ }^{32,95)}$ Finally, given the experimental findings that indicate high glucose concentrations have a range of negative effects, including increasing the production or expression (or both) of pro-inflammatory mediators, decreased chemotaxis and phagocytosis, alteration in leukocyte adherence, reduced release of reactive oxygen species from neutrophils and alterations in endothelial integrity, insulin requirement was selected as a surrogate marker of glycaemic control..$^{(224,225)}$ In addition, given the range of metabolic disturbances seen in the critically ill obese patient, glycaemic control is arguably more important in this group than in their lean counterparts. ${ }^{(34,92,95)}$ 


\subsection{Types of Studies}

Studies eligible for retrieval included, in the first instance, randomised controlled studies. In the absence of randomised controlled trials, any study with a non-randomised control, quasi-experimental, controlled before and after, or cohort study (whether prospective or retrospective) design was considered for inclusion in order to provide a sufficient evidence base to inform the effectiveness of different feeding regimes targeting calories and protein in the critically ill obese patient.

\subsection{Review Method}

\subsubsection{Search Strategy}

The search strategy involving a three-step process commenced in August 2015 , culminating in the final database searches reported in this thesis on $16^{\text {th }}$ October 2016. An initial limited scoping search of PubMed and CINAHL was undertaken using the following key words: ("critically ill" OR "intensive care") AND (obese OR overweight) AND (nutrition OR diet OR feed*). This was followed by an analysis of keywords contained in the titles and abstracts of articles identified by the scoping search. In addition, the index terms used to describe the articles were reviewed, and a Thesaurus search of the commonly used terms undertaken to ensure that the final search framework was as broad as possible. Logic grids for each database to be searched were constructed from the terms identified in a manner described by Aromataris and Riitano. ${ }^{(214)}$ 
A second search with all identified key words was undertaken across PubMed, Embase, ProQuest Dissertations and Theses and conference papers index, CINAHL, Cochrane Central Trials Register and the WHO Clinical Trials Register. Only studies published in English were eligible for retrieval, and there were no date limits applied.

Finally, the reference lists of all citations retrieved for full text screening were searched by hand for additional studies.

Details of the databases searched including the complete set of search strategies and logic grids are presented in Appendix 2.

\subsubsection{Study Selection}

Citations identified from the search strategy were exported into a bibliographic citation software (Endnote X7.5, Thomson Reuters, New York, USA) to facilitate assessment of eligibility for inclusion in the review.

Identification of relevant studies was performed by title and abstract review of all records retrieved against the a priori inclusion criteria (Sections $2.1-2.4$ ). If there was insufficient information in the abstract to make a decision about eligibility, the full text article was retrieved and the full text screened. Records that did not meet the inclusion criteria were excluded.

\subsubsection{Assessment of Methodological Quality}


Studies selected for retrieval were assessed by the author and a second independent reviewer (Dr S Harley) for methodological validity using a standardised critical appraisal instrument (Appendix 3) from the Joanna Briggs Institute Meta Analysis of Statistics Assessment and Review Instrument (JBI-MAStARI). There was no disagreement between the two independent reviewers that could not be resolved through discussion, and therefore no third independent reviewer was required.

Studies selected for retrieval were graded as high, moderate or low quality on the basis of the score achieved using the JBI-MAStARI tool. ${ }^{(216)}$ A score of 4 or less was considered low quality, $5-7$ moderate quality, and 8 or more high quality. It was decided a priori that studies would not be excluded from the analysis on the basis of quality, but were retrieved and analysed. In addition, the GRADE (Grading of Recommendations Assessment, Development and Evaluation) methodology as outlined by the British Medical Journal (BMJ) was applied to each retrieved study. ${ }^{(226,}$ 227) A GRADE score of 1 or less was considered very low quality, 2 low quality, 3 moderate quality and 4 or more high quality. ${ }^{(226)}$

\subsubsection{Data Extraction}

Data were extracted from papers included in the review using a standardised data extraction tool from JBI-MAStARI (Appendix 3). The data extracted included specific details about the intervention(s), populations, study methods and outcomes of significance to the review question and specific objectives. 
Studies that potentially contained subgroup data that was relevant to the research question and that could not be extracted directly from the published paper were identified for subsequent contact with the corresponding author. Contact was attempted between November 2015 and November 2016. Details of this correspondence are recorded in Appendix 4.

\subsubsection{Data Synthesis}

Analysis was conducted for the primary and all secondary outcomes where data could be obtained. Where data was provided by authors, mean and standard deviation was calculated for the production of forest plots, and, given the small sample sizes and to allow for more complete illustration of the distribution of the available data, median and IQR were calculated and presented in the accompanying narrative and tables. Outcome data were entered into Revman v5.3 (Cochrane, 2014) software to produce graphical visualisation (forest plot) of results (categorical data as odds ratios [Mantel-Haenszel method] and continuous as mean difference [inverse variance method]) to complement the accompanying narrative. 


\section{Chapter 3 Results}

This chapter presents the results of the systematic review. The results of the comprehensive search for studies, study selection processes, assessment of the methodological quality of the included studies, and important clinical and methodological characteristics of the included studies are presented. Narrative synthesis of available outcomes with accompanying figures and tables is also presented.

\subsection{Searching and Study Selection}

The search for published literature returned a total of 1000 citations from the included databases (PubMed 183; Embase 722; ProQuest Dissertations and Theses and Conference Papers Index 13; CINAHL 56; Cochrane Central Trials Register 12; and the WHO Clinical Trials Register 14). A total of 123 duplicate citations were identified and removed (Figure 7).

Of the remaining 877 unique citations that were screened against the inclusion criteria, 862 were excluded following review of the title and abstract, leaving 15 citations. Eighteen full text studies were retrieved and reviewed in detail for eligibility, including three identified following a hand search of the references of the 15 citations. Six of these studies were excluded outright: one contained an ineligible population (Genton et al. recruited hospitalised patients, not ICU patients $\left.{ }^{(228)}\right)$; two were of an ineligible design (Alberda et al. was an observational study describing current practice and did not include an intervention arm, ${ }^{(57)}$ and Dickerson 
et al. was an observational study comparing old and young patients, all of whom received the same nutrition prescription $\left.{ }^{(220)}\right)$; and three presented no primary data (Charles et al. was a conference abstract containing data which was subsequently published, ${ }^{(229)}$ and Arabi $^{(230)}$ and a study sponsored by Nestle ${ }^{(231)}$ were study protocols). Details of these studies and reasons for exclusion are listed in Appendix 5.1.

Of the remaining 12 studies, only one exclusively recruited an obese population (Dickerson). ${ }^{(11)}$ This study used a non-standard definition of obesity (125\% of IBW), and, despite subsequent contact with the corresponding author it was not possible to determine what proportion of patients were obese by the definition proposed for this review (See Section 2.1), nor the observational study arm in which they belonged (Appendix 4). ${ }^{(217)}$ Of the 11 remaining studies, none exclusively recruited an obese population nor reported outcomes in obese patients separately. ${ }^{(52-54,123,124,126,232-235)}$ With the exception of the studies by Rugeles and colleagues, ${ }^{(52,53)}$ all of the remaining studies identified in the search recruited ICU populations of which a proportion was obese (as would be expected, given the distribution of obesity in the population see Section 1.2.2). Given that each study contained a subset of patients who were obese, contact was attempted with the corresponding authors in order to obtain the relevant subgroup data. ${ }^{(11,54,123,124,126,232-234)}$ 


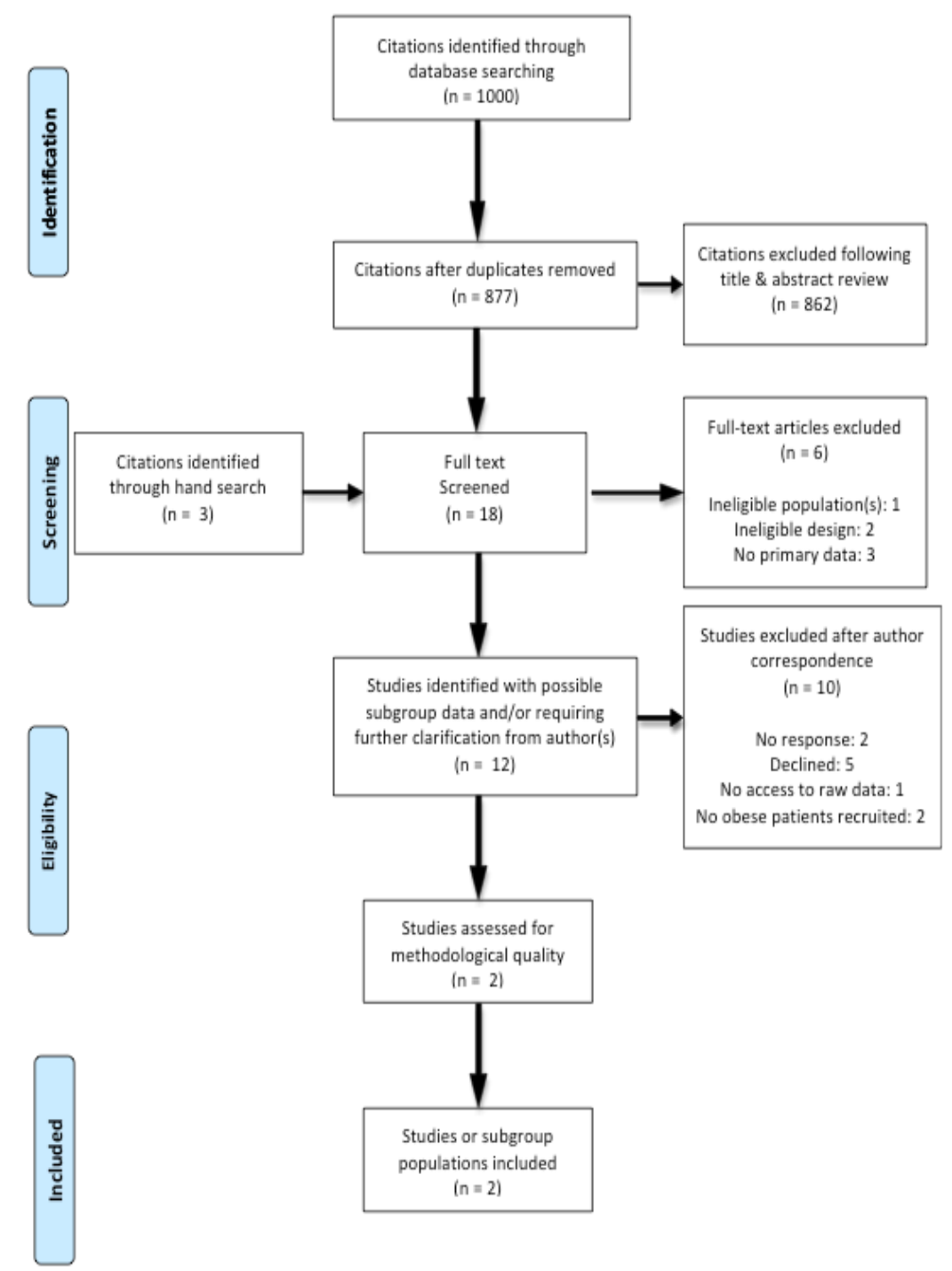

Figure 7: PRISMA flow diagram illustrating the study selection and inclusion process

One author (Dickerson ${ }^{(11)}$ ) declined on the basis that he did not have time to locate the data. Two authors $\left(\mathrm{Arabi}^{(54,123)}\right.$ and Charles $\left.{ }^{(124)}\right)$ representing three studies declined the invitation to forward subgroup data on the basis that they were preparing manuscripts for publication that contained 
the data requested. Charles provided data in the public domain from a conference presentation. ${ }^{(229)}$ Although it could be elucidated from this presentation that there were 30 obese patients enrolled in the study, and that there appeared to be a signal for increased infectious complications in the hypo-caloric group, there was insufficient information to adequately describe the characteristics of the obese subgroup. For this reason, the study was excluded from further analysis. No data were provided by Arabi who was deemed to have declined involvement. Doig ${ }^{(235)}$ declined to provide subgroup data. There was no response from either Rice on behalf of the National Heart, Lung and Blood Institute Acute Respiratory Distress Syndrome Clinical Trials Network ${ }^{(122)}$ or Ulusoy. ${ }^{(232)}$ Copies of the corresponding authors responses, where they were received, are catalogued in Appendix 4.2.

One author replied (Komjathy ${ }^{(234)}$ ), but was unable to contribute data (Appendix 4.2). Unfortunately, despite there being 26 obese patients (52\% of the total study population), it was not possible to extract data on the obese subgroup from the thesis. ${ }^{(234)}$ Requests for access to the raw data were unable to be fulfilled as the Institutional Review Board (IRB) conditions had required that the raw data be destroyed five years after thesis submission. This study was excluded from further analysis.

Rugeles and colleagues ${ }^{(53)}$ responded (Appendix 4.2); however, after reviewing their primary data no patients were found in their dataset who had a $\mathrm{BMI} \geq 30 \mathrm{~kg} / \mathrm{m}^{2}$. The methodological quality of all the excluded 
studies, as judged by JBI-MAStARI appraisal criteria, is detailed in Appendix 5.3. ${ }^{(216)}$

Subgroup data were provided by the TARGET investigators on behalf of Peake et $\mathrm{al}^{(126)}$ and by Petros et $\mathrm{l}^{(233)}$ for analysis following contact via email (Appendix 4.1). Inclusion of subgroup data such as this from randomised controlled trials necessarily reduces the methodological quality of the data since the subgroups are not randomised, and neither study reported stratification of patients by weight. Results of the literature search and the process of study selection and inclusion are shown in a PRISMA diagram (Figure 7).

\subsection{Methodological Quality of the Included Studies}

Critical appraisal of the two included studies are summarised in Tables 2 and 3, while results of the critical appraisal of those studies that were excluded due to an inability to supply data for the obese patients are presented in Appendix 5. Both of the included studies were prospective randomised controlled studies. Peake et al. ${ }^{(126)}$ was of high methodological quality by JBI-MAStARI criteria (Table 2 ) and moderate quality by GRADE criteria (Table 3), downgraded for sparse data. ${ }^{(226)}$ Petros et al. ${ }^{(233)}$ was of high methodological quality by JBI-MAStARI criteria (Table 2) and low quality by GRADE criteria (Table 3), downgraded on the basis of the lack of blinding and for sparse data. $(126,216,226,227,233)$ 
Table 2: Results of the critical appraisal of included studies using the JBIMAStARI tool ${ }^{(216)}$

\begin{tabular}{|l|c|c|c|c|c|c|c|c|c|c|c|c|}
\hline $\begin{array}{l}\text { Question } \\
\text { Number* }\end{array}$ & 1 & 2 & 3 & 4 & 5 & 6 & 7 & 8 & 9 & 10 & Total & Included \\
\hline $\begin{array}{l}\text { Peake, } \\
2014^{(126)}\end{array}$ & $\mathrm{Y}$ & $\mathrm{Y}$ & $\mathrm{Y}$ & $\mathrm{Y}$ & $\mathrm{Y}$ & $\mathrm{Y}$ & $\mathrm{Y}$ & $\mathrm{Y}$ & $\mathrm{Y}$ & $\mathrm{Y}$ & 10 & $\mathrm{Y}^{\wedge}$ \\
\hline $\begin{array}{l}\text { Petros, } \\
2016^{(233)}\end{array}$ & $\mathrm{Y}$ & $\mathrm{N}$ & $\mathrm{Y}$ & $\mathrm{Y}$ & $\mathrm{Y}$ & $\mathrm{N}$ & $\mathrm{Y}$ & $\mathrm{Y}$ & $\mathrm{Y}$ & $\mathrm{Y}$ & 8 & $\mathrm{Y}^{\wedge}$ \\
\hline
\end{tabular}

* JBI-MAStARI Critical Appraisal Tool for Randomised Control/Pseudo-randomised Trial (Appendix $3)^{(216)}$

$\wedge$ subgroup (obese patients) data only

$\mathrm{Y}$ - yes, meets criterion

$\mathrm{N}-$ no, does not meet criterion

Table 3: GRADE evaluation of included studies

\begin{tabular}{|l|c|c|c|c|c|c|}
\hline $\begin{array}{l}\text { GRADE } \\
\text { Criteria }\end{array}{ }^{(226)}$ & $\begin{array}{c}\text { Type of } \\
\text { Evidence }\end{array}$ & Quality & Consistency & Directness & $\begin{array}{c}\text { Effect } \\
\text { Size }\end{array}$ & GRADE \\
\hline $\begin{array}{l}\text { Peake, } \\
2014^{(126)}\end{array}$ & 4 & -1 & 0 & 0 & 0 & 3 \\
\hline $\begin{array}{l}\text { Petros, } \\
2016^{(233)}\end{array}$ & 4 & -2 & 0 & 0 & 0 & 2 \\
\hline
\end{tabular}

\subsection{Characteristics of the Included Studies}

In this section the study characteristics including the intervention for each of the studies are described in narrative form and are summarised in Table

4. As phase II trials, both studies recruited relatively a small number of patients, and contained even fewer obese patients (Peake et al. provided data for 21 obese patients from their total cohort of 112 patients, while Petros et al. provided data for 12 obese patients from their cohort of 100 patients). ${ }^{(126,233)}$

\subsubsection{Geographical Location of the Included Studies}

The study by Peake et al. ${ }^{(126)}$ was a multi-centre study undertaken across five ICUs in Australia, while the study by Petros et al. ${ }^{(233)}$ was a single- 
centre study conducted in a University hospital in Germany. The geographical location is important since ICU admission criteria are known to differ across countries, and local practices can differ markedly - for example, European and Australasian practices diverge, particularly around the role of supplemental parenteral nutrition and glycaemic targets. ${ }^{(83)}$ The possible confounding effects of supplemental parenteral nutrition were gcontrolled for by only including patients in the obese group analysis who had received enteral nutrition exclusively for the purposes of this review. 
Table 4: Characteristics of included studies

\begin{tabular}{|c|c|c|c|c|c|}
\hline Study Design & Population/Participants & Intervention & Outcome Measure(s) & Results & Comments \\
\hline $\begin{array}{l}\text { Peake et al. }{ }^{(126)} \\
\text { Prospective randomised double } \\
\text { blind control trial } \\
\text { Inclusion criteria } \\
\text { age } \geq 18 \text { years } \\
\text { invasive ventilation } \\
\text { expected to receive enteral } \\
\text { nutrition for } \geq 48 \text { hours } \\
\text { Exclusion criteria } \\
\text { received } \geq 12 \text { hours nutrition } \\
\text { fluid restriction } \\
\text { requirement for a specific } \\
\text { enteral formula }\end{array}$ & $\begin{array}{l}\text { Heterogenous ICU } \\
\text { population recruitment } \\
\text { between January and } \\
\text { May } 2013 \\
\text { Multi-centre (Australian) } \\
\mathrm{n}=112 \\
1.0 \mathrm{kcal} / \mathrm{ml} \mathrm{n}=55 \\
\text { obese } \mathrm{n}=7 \\
1.5 \mathrm{kcal} / \mathrm{ml} \mathrm{n}=57 \\
\text { obese } \mathrm{n}=14\end{array}$ & $\begin{array}{l}1.0 \text { kcal Vs } 1.5 \mathrm{kcal} \\
\text { Duration: up to } 10 \text { days } \\
\text { Protein delivered was the same } \\
\text { in each arm } \\
\text { IBW used in energy } \\
\text { calculations } \\
\text { Accounted for "incidental" } \\
\text { calories provided by propofol } \\
\text { and dextrose infusions. }\end{array}$ & $\begin{array}{l}\text { Daily calorie delivery }\left(1^{\circ}\right) \\
\text { Mortality (ICU, hospital, } 28 \\
\& 90 \text { day) } \\
\text { ICU LoS } \\
\text { Hosp LoS } \\
\text { VFD's (D28) } \\
\text { Feasibility }\end{array}$ & $\begin{array}{l}\text { Overall } \\
\text { Increased caloric delivery in } \\
\text { the } 1.5 \mathrm{kcal} / \mathrm{ml} \text { arm. } \\
\text { Mortality - trend towards } 90 \\
\text { day mortality benefit } \\
\text { ICU / hospital LoS - no } \\
\text { difference } \\
\text { VFD's - no difference } \\
\text { GI intolerance - no difference } \\
\text { GRV - no difference } \\
\text { Diarrhoea - no difference } \\
\text { Insulin dose - no difference } \\
\\
\text { Obese subgroup } \\
\text { Increased caloric delivery in } \\
\text { the } 1.5 \text { kcal/ml arm. } \\
\text { Mortality - no difference. } \\
\text { ICU / hospital LoS - no } \\
\text { difference } \\
\text { VFDs - no difference } \\
\text { GRV - no difference } \\
\text { Intolerance - no difference } \\
\text { Diarrhoea - no difference } \\
\text { Insulin dose - no difference }\end{array}$ & $\begin{array}{l}\text { Subgroup data } \\
\text { Feasibility, pilot study. } \\
\begin{array}{c}\text { Not powered for } \\
\text { mortality }\end{array}\end{array}$ \\
\hline
\end{tabular}




\begin{tabular}{|c|c|c|c|c|c|}
\hline Study Design & Population/Participants & Intervention & Outcome Measure(s) & Results & Comments \\
\hline $\begin{array}{l}\text { Petros et al. }{ }^{(233)} \\
\text { Prospective randomised, non-blinded } \\
\text { control study } \\
\text { Inclusion criteria } \\
\text { need for artificial nutrition for } \geq 3 \text { days } \\
\text { Exclusion criteria } \\
\text { malnutrition } \\
\text { age }<18 \text { or }>80 \\
\text { pregnancy } \\
\text { active malignancy } \\
\text { re-admission } \\
\text { DNR in place } \\
\text { refusal } \\
\text { consented too late }\end{array}$ & $\begin{array}{l}\text { Medical ICU single centre } \\
\begin{array}{l}\text { July } 08 \text { - Dec } 10 \\
n=100 \\
\text { normo } n=54 \\
\text { obese } n=6 \\
\text { hypo } n=46 \\
\text { obese } n=6\end{array}\end{array}$ & $\begin{array}{l}\text { Normocaloric } \\
\text { Vs } \\
\text { Hypo-caloric } \\
\text { Energy target derived from } \\
\text { IC or Ireton-Jones formula } \\
\text { using actual body weight } \\
\text { Duration: up to } 7 \text { days } \\
\text { Do not specifically mention } \\
\text { calories derived from } \\
\text { propofol, but account for } \\
\text { "non-nutrition calories" } \\
\text { Up to } 30 \% \text { of daily caloric } \\
\text { delivery derived from } \\
\text { supplemental } \mathrm{PN}^{\star}\end{array}$ & $\begin{array}{l}\text { Nosocomial infection } \\
\left(1^{\circ}\right)^{\wedge} \\
\text { Insulin requirement } \\
\text { Gl intolerance }\end{array}$ & $\begin{array}{l}\text { Overall } \\
\text { Hypo-caloric group } \\
\text { increased nosocomial } \\
\text { infections } \\
\text { reduced insulin } \\
\text { requirement } \\
\text { less diarrhoea } \\
\text { Obese subgroup* } \\
\text { Mortality - no difference } \\
\text { Insulin requirement - no } \\
\text { difference. } \\
\text { Nosocomial infection - no } \\
\text { difference } \\
\text { Diarrhoea - no difference } \\
\text { Intolerance - no difference } \\
\text { ICU LoS - no difference } \\
\text { Hospital LoS - no } \\
\text { difference }\end{array}$ & $\begin{array}{l}\text { Subgroup data } \\
\text { Feasibility, pilot } \\
\text { study. } \\
\text { Used both IC and } \\
\text { formulae to } \\
\text { estimate caloric } \\
\text { requirements } \\
\text { In the obese } \\
\text { subgroup, } 7 / 12 \\
\text { patients had IC } \\
\text { used to calculate } \\
\text { energy } \\
\text { requirements } \\
\text { Not powered for } \\
\text { mortality }\end{array}$ \\
\hline
\end{tabular}

* no supplemental PN used in the obese subgroup

^ defined by the Centres for Disease Control (CDC) and by consensus between the non-

blinded treating intensivist, and blinded microbiologist and infectious diseases specialist. ${ }^{(236)}$

$\mathrm{IC}$ - indirect calorimetry

DNR - Do Not Ri

$n$ - number of patients

$\mathrm{ml}-$ millilitres kcal - kilocalories

IBW - Ideal Body Weight calculated using modified Devine formula. ${ }^{(12,15)}$

VFD - ventilator free days

LoS - Length of Stay

GRV - gastric residual volume

$1^{\circ}$ - primary outcome measure

SOFA - Sequential Organ Failure Assessment 


\subsubsection{Study Populations of the Included Studies}

The two identified studies for which data was provided contributed a total of 33 obese participants: 21 patients from a mixed (medical/surgical) ICU (Peake et al.), ${ }^{(126)}$ and 12 recruited from a medical ICU (Petros et al.). ${ }^{(233)}$ Baseline demographic data from each study are presented in Tables 5 (Peake et al..) ${ }^{(126)}$ and 6 (Petros et al.). ${ }^{(233)}$ Obese patients recruited to the TARGET study by Peake et al. are younger, heavier and seem to have a lower acuity of illness as measured by the acute physiology and chronic health evaluation II (APACHEII) score. 
Table 5: Obese group demographic data derived from raw data provided by Peake et al. ${ }^{(126)}$

\begin{tabular}{|c|c|c|c|}
\hline Peake et al. ${ }^{(126)}$ & $\begin{array}{c}1.0 \mathrm{kcal} / \mathrm{ml} \\
(\mathrm{n}=7)\end{array}$ & $\begin{array}{c}1.5 \mathrm{kcal} / \mathrm{ml} \\
(\mathrm{n}=14)\end{array}$ & p Value \\
\hline Age (years) & $56.0(48.5-67.0)$ & $59(45-67)$ & 0.85 \\
\hline Body weight (kg) & $111(98.0-117.5)$ & $104(97.8-125.8)$ & 0.97 \\
\hline Body mass index $\left(\mathrm{kg} / \mathrm{m}^{2}\right)$ & $41.5(35.8-44.3)$ & $35.6(33.5-41.1)$ & 0.41 \\
\hline Ideal body weight (kg) & $56.0(53.7-60.2)$ & $65.1(61.5-73.3)$ & 0.05 \\
\hline APACHE II & $15.5(13.5-31.5)$ & $24(18-34.3)$ & 0.39 \\
\hline Diabetes mellitus, n(\%) & $4(57 \%)$ & $6(42 \%)$ & 0.88 \\
\hline \multicolumn{4}{|c|}{ APACHE III admission category } \\
\hline Neurological & 4 & 1 & 0.05 \\
\hline Respiratory & 1 & 3 & 0.84 \\
\hline Cardiovascular & 0 & 3 & 0.50 \\
\hline Sepsis & 0 & 4 & 0.33 \\
\hline Gastro-intestinal & 1 & 1 & 0.79 \\
\hline Other & 1 & 2 & 0.51 \\
\hline
\end{tabular}

APACHE - Acute Physiology and Chronic Health Evaluation 
Table 6: Obese group demographic data derived from raw data provided by Petros et al. ${ }^{(233)}$

\begin{tabular}{|c|c|c|c|}
\hline & $\begin{array}{c}\text { Eucaloric } \\
\left(13 \mathrm{kcal} / \mathrm{kg}^{\wedge} / \text { day }\right) \\
(\mathrm{n}=6)\end{array}$ & $\begin{array}{c}\text { Hypo-caloric } \\
(8.8 \mathrm{kcal} / \mathrm{kg} \wedge / \text { day }) \\
(\mathrm{n}=6)\end{array}$ & p Value \\
\hline Age (years) & $64(56.5-71.75)$ & $67(61-69.25$ & 0.93 \\
\hline Actual body weight (kg) & $95(95.0-107.5)$ & $95(95.0-129.3)$ & 1.0 \\
\hline Body mass index $\left(\mathrm{kg} / \mathrm{m}^{2}\right)$ & $33.8(33.1-35.3)$ & $34.9(34.0-40.6)$ & 0.81 \\
\hline APACHE II & $27(25.5-34.3)$ & $27(25.5-37.0)$ & 0.75 \\
\hline Diabetes mellitus & 3 & 0 & 0.18 \\
\hline \multicolumn{4}{|l|}{ Admission diagnosis } \\
\hline Sepsis & 2 & 4 & 0.56 \\
\hline Cardiac failure & 1 & 0 & 1.0 \\
\hline Cardiac arrest & 2 & 0 & 0.44 \\
\hline Respiratory failure & 1 & 2 & 1.0 \\
\hline
\end{tabular}

APACHE - Acute Physiology and Chronic Health Evaluation 


\subsubsection{Study Design and Interventions of the Included Studies}

Peake et al. ${ }^{(126)}$ randomised patients to receive either a $1.0 \mathrm{kcal} / \mathrm{ml}$ or a 1.5 $\mathrm{kcal} / \mathrm{ml}$ enteral solution for up to 10 days (Table 4). The difference in caloric concentration was shared between fat and carbohydrate, while protein and fibre concentrations of the solutions were approximately the same. The enteral nutrition was delivered at a goal rate of $1 \mathrm{ml} / \mathrm{kg} /$ hour (to a maximum of $100 \mathrm{ml} / \mathrm{hr}$ ) where weight was IBW determined by a modified Devine formula, which is the same equation as that used in the ARDSNet ARMA study. ${ }^{(12,15)}$ Importantly, unlike Petros et al., ${ }^{(233)}$ the protein component in each arm was the same and resulted in $\sim 1.2 \mathrm{~g} / \mathrm{kg}$ IBW/day being delivered for patients with an absolute weight of $\leq 100 \mathrm{~kg}$. For patients $>100 \mathrm{~kg}$, there would be less protein delivered (since delivery was determine by $\mathrm{ml} / \mathrm{kg}$ ), and this resulted in under-dosing of protein. Follow=up for the primary outcome (calorie delivery) was up to 14 days, while 90-day mortality was included as a secondary endpoint. ${ }^{(126)}$

Petros et al. ${ }^{(233)}$ randomised patients to either a hypo-caloric (50\% of calculated energy requirement) nutritional target or a eucaloric target (targeting the total daily energy expenditure) at a single centre (Table 4). Energy expenditure was determined by indirect calorimetry or using the 1992 Ireton-Jones formula in which IBW derived from the Hamwi calculation was used. The use of IBW in the 1992 Ireton-Jones formula is an interesting decision since the original formula appeared to use actual body weight, and other work by Ireton-Jones and colleagues supported the use of actual body weight in determining caloric requirements. ${ }^{(237,238)}$ 
Subsequent personal correspondence with the author (Appendix 4)

confirmed that actual body weight was used in the Ireton-Jones equation but that the data published was referenced to IBW at the request of peer reviewers. Due to technical difficulties (malfunction of the indirect calorimeter), the majority of patients (63\%) had their caloric requirements calculated from the Ireton-Jones formula. Because a single standard solution was used, protein delivery would have been reduced by the same proportion as calories. None of the patients in the subgroup data supplied by the authors received supplemental parenteral nutrition. The intervention was limited to seven days or the commencement of volitional nutritional intake, while follow-up was until ICU discharge for the primary outcome (nosocomial infection) or 28-day all-cause mortality. ${ }^{(233)}$ The primary outcome (nosocomial infection) used the Centres for Disease Control ( $C D C)$ definition and was by consensus between the non-blinded treating intensivist, and the blinded microbiologist and infectious diseases specialist. $^{(233,236)}$

\subsection{Outcomes}

Neither study identified provided outcome data on all the endpoints specified in Section 2.4. Outcome data that could be ascertained from data provided by the authors is shown in Table 7. 
Table 7: Review endpoints that could be ascertained from data provided by authors of the included studies

\begin{tabular}{|l|c|c|}
\hline Endpoint & Peake et al $^{(126)}$ & Petros et al $^{(233)}$ \\
\hline Mortality (any time point) & Yes & Yes \\
\hline Mortality (ICU) & Yes & No \\
\hline Mortality (30-day) & Yes (28-day) & Yes (28-day) \\
\hline Mortality (60-day) & No & No \\
\hline Mortality (90-day) & Yes & No \\
\hline ICU Length of stay & Yes & Yes \\
\hline Hospital length of stay & Yes & Yes \\
\hline Duration of mechanical \\
ventilation
\end{tabular}

ICU - Intensive care unit

BMI - Body mass index 


\subsubsection{Data Synthesis}

Data from the two included studies could not be statistically meta analysed due to the vastly different delivery of calories and by the different "dose" of protein provided in each study - Peake et al. ${ }^{(126)}$ delivered a median $19.9 \mathrm{kcal} / \mathrm{kg}$ IBW/day to the "control" arm and 30.1 $\mathrm{kcal} / \mathrm{kg} \mathrm{IBW/day}$ to the "intervention" arm (Table 8), while Petros et al. ${ }^{(233)}$ delivered a median $13.0 \mathrm{kcal} / \mathrm{kg} \mathrm{IBW} /$ day to the "control" arm and a median $8.8 \mathrm{kcal} / \mathrm{kg} \mathrm{IBW} /$ day to the "intervention" arm (Table 9). The net result of these observations is a notable difference in the intervention delivered to trial participants in each of the studies included, and combining these would not produce meaningful results. For these reasons, results are presented in the next section in chronological publication order, firstly with an overview of the study results as a whole, followed by more detailed results from an analysis of the obese patient data provided by the authors.

For both studies included in the review, it is important to acknowledge that the use of subgroup data necessarily substantially reduces the power of the analysis (in phase II trials that were likely already underpowered). Furthermore, because obesity was not stratified in the original study, there can be no guarantee that randomisation had been effective at the subgroup level.

\subsubsection{Peake et al.}


Overall, the study by Peake et al. ${ }^{(126)}$ demonstrated good group separation with a mean $1504 \mathrm{kcal} /$ day delivered to the $1.0 \mathrm{kcal} / \mathrm{ml}$ group, and 2040 $\mathrm{kcal} /$ day to the $1.5 \mathrm{kcal} / \mathrm{ml}$ group, representing a statistically and clinically significant difference in the primary outcome $a$ priori specified by the authors. ${ }^{(126)}$ There were no statistically significant differences reported in any of the secondary outcomes.

The outcome data for the obese group (seven in the $1.0 \mathrm{kcal} / \mathrm{ml}$ group and 14 in the $1.5 \mathrm{kcal} / \mathrm{ml}$ group) provided by the authors are presented in Table 8. Examination of the demographic data presented in Table 5 shows the groups were reasonably well matched at baseline. There continued to be good group separation with the $1.0 \mathrm{kcal} / \mathrm{ml}$ group receiving a median $19.9 \mathrm{kcal} / \mathrm{kg} \mathrm{IBW} /$ day compared to $30.1 \mathrm{kcal} / \mathrm{kg} \mathrm{IBW} /$ day in the $1.5 \mathrm{kcal} / \mathrm{kg}$ group (Table 8). Importantly, both groups received the same amount of protein (median $62 \mathrm{~g} /$ day versus $59.5 \mathrm{~g} /$ day; $\mathrm{p}=0.97$ ). This is slightly below international recommendations $(1.2-2 \mathrm{~g} / \mathrm{kg} /$ day, and $/ \mathrm{or}>2 \mathrm{~g} / \mathrm{kg}$ IBW/day for the obese). ${ }^{(32,83)}$ The specific outcomes of interest to the review are presented in the next section. 
Table 8: Obese group outcome data derived from raw data provided by Peake et al. ${ }^{(126)}$

\begin{tabular}{|c|c|c|c|}
\hline Peake et al. ${ }^{(126)}$ & $\begin{array}{c}1.0 \mathrm{kcal} / \mathrm{ml} \\
(\mathrm{n}=7)\end{array}$ & $\begin{array}{c}1.5 \mathrm{kcal} / \mathrm{ml} \\
(\mathrm{n}=14)\end{array}$ & p Value \\
\hline Estimated energy requirement (kcal/day) & $\begin{array}{c}1560(1538-1700) \\
(n=5)\end{array}$ & $\begin{array}{c}2034(1850-2369) \\
(n=9)\end{array}$ & 0.43 \\
\hline Estimated protein requirement (grams/day) & $\begin{array}{c}84.5(83.0-91.0) \\
(n=5)\end{array}$ & $\begin{array}{c}103.5(90.0-113.0) \\
(n=9)\end{array}$ & 0.25 \\
\hline Targeted calories (kcal/kg*/day) & $19.9(18.3-21.6)$ & $29.3(20.6-33.3)$ & 0.17 \\
\hline Targeted EN per day (kcal/day) & $1081(1043.5-1173.5)$ & $1670(1296.75-2299.0)$ & 0.05 \\
\hline Targeted protein (grams/kg*/day) & $1.10(1.01-1.19)$ & $1.10(0.77-1.25)$ & 0.55 \\
\hline $\begin{array}{l}\text { Energy delivered (kcal/day) } \\
\text { (all sources) }\end{array}$ & $1114.5(1092-1288.5)$ & $1800(1371.5-2414.8)$ & 0.01 \\
\hline Energy delivered (kcal/kg*/day) & $19.9(18.6-24.4)$ & $30.1(22.3-36)$ & 0.01 \\
\hline Energy delivered less GRV & $1073(1006-1278.5)$ & $1798(1371-2415.8)$ & 0.03 \\
\hline $\begin{array}{l}\text { Protein delivered (grams/day) } \\
\text { (all sources) }\end{array}$ & $59.5(57.5-64.5)$ & $62(48.3-87)$ & 0.97 \\
\hline Aspirate volume (ml per 24 hours) & $48(35-102)$ & $168(51.8-280.5)$ & 0.85 \\
\hline Largest aspirate (ml) & $200(165-262.5)$ & $150(42.5-315)$ & 0.740 \\
\hline Regurgitation & $2(29)$ & $0(0)$ & 0.19 \\
\hline
\end{tabular}




\begin{tabular}{|c|c|c|c|}
\hline PEAKE et al. (cont'd) & $1.0 \mathrm{kcal} / \mathrm{ml}$ & $1.5 \mathrm{kcal} / \mathrm{ml}$ & p Value \\
\hline Diarrhoea & $2(29)$ & $4(29)$ & 0.61 \\
\hline Required insulin & $4(57)$ & $8(57)$ & 0.64 \\
\hline Days with $B G L<2.2 \mathrm{mmol} / \mathrm{L}$ (days) & $0(0)$ & $0(0)$ & N/A \\
\hline Mean insulin dose (U) & $32(24.5-52.2)$ & $69.1(43.8-131.9)$ & 0.15 \\
\hline Day 28 VFD & $22.4(16.2-25.3)$ & $22.6(0.9-25.2)$ & 0.88 \\
\hline ICU LoS (days) & $7.7(6.0-10.6)$ & $7.5(5.0-10.5)$ & 0.97 \\
\hline Hospital LoS (days) & $9.1(7.7-26.3)$ & $16.5(12.8-20.3)$ & 0.25 \\
\hline ICU mortality & $1(14 \%)$ & $2(15 \%)^{\wedge}$ & 0.55 \\
\hline Hospital mortality & $1(14 \%)$ & $2(15 \%)^{\wedge}$ & 0.55 \\
\hline 28-day mortality & $1(14 \%)$ & $2(15 \%)^{\wedge}$ & 0.55 \\
\hline 90-day mortality & $1(14 \%)$ & $2(15 \%)^{\wedge}$ & 0.55 \\
\hline Mortality (any time point) & 1 & 2 & 0.55 \\
\hline
\end{tabular}

Data presented as median (and inter-quartile range) * kilograms ideal body weight

$\wedge$ one patient lost to follow up, 2 deaths of 13 patients followed up

Mann-Whitney $U$ test ( 2 sided) for continuous variables

GRV - gastric residual volume

LoS - Length of Stay

VFD - Ventilator Free Days

Yates corrected $\chi^{2}$ for dichotomous variables

BGL - Blood glucose level 


\subsubsection{Mortality}

Considering only the obese patients, there was no difference in the primary outcome of mortality at any time point (Table 8) nor was there a significant difference in any of the secondary mortality outcomes (ICU and 90-day mortality) that were ascertainable from the data provided by the authors (Figure 8, Panels $\mathrm{A}-\mathrm{C}$ ). The review protocol specified 30-day mortality as a secondary endpoint, while the study by Peake et al. ${ }^{(126)}$ reported 28-day mortality. ${ }^{(217)}$ There was nevertheless no significant difference in 28-day mortality between the two groups.

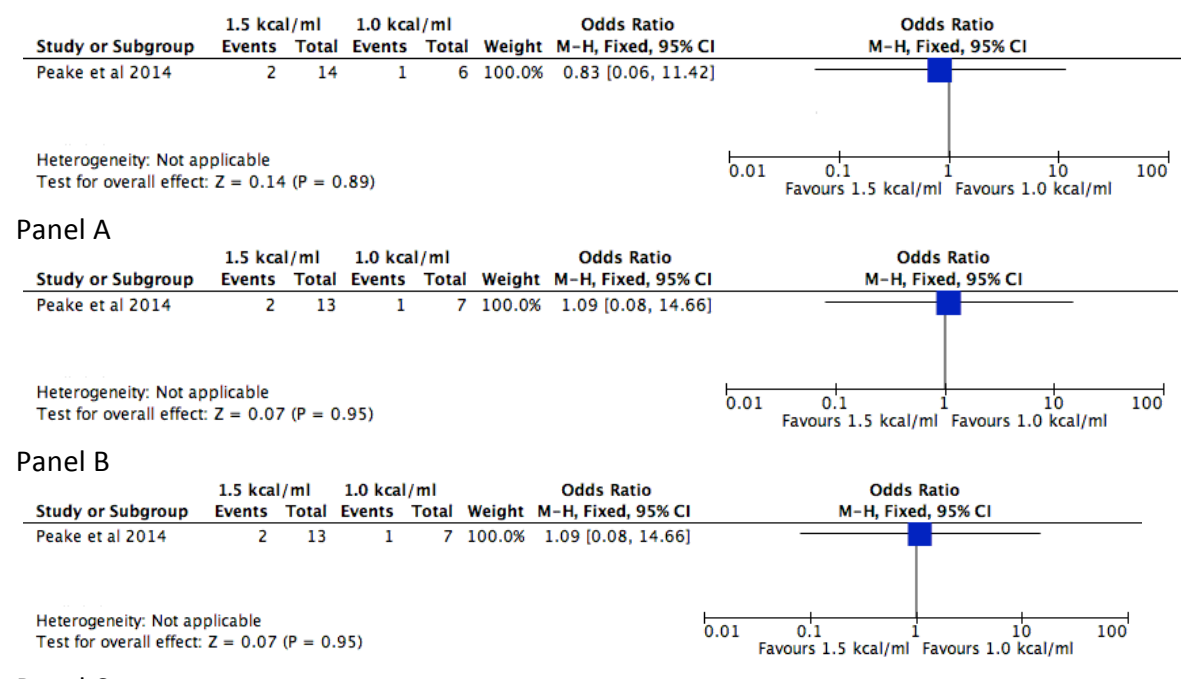

Panel C

Figure 8: Mortality endpoints derived from data provided by Peake et al. ${ }^{(126)}$ comparing a standard feed $(1.0 \mathrm{kcal} / \mathrm{ml})$ and an energy dense feed $(1.5 \mathrm{kcal} / \mathrm{ml})$ in obese critically ill adult patients (BMI $\geq 30 \mathrm{~kg} / \mathrm{m}^{2}$ ) Panel A - mortality (any time point); Panel B - ICU mortality; Panel C - 90-day mortality 


\subsubsection{Length of Stay and Duration of Mechanical Ventilation}

When ICU LoS for critically ill obese patients who received a standard feed $(1.0 \mathrm{kcal} / \mathrm{ml})$ was compared to those who received an energy dense feed $(1.5 \mathrm{kcal} / \mathrm{ml})$, there was no statistically significant difference between the groups (Figure 9, Panel A). Similarly, there was no significant difference between the two obese groups when hospital LoS was compared (Figure 9, Panel B). The Forest plot for ventilator free days (at day 28), demonstrating no significant difference between the groups is displayed in Figure 9, Panel C.

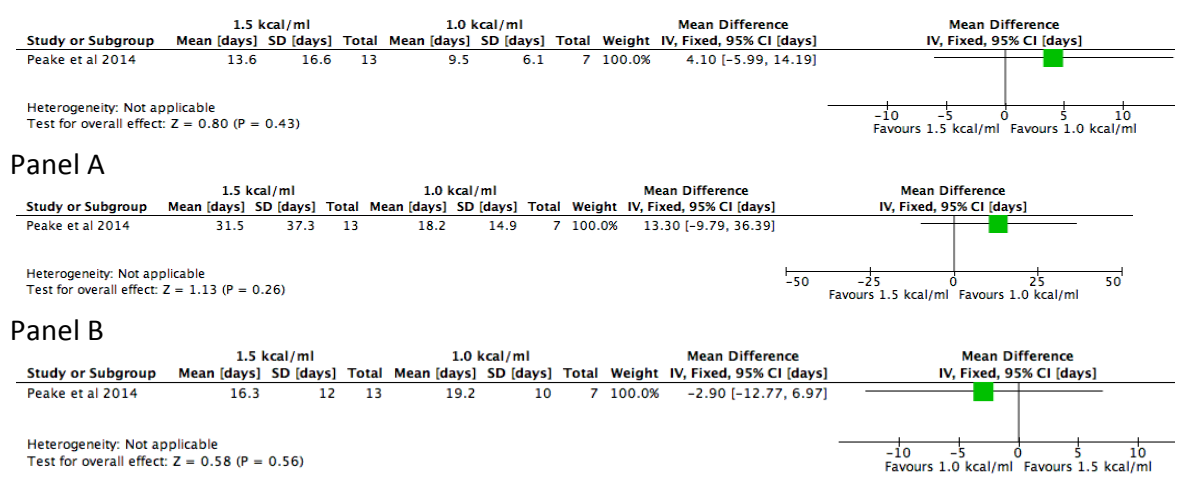

Panel C

Figure 9: Secondary endpoints related to hospital course derived from data provided by Peake et al. ${ }^{(126)}$ comparing a standard feed $(1.0 \mathrm{kcal} / \mathrm{ml})$ and an energy dense feed $(1.5 \mathrm{kcal} / \mathrm{ml})$ in adult critically ill obese patients $(\mathrm{BMI} \geq 30$ $\mathrm{kg} / \mathrm{m}^{2}$ ) (all mean difference values are in days) Panel A - ICU LoS; Panel B - Hospital LoS; Panel C - Duration of mechanical ventilation (recorded as ventilator free days) 


\subsubsection{Gastro-intestinal Intolerance}

Measures of gastro-intestinal intolerance that were recorded by Peake et al. ${ }^{(126)}$ included gastric residual volumes (recorded as aspirate), regurgitation (vomiting) and diarrhoea. For the obese groups in each arm $(1.0 \mathrm{kcal} / \mathrm{ml}$ Vs $1.5 \mathrm{kcal} / \mathrm{ml})$, there was no significant difference in any of the measures of gastro-intestinal intolerance (Figure 10, Panels A - C). Indeed, for the gastric residual volume, there was no difference in the largest aspirate measured nor in the average daily aspirate (Table 8).

\subsubsection{Insulin Requirement}

Obese patients receiving the energy dense formulation $(1.5 \mathrm{kcal} / \mathrm{ml})$ were no more likely to require insulin (Table 8), but when they did, required a statistically non-significantly higher daily dose of insulin (Figure 10, Panel D). 

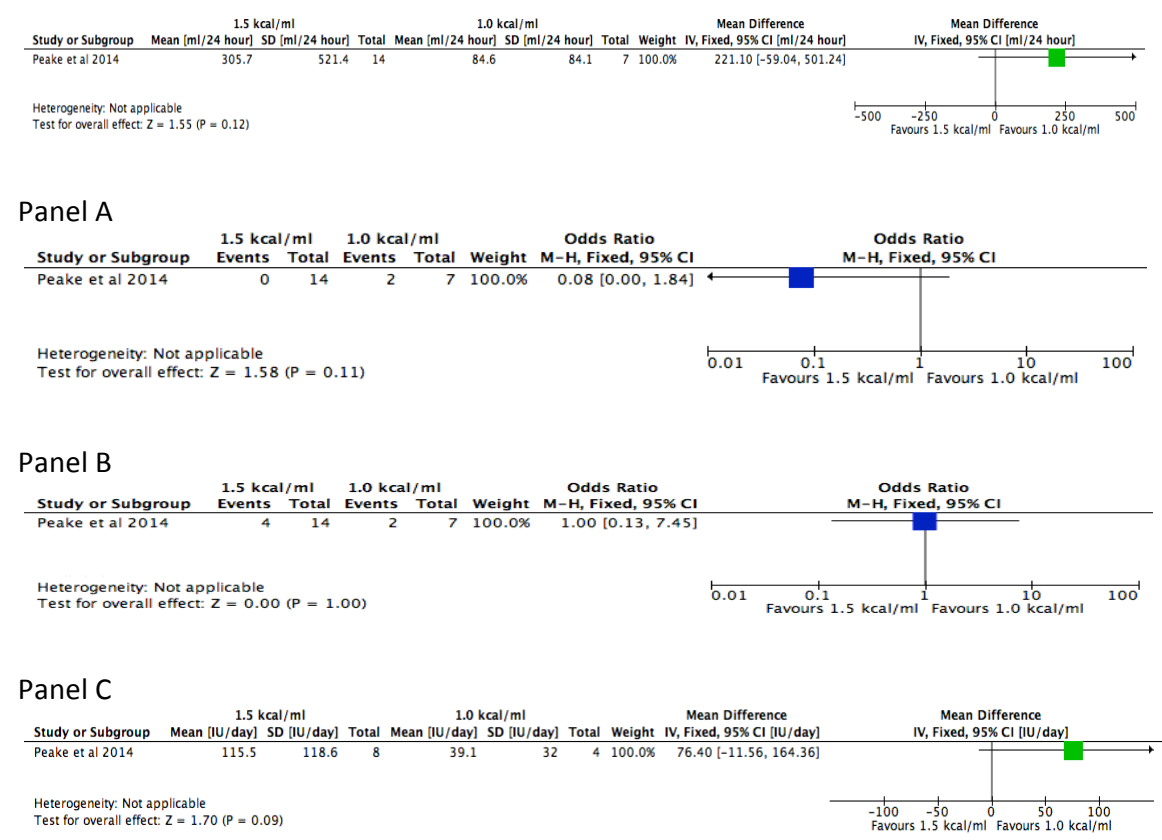

Panel D

Figure 10: Secondary endpoints related to hospital course derived from data provided by Peake et al. ${ }^{(126)}$ comparing a standard feed $(1.0 \mathrm{kcal} / \mathrm{ml})$ and an energy dense feed $(1.5 \mathrm{kcal} / \mathrm{ml})$ in obese critically ill adult patients $\left(\mathrm{BMI} \geq 30 \mathrm{~kg} / \mathrm{m}^{2}\right.$ ) Panel A - Gastric residual volume (ml); Panel B - Regurgitant events (vomiting); Panel C - Diarrhoea; Panel D - Insulin requirement* (IU)

* 4/7 patients in the $1.0 \mathrm{kcal} / \mathrm{ml}$ arm and $8 / 14$ patients in the $1.5 \mathrm{kcal} / \mathrm{ml}$ arm required insulin

\subsubsection{Petros et al.}

Overall, the study by Petros et al. ${ }^{(233)}$ also demonstrated good group separation after day 1, with the hypo-caloric group receiving significantly fewer calories per day until day $7 .{ }^{(233)}$ The group also received significantly less protein. ${ }^{(233)}$ There was a significant increase in the incidence of the primary outcome specified by Petros et al. (nosocomial infection) in patients randomised to the hypo-caloric group. This group also had a 
significantly lower insulin requirement and less gastro-intestinal intolerance measured by gastric residual volume (GRV). ${ }^{(233)}$ There was no statistically significant difference in any of the remaining a priori specified secondary outcome measures, including ICU, hospital or 28-day mortality. ${ }^{(233)}$

In the obese group, IC was used in seven of the 12 patients to calculate energy requirements (see Section 1.3.1). In the remaining five patients, the Ireton-Jones formula using actual body weight as the co-efficient was used. The obese group demographic data provided by the authors, presented as median and IQR in parenthesis (Table 6), showed the groups were well matched at baseline. There was group separation with a significant difference in the calories provided in each arm (median 8.8 $\mathrm{kcal} / \mathrm{kg}$ actual body weight/day in the hypo-caloric arm versus $13.0 \mathrm{kcal} / \mathrm{kg}$ actual body weight/day in the eucaloric arm; $p=0.01$ ). There was also a significant difference in the amount of protein delivered in each arm (median $0.40 \mathrm{~g} / \mathrm{kg}$ actual body weight/day versus $0.29 \mathrm{~g} / \mathrm{kg}$ actual body weight/day; $p=0.05$ ) for the hypo-caloric and eucaloric arms, respectively, both of which were substantially below current recommendations. ${ }^{(32,83)}$ This is consistent with recent observational data showing that protein is frequently under delivered. ${ }^{(106)}$ The specific outcomes of interest to the review are presented in the next section and summarised in Table 9. 
Table 9: Obese group outcome data derived from raw data provided by Petros et al. ${ }^{(233)}$

\begin{tabular}{|c|c|c|c|}
\hline & $\begin{array}{l}\left.\text { Eucaloric (13 kcal/ } / \mathrm{kg}^{\wedge} / \mathrm{day}\right) \\
\qquad(\mathrm{n}=6)\end{array}$ & $\begin{array}{l}\text { Hypo-caloric (8.8 kcal } / \mathrm{kg}^{\wedge} / \text { day) } \\
\qquad(n=6)\end{array}$ & p Value \\
\hline Estimated energy expenditure (kcal/kg*/day) & $15.7(14.4-19.8)$ & $17.7(16.3-19.2)$ & 0.58 \\
\hline Calories delivered (kcal/kg^/day) & $13.0(11.4-18.6)$ & $8.8(7.4-9.5)$ & 0.01 \\
\hline Protein delivered (grams/kg^/day) & $0.40(0.39-0.62)$ & $0.29(0.25-0.33)$ & 0.05 \\
\hline Insulin requirement (IU/day) & $84.0(75.0-126.3)$ & $24.5(15.1-65.0)$ & 0.07 \\
\hline EN intolerance (days) & $1.0(0.3-3.0)$ & $0(0-1)$ & 1.0 \\
\hline Diarrhoea (Y/N) & 4 & 3 & 1.0 \\
\hline Diarrhoea (number of days) & $1(0.25-3)$ & $0(0-1)$ & 0.58 \\
\hline Nosocomial infection ${ }^{\#}$ & $0(0-0)$ & $0(0-0)$ & 1.0 \\
\hline ICU LoS (days) & $22.0(13.8-35.3)$ & $31.0(28.8-41.8)$ & 0.17 \\
\hline Hospital LoS (days) & $30.0(25.5-57.3)$ & $41(41.0-68.3)$ & 0.57 \\
\hline Mortality (28-day) & 1 & 0 & 1.0 \\
\hline
\end{tabular}

Data presented as median (and inter-quartile range)

* kilograms ideal body weight

LoS - Length of Stay

kilograms actual body weight

\# defined by the criteria published by the Centres for Disease Control, and by discussion

Mann-Whitney $U$ test $(2$ sid

between treating physicians, a Microbiologist and an Infectious Disease Specialist. ${ }^{233,236}$

Yates corrected $\chi^{2}$ for dichotomous variable 


\subsubsection{Mortality}

Considering only the obese patients, there was no difference in the primary outcome of mortality at any time point (Table 9). Data for the pre-specified time points of ICU or hospital mortality were not collected by the authors. The review protocol specified 30-day mortality as a secondary endpoint, while the study by Petros et al.., ${ }^{(233)}$ similar to Peake et al.. ${ }^{(126)}$ reported 28-day mortality (Tables 4 and 7). ${ }^{(214)}$ There was nevertheless no significant difference in 28-day mortality between the two groups, and, as this was the only mortality outcome measured is reported as mortality (any time point) for the purposes of this review (Figure 11).

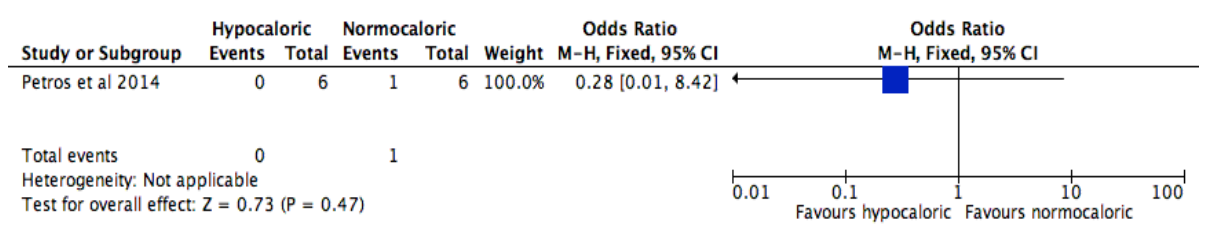

Figure 11: Mortality at any time point from data provided by Petros et al. ${ }^{(233)}$ comparing a hypo-caloric regimen $(8.8 \mathrm{kcal} / \mathrm{kg} / \mathrm{day})$ and a eucaloric regimen $(13.0$ $\mathrm{kcal} / \mathrm{kg} /$ day) in obese critically ill adult patients (BMI $\geq 30 \mathrm{~kg} / \mathrm{m}^{2}$ )

\subsubsection{Length of Stay}

When both ICU and hospital LoS for critically ill obese patients who received a hypo-caloric regimen ( $8.8 \mathrm{kcal} / \mathrm{kg}$ actual body weight) were compared to those who received a eucaloric regimen ( $13 \mathrm{kcal} / \mathrm{kg}$ actual body weight/day), with proportionately fewer grams of protein per day (Table 9), there was no significant difference between the groups for either of the LoS outcomes (Figure 12, Panels A and B). 


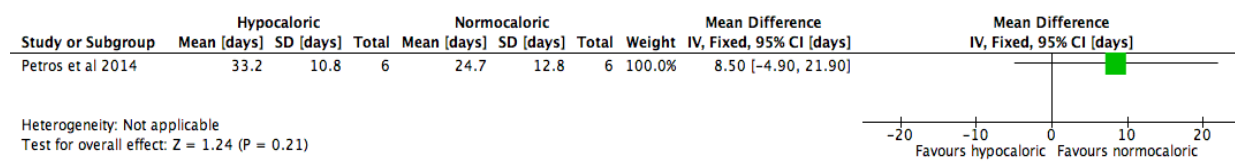

Panel A

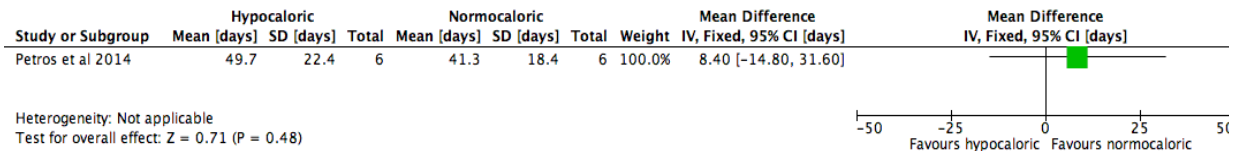

Panel B

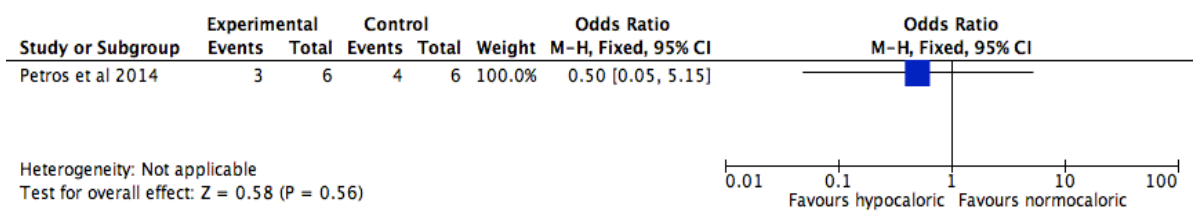

Panel C

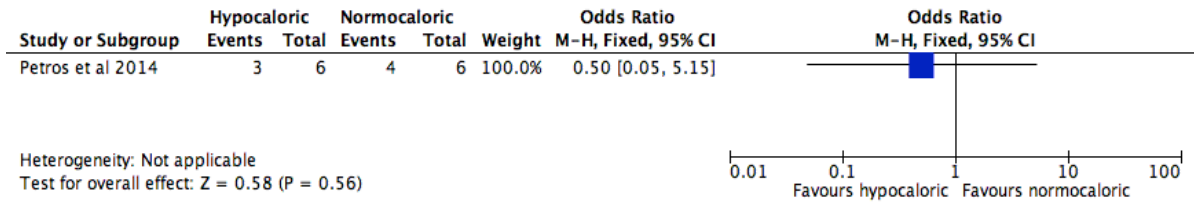

Panel D

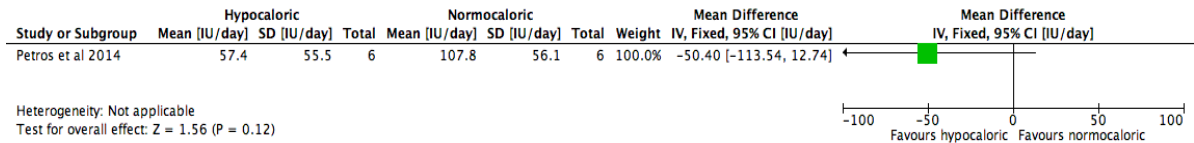

Panel E

Figure 12: Secondary endpoints derived from data provided by Petros et al. ${ }^{(233)}$

comparing a hypo-caloric regimen $(8.8 \mathrm{kcal} / \mathrm{kg} / \mathrm{day})$ and a eucaloric regimen $(13.0$

$\mathrm{kcal} / \mathrm{kg} /$ day $)$ in obese critically ill adult patients $\left(\mathrm{BMI} \geq 30 \mathrm{~kg} / \mathrm{m}^{2}\right)$

Panel A ICU LoS (days); Panel B Hospital LoS (days); Panel C Gastric residual volume;

Panel D Diarrhoea; Panel E Insulin requirement

\subsubsection{Nosocomial Infection}

There were no reported episodes of nosocomial infection in either arm. ${ }^{(233)}$ 


\subsubsection{Gastro-intestinal Intolerance}

Petros et al. ${ }^{(233)}$ measured gastro-intestinal intolerance by gastric residual volumes (recorded as aspirate) and the incidence of diarrhoea. There was no statistically significant difference in either of these endpoints between the groups (Figure 12, Panels $C$ and D). Nor was there a statistically significant difference in the number of days of diarrhoea (Table 9).

\subsubsection{Insulin Requirement}

The obese group receiving a eucaloric regimen $(13.0 \mathrm{kcal} / \mathrm{kg}$ actual body weight/day) required a higher daily dose of insulin than the hypo-caloric group (Figure 12, Panel E), although this was not statistically significant (Table 9). 


\section{Chapter 4 Discussion}

This chapter discusses the findings of the systematic review and attempts to place these findings within the wider context of the nutritional support for the critically ill obese patient. Limitations and issues that potentially confound the current literature field, and by extension the limited results obtained from the systematic review, are also explored. Finally, the strengths and weaknesses of the systematic review are discussed as well as implications for future research.

\subsection{Results in Context}

The systematic review was unable to demonstrate a clinical benefit in altering the nutritional prescription for critically ill obese patients. However, this finding is limited by the paucity of data available, and was highly reliant on subgroup data provided by the research groups led by Peake ${ }^{(126)}$ and Petros. ${ }^{(233)}$ Peake et al. ${ }^{(126)}$ randomly allocated patients to receive either a high density formula $(1.5 \mathrm{kcal} / \mathrm{ml})$ or a standard formula $(1.0 \mathrm{kcal} / \mathrm{ml})$. This effectively resulted in the obese subgroup receiving $20 \mathrm{kcal} / \mathrm{kg} \mathrm{IBW} /$ day in the $1.0 \mathrm{kcal} / \mathrm{ml}$ arm and $30 \mathrm{kcal} / \mathrm{kg} \mathrm{IBW} /$ day in the $1.5 \mathrm{kcal} / \mathrm{ml}$ arm, while, importantly, protein delivery was essentially the same. This equates to something more like a "eucaloric versus hyper-caloric" approach by the definitions proposed in Section 2.2. Petros et al. ${ }^{(233)}$ randomly allocated patients to either a hypocaloric ( $50 \%$ of energy requirements) or eucaloric ( $100 \%$ of energy requirements) group and achieved separation of groups. Both studies are, however, phase II studies powered to detect a statistically significant 
difference in a surrogate outcome (nosocomial infection for Petros et al. ${ }^{(233)}$, and calorie delivery in Peake et al..). ${ }^{(126)}$ Given that a subset of the patients recruited to a phase II study (and therefore likely underpowered for rare outcomes such as mortality) were used for the outcomes in this review, it is almost certainly the case that the review analysis was also underpowered.

The systematic review clearly demonstrates the dearth of evidence around nutritional support for the critically ill obese patient. Of the 880 unique citations identified from the exhaustive search strategy, only one study (Dickerson) $^{(11)}$ specifically addressed the question of a nutritional strategy in critically ill obese patients. This study was of poor methodological quality (Appendix 5) and was not included in the data synthesis since an outdated definition of obesity was used, and the corresponding author was unable to provide clarification (Appendix 4). Given that there was no other study that specifically addressed the review question, the review relied on studies that included obese patients amongst their participants and contact with the corresponding authors to obtain data pertaining to this subset of their study population. In many ways this is symptomatic of the evidence base for nutritional therapy in the intensive care generally. This evidence base contains conflicting evidence from small randomised trials and larger observational trials, complicated by the results of poor quality trials - such as Dickerson's retrospective study - that have guided the approach to the nutritional therapy of the critically ill obese patient following its publication in $2002 .{ }^{(11,71)}$ In the recent ASPEN guidelines for the provision and assessment of nutrition support therapy in the adult critically ill patient, only 10 of the 95 recommendations were based on evidence judged to be of moderate quality or better, while all 
of the recommendations around nutritional therapy for the critically obese patient were arrived at by "expert consensus". ${ }^{(32)}$

The results from the systematic review examining energy (calorie) and protein delivery in critically ill obese patients are congruent with two recent research syntheses examining caloric delivery in the intensive care setting. ${ }^{(107,108)}$ Marik and colleagues undertook a systematic review and meta-analysis of the literature comparing eucaloric and hypo-caloric regimens on a range of outcomes including nosocomial infections, hospital mortality, ICU LOS and ventilator free days. ${ }^{(107)}$ Using a search strategy similar to the current review's, the same citations were identified, although there was no search of grey literature, and as a result the thesis by Komjashy ${ }^{(234)}$ was not identified nor the conference abstract by Ulusoy. ${ }^{(232)}$ The mean BMI across the six studies recruiting nearly 800 patients included in the meta-analysis was $29.1 \mathrm{~kg} / \mathrm{m}^{2}$, suggesting that a substantial proportion of ICU patients recruited to nutritional studies were obese. ${ }^{(107)}$ The meta-analysis failed to demonstrate any benefit from hypo-caloric feeding, and the authors concluded that "the optimal strategy for providing calories and protein in critically ill patients has yet to be determined" ${ }^{(107) p .321}$ Parikh and colleagues ${ }^{(108)}$ in their systematic review and meta-analysis, by contrast, examined the effect of calorie delivery on inhospital mortality, ICU and hospital LoS, duration of mechanical ventilation and nosocomial infections in critically ill patients receiving (predominantly) enteral nutrition. They identified 16 studies in which there were treatment groups who had a significant difference in calorie delivery, but failed to demonstrate any difference in calorie delivery on hospital mortality. ${ }^{(108)}$ Of the secondary outcomes they examined, only duration of mechanical ventilation was 
statistically significant, with a modest reduction in the groups that had fewer calories delivered. A multivariate meta-regression analysis failed to demonstrate a significant interaction with either protein delivery or BMI, both of which varied substantially between the included studies. ${ }^{(108)}$

The reviews by Marik et al. and Parikh et al., although recruiting a wider population than that examined in this thesis, ultimately supported the same result - altering the caloric target for critically ill patients appears to have little bearing on short term mortality outcomes. It is possible that this is because of the heterogeneity of patients recruited to critical care studies (a mix of medical and surgical patients, with a broad range of age, pre-existing co-morbidity, weight and build, and variable ICU LoS) that results in small effects in subgroups being washed out in a broad analysis. It is also possible, albeit intuitively unlikely, that targeting a caloric and/or protein goal in critically ill patients indeed makes no difference.

The evidence base supporting a hypo-caloric, high protein regimen - as recommended by ASPEN - is questionable. ${ }^{(32)}$ Dickerson et al. ${ }^{(11)}$ retrospectively examined the outcomes in 40 obese patients located in a surgical intensive care unit at a single centre. ${ }^{(11)}$ The feeding regimen (hypocaloric high protein regimen versus eucaloric feeding) was determined at the discretion of the nutrition support service. The disparate numbers in each arm (28 in the hypo-caloric arm versus 12 in the eucaloric arm) and the high rate of crossover (17\% of the eucaloric arm received a hypo-caloric high protein formula and $35 \%$ of the hypo-caloric group received a low protein formula during their admission) suggest that there may have been a clinician led 
preference of one over the other, introducing the strong possibility of researcher bias. The vast majority (90\%) were trauma patients, while the remaining $10 \%$ were surgical patients. ${ }^{(11)}$ The definition of obesity used for inclusion in the study ( $125 \%$ of IBW) differed markedly from the definition in current use $\left(\mathrm{BMI} \geq 30 \mathrm{~kg} / \mathrm{m}^{2}\right)$, and, on the basis of the standard deviation significantly crossing $30 \mathrm{~kg} / \mathrm{m}^{2}$, there is a strong possibility that a not insignificant number of "obese" patients by Dickerson's definition were not obese by current definitions (albeit with the caveats and flaws discussed in Section 1.1.3). Finally, the outcomes reported as statistically significant were surrogate outcomes (shorter ICU LoS and fewer days of antimicrobial therapy), both of which are prone to the confounding effects of patient selection. Basing an intervention on a single centre study with significant methodological flaws is fraught with risk. Similar interventions that have attracted widespread uptake in the critical care community have subsequently been shown to be much less efficacious when subjected to the rigours of a double blind randomised controlled trial. ${ }^{(146,239,240)}$ Recent examples include tight glycemic control, hypothermia after cardiac arrest and early goal directed therapy, all of which, although taken up with considerable fervour by the critical care community, were subsequently shown to be less efficacious in rigorous heterogeneous multi-centre studies. ${ }^{(146,239-244)}$

There is further evidence that the approach advocated by ASPEN is not well supported in the broader ICU community. Alberda et al., in a large observational study of nutritional practice across 167 intensive care units in 37 countries, demonstrated that all patients (and not just the obese) were underfed, but that there was no evidence of protein supplementation in the 
obese group. ${ }^{(57)}$ This is further supported by Borel et al.'s ${ }^{(173)}$ multi-centre observational study that demonstrated implementation of nutritional therapy in the critically ill obese patient was significantly delayed compared to their lean counterparts.

Given that it is not obvious that ASPEN's recommendations are in broad clinical use, it is not even possible to postulate that a hypo-caloric high-protein feeding regimen is safe. Despite an extensive and exhaustive literature search conducted in the systematic review, no further evidence of the benefit of a hypo-caloric high-protein regimen could be found. In the context of Alberda's ${ }^{(57)}$ observational study, which found that increased intakes of energy and protein were associated with improved clinical outcomes, restricting caloric intake in the critically ill obese patient could be harmful.

\subsection{Limitations of Research in the Field}

A number of factors potentially confound the results of the systematic review, some of which are likely to contribute to the conflicting results observed in the literature that describes the nutritional approach to the critically ill patient.

\subsubsection{Research Population}

The issue of clinical heterogeneity in the ICU population has long been problematic, and this was observed in the results of the systematic search. ${ }^{\left({ }^{(2)}\right.}$ Some research populations in this field have contained exclusively medical patients such as that by Petros and colleagues, ${ }^{(233)}$ others have recruited almost exclusively postoperative patients (for example Charles and 
colleagues), ${ }^{(124)}$ while others have been conducted in trauma units, recruiting almost exclusively a trauma population (for example, Dickerson's study comparing a hypo-caloric high protein prescription with a eucaloric prescription). ${ }^{(11)}$ This is important as there is evidence that the type of admission influences outcome. ${ }^{(245)}$ Moreover, the complete absence of any randomised, blinded clinical trials recruiting exclusively obese patient, or any study that stratified recruitment on the basis of obesity (despite ASPEN's guidelines that this population have a modified nutrition prescription) further clouds this problem. ${ }^{(32)}$ Appropriate randomisation of patients to control and intervention arms is essential in reducing confounders, yet this crucial component of research design is absent when evidence is sought for the optimal calorie and protein goal for the critically ill obese patient.

\subsubsection{Use of Observational Data}

Observational data have driven the majority of recommendations around nutritional support, particularly around caloric targets, due to the observation that energy deficit has been associated with mortality. The use of observational data in this way, although inherently essential, is potentially fraught with complications. Patients who have a short ICU LoS are less likely to require nutritional support and have a substantially reduced risk of death. Any analysis of observational data that includes these patients is likely to be skewed towards an association between decreased calorie prescription and reduced mortality. ${ }^{(71,76)}$ Furthermore, when patients progress to volitional nutritional intake, it is routine to cease recording daily calorie delivery which would then be entered as zero. Inclusion of these data would again skew the analysis. This is not to underestimate the value of observational data which 
remains an important means of hypothesis generation and investigating adverse events, but there is a need to be aware of the limitations of these data in making assumptions about interventions and its impact on trial design.

Given the significant volume of observational data used in generating the underlying assumptions around nutritional support, a further possible confounder in the interpretation of results is introduced. In addition, it becomes clear that the heterogenous nature of the populations that are included in ICU trials may mask subgroups for whom both early aggressive nutritional therapies may be appropriate, and/or for whom specialised macronutrient prescriptions are beneficial. In an attempt to control for this, only randomised controlled trials were sought in the first instance. When no trials such as this were identified, despite an extensive search, studies with a non-randomised control, quasi-experimental, controlled before and after, or cohort study (whether prospective or retrospective) design were considered for inclusion in order to provide a sufficient evidence base from which the effectiveness of different enteral nutrition targets to support the critically ill obese patient can be informed.

\subsubsection{Uncounted calories}

Propofol, a common agent used for sedation in the critically ill patient, is presented in a lipid emulsion. ${ }^{(246)}$ The lipid substrate provides $1.1 \mathrm{kcal} / \mathrm{ml}$ of energy, and if infused at $15-20 \mathrm{ml} /$ hour (not uncommon in the critically ill patient) it could contribute $396-528 \mathrm{kcal} / \mathrm{day}$, a not insignificant amount. ${ }^{(247)}$ Although the caloric load that propofol contributes has been recognised for 
some time, not every nutritional study seems to account for this additional caloric load, nor for the fact that this caloric load is delivered parenterally and as lipid (fat). While this is a weakness in the wider nutritional literature, both studies included in the systematic review accounted for "non-nutritional calories" (Table 4), which presumably accounted for this source of energy. ${ }^{(126,}$ 233)

\subsubsection{The Assumption of Constant Metabolic Demand}

In both studies included in the review, the targeted rate of caloric and protein delivery was assumed to be constant over the study period, yet this assumption may be flawed. There is a physiological mechanistic process as well as empirical evidence that suggest that the metabolic needs of a critically ill patient change over time as the inflammatory insult abates. This is reflected in the ESPEN guidelines which stipulate a different caloric prescription, depending on the phase of the critical illness. ${ }^{\left({ }^{83)}\right.}$ The early phase of critical illness is not necessarily a hyper-metabolic state, and as a result caloric demand may not increase. ${ }^{(134,248)}$ However, the later chronic or recovery phase of critical illness is associated with a large increase in metabolic need with total energy expenditure increasing to as much as 1.7-fold the resting energy

expenditure. ${ }^{(134,248)}$ An interpretation of these data is that the focus during the first days of critical illness should not be on the delivery of non-protein calories but rather on protein delivery, particularly given the evidence that protein losses are very high during the early phases of critical illness and that replacement is suboptimal. ${ }^{(57,106,134,135)}$ 
It is not clear how this impacts on the nutritional goals for the critically ill obese patient. However, it is clear that, until controversy over how best to feed the critically ill patient is resolved, the optimal calorie and protein goal for the critically ill obese patient will remain problematic. It certainly justifies the $a$ priori specified subgroup analysis of lean versus obese patients and the inclusion of weight as a stratification variable in all future studies of nutrition in the intensive care unit.

\subsubsection{The Use of Ideal Body Weight}

As discussed in Section 1.5.1 and depicted in Figures 5 and 6, the choice to use IBW as the basis for the nutritional prescription and the subsequent choice of which IBW formula to use can have significant implications. Both Peake et al. ${ }^{(126)}$ and Petros et al. ${ }^{(233)}$ used IBW. However, while Peake et al. used a modification of Devine's formula, Petros et al. used the Hamwi equation which, for a $180 \mathrm{~cm}$ male, would result in a $3 \mathrm{~kg}$ (or 4\%) difference in IBW. ${ }^{(12,14,}$ 126, 233) This has flow-on effects to the total "calorie dose" delivered to the patient. For example, Peake et al. ${ }^{(126)}$ targeted $29.9 \mathrm{kcal} / \mathrm{kg}$ IBW/day using the Devine formula for IBW, resulting in a $2036 \mathrm{kcal} /$ day target calorie delivery. Had the Hamwi formula been used instead, this would have resulted in the delivery of an additional $90 \mathrm{kcal} /$ day.

\subsection{Limitations of the Systematic Review}

In the National Health and Medical Research Council's (NHMRC, Australia) hierarchy of evidence of effectiveness, a systematic review and meta-analysis of randomised controlled trials occupies the highest level of evidence, and is 
thought to be the gold standard in the framework of evidence based medicine, albeit with the caveat that the strength of a systematic review is limited by the strength of the studies included. ${ }^{(212)}$ As such, a systematic review, although representing the highest level of evidence, should only be assigned a level of evidence that is as high as the studies it comprises, since the review is highly likely to contain results that are of poor internal validity and likely to have been affected by bias. ${ }^{(212)}$

Despite an exhaustive search strategy, there was a paucity of published evidence identified that directly addressed the question: what is the optimal enteral protein and calorie target for the critically ill obese patient that improves morbidity and mortality? This necessarily weakened the results of the systematic review. Interpretation of the data sourced for the systematic review was made difficult by a number of additional factors.

Firstly, the choice of outcomes. There was limited data for the primary outcome of interest - all cause mortality. Mortality as a primary outcome was chosen as it has a number of advantages, most notably that it is less susceptible to bias and confounders than other surrogate endpoints. Studies of the critically ill often have the "luxury" of being able to use this hard endpoint since it occurs frequently enough in the intensive care population to be readily measurable, and therefore enables studies to be powered sufficiently to achieve this endpoint. Nevertheless, as ICU mortality is currently falling for some admission diagnoses particularly, it is not infrequent that single-centre studies, even on the critically ill, fail to achieve sufficient power, 
and studies with a large multi-centre design are required to demonstrate benefits following a therapeutic intervention. ${ }^{(249)}$

Similarly, there are potential confounders in the interpretation of the results of the secondary outcomes of interest in this review. While ICU and hospital LoS are important measures for patients, clinicians and hospital managers, since LoS can also have significant economic implications, they have limitations since both can be influenced by extraneous factors such as bed block. ${ }^{(219,250)}$ The duration of mechanical ventilation (or ventilator free days) as an endpoint has similar failings, with different facilities or indeed different clinicians within facilities adopting a different approach to ventilator weaning and extubation criteria. Despite these reservations, it was anticipated that similar issues would affect all arms (whether treatment or control) within each study, decreasing the effect of confounding.

Secondly, the data used for the review utilises a subgroup drawn from phase II trials. Phase II trials, by their nature, are underpowered for most important outcomes. The primary outcome in both phase II trials identified in the systematic review was a surrogate outcome (nosocomial infection incidence for Petros et al. ${ }^{(233)}$ and calorie delivery in Peake et al..). ${ }^{(126)}$ The lack of power within each study as a whole was further hampered by the relatively small number of obese patients in each study (21 in Peake et al. ${ }^{(126)}$ and 12 in Petros et al.). ${ }^{(233)}$ This is the necessary, albeit unfortunate, consequence of finding no appropriate studies that directly addressed the review question. 
Thirdly, in neither study was randomisation stratified for weight. It is therefore possible that there was not equal distribution of potential confounders, even though the groups appeared well matched on superficial examination of the available data (Tables 5 and 6 ).

Fourthly, the review focussed on studies that delivered nutrition via the enteral route. This was deliberately done as the enteral route is the preferred route, and there are a number of non-nutritional benefits (Section 1.3.5). In doing so, however, it is accepted that tolerance for enteral nutrition may be a marker of illness severity rather than a mediator of complications and poor outcomes. $^{(85)}$

Finally, the analysis did not include all the datasets that were potentially available including those of Arabi et al., ${ }^{(54,123)}$ Ulusoy, $^{(232)}$, Dickerson ${ }^{(11)}$ and Charles et al. ${ }^{(124)}$ If these datasets had been made available for data synthesis by the corresponding author, the findings of the systematic review may have been different - their absence weakens the findings substantially. The impending introduction of mandated raw data sharing suggested by the International Committee of Medical Journal Editors would obviate this weakness, albeit with the possible introduction of a range of further potential complications. $^{(251)}$

Had there been sufficient data, further exploratory synthesis and subgroup analysis performed on the basis of ICU admission type (medical versus surgical and emergent versus elective) would have been carried out to explore anticipated heterogeneity across studies. ${ }^{(217)}$ These subgroups were considered 
important as there is evidence that admission type effects ICU mortality. ${ }^{(245)}$

Furthermore, since it is possible that older patients paradoxically require more protein to achieve a neutral nitrogen balance while having a lower glomerular filtration rate, a comparison of outcomes in a cohort of younger patients $(<60$ years of age), compared to older patients ( $>60$ years of age) was thought to be appropriate. ${ }^{(220)}$ It was unfortunate that sufficient data could not be obtained to explore these subgroups further.

\subsection{Implications for Practice}

Given the lack of evidence identified by the systematic review it is difficult to make strong statements about current practice in this area, particularly given that there is already a wide variation in current practice. ${ }^{(57)}$ In the absence of a well designed randomised controlled trial, it seems reasonable to continue providing enteral nutrition to the critically ill obese patient guided by arbitrary weight based formulae and to continue using IBW, despite the concerns with this that have been discussed. This is addressed further in Section 4.5.

Conducting a randomised control trial examining the influence of nutritional intervention on the outcomes of critically ill obese patients is unlikely to be undertaken in the foreseeable future given the scarcity of research funding, the likely size of the study that would be needed and the need for prolonged follow-up. Given that hospital mortality for ICU patients in Australia and New Zealand is currently $7.8 \%$, to achieve an absolute risk reduction of $5 \%$ and a power of 0.8 , with an alpha of 0.05 , a minimum sample size would be 700 patients (Figure 13). ${ }^{(252,253)}$ The alternative is for researchers in the field to stratify recruitment by weight, pre-plan subgroup analysis by weight, and 
design data sets that allow data harmonisation so that further individual patient meta-analyses can be undertaken sourcing similar data from similar studies.

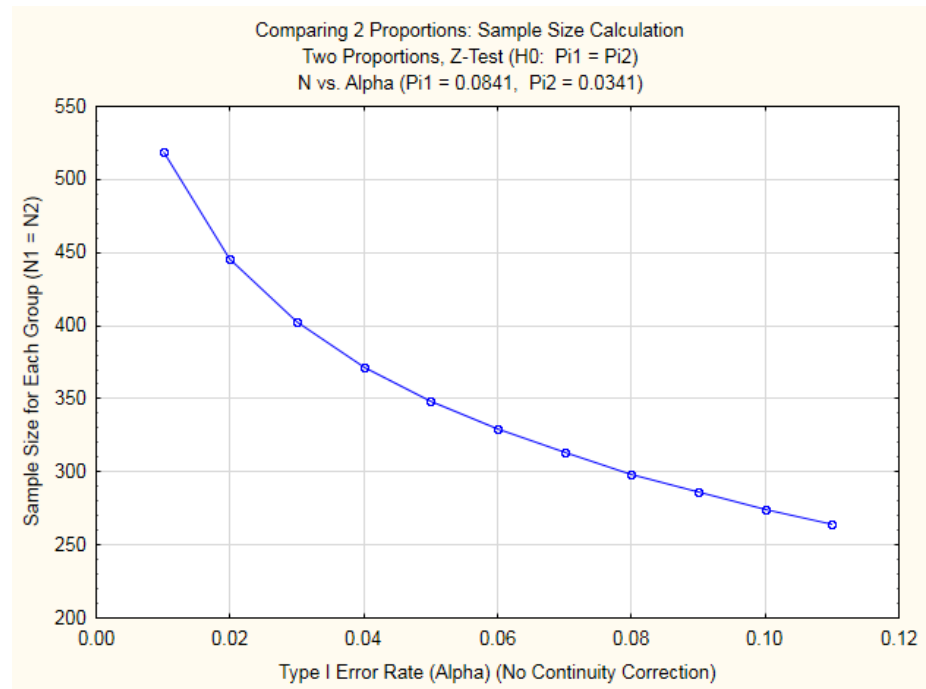

Figure 13: Power calculation assuming Australia/New Zealand hospital mortality of ICU patients of $8.4 \%$, and a $5 \%$ absolute risk reduction ${ }^{(253)}$

\subsection{Implications for Future Research}

The need for further large-scale research is emphasised by the small number of identified studies, none of which were designed to directly answer the review questions. That nutritional prescription remains relatively free of evidence is further demonstrated by the fact that both included studies were exploratory or pilot studies in nature, and also by the very small number of recommendations in the most recent ASPEN guideline that are based on moderate quality evidence or better. ${ }^{(32)}$

The influence of a nutritional intervention on clinically important outcomes is unlikely to be short term. As a result, endpoints of interest should include both short-term markers encompassing a hospital admission, but more 
importantly also those that extend beyond the walls of the ICU, and preferably the hospital. ${ }^{(126)}$ Longer term outcomes are more difficult to gather due to loss to follow-up and necessarily add significant economic costs that need to be addressed in funding submissions.

All future nutritional studies should plan a priori to analyse obese patients separately and should stratify patients by obesity in order for this occur in a meaningful fashion. There is insufficient data to justify a different approach to the critically ill obese patient compared to their lean peers, despite a reasonable physiological rationale. This in itself should suggest equipoise and the basis for further large scale randomised controlled trials, but, as discussed in Section 4.4, this seems unlikely in the current funding environment, particularly given the large numbers of patients (Figure 13) that would need to be recruited to such a study in order to show a clear result.

Studies should clearly distinguish the dose prescribed and the dose delivered to the gut. In addition, given the virtually ubiquitous use of propofol as the sedation agent of choice in the intensive care, the contribution to the total caloric load delivered parenterally through this agent must be allowed for and explicitly reported.

There is an urgent need, partly addressed in ASPEN's most recent guidelines, for the standardisation of both the terminology and approach for the critically ill patient. ${ }^{(32)}$ This includes which weight is used, how energy requirements are best estimated and what proportion of the estimated energy requirement needs to be delivered at any particular stage of the disease process. Finally, 
given the problems that have been identified and discussed with BMI and IBW (see Sections 1.1.3), and in particular given the evolving evidence that both $\mathrm{BMI}$ and by extension IBW are unstable across both time and age, a reevaluation is overdue. ${ }^{(24,25)} \mathrm{A}$ new term, perhaps "standardised body weight", should be introduced to better reflect the changes that are being observed in the weight at which mortality is lowest and to better denote its use in the ICU. An extension of this concept is to achieve consensus in clinical practice around which weight to be used when calculating caloric and protein goals. Recommendations published by ASPEN cloud this issue, recommending that caloric goals be based on IBW (or, if using the recommended nomenclature, standardised body weight), while protein goal is based on actual body weight. ${ }^{(32)}$ While there is some mechanistic basis to this, it only adds to the confusion around what goals should be targeted. However, it seems intuitive that a critically ill obese patient should not have caloric targets based on their actual body weight, given the reduced metabolic demands of adipose tissue.

There were significant issues in the conduct of the systematic review with regards to accessing raw data, and the inclusion of studies was reliant on the goodwill of authors in making subgroup data available. A further three studies that had been identified could not be included as authors, quite reasonably, were not prepared to make data available due to their own publication priorities. ${ }^{(54,123,124)}$ The impending availability of raw data to allow subgroup analysis (even if post hoc) as suggested by the International Committee of Medical Journal Editors would be welcomed in order to increase the power of analyses. $^{(251)}$ 


\subsection{Conclusions}

The systematic review was unable to generate sufficient evidence to clearly answer the clinical question of the optimal targeted protein and calorie goal for the critically ill obese patient. However, the evidence from which recommendations for the utility of a hypo-caloric, high protein regimen are to be generated is certainly poor, despite the contention from some authors that this regimen "is emerging as the standard of practice for the critically ill patient with obesity". ${ }^{(220) p .342}$ There is a signal for harm in the observational study by Alberda et al. which should give clinicians cause for thought. ${ }^{(57)}$ The absence of evidence is not altogether surprising since the optimal strategy for providing calories and proteins in any critically ill patient has yet to be determined. ${ }^{(107)}$

It is far more likely that the approach to the nutritional support of the critically ill obese patient will require a tailored individualised approach rather than a one-size-fits-all protocolised one which reflects the heterogenous nature of critical illness. A tailored approach could consider patient related factors (including weight and ability to withstand physiological stressors), disease related factors (including the type and degree of physiological stress resulting from a trauma, surgical or medical insult), and stage of disease (acute or convalescent) in the development of the ideal nutritional approach to the critically ill patient.

Supporting the critically ill obese patient will become an increasingly important skill in the intensivist's armamentarium. Yet there is little to no evidence to guide the prescription of nutritional therapy for this vulnerable group. Further 
research into this evolving and fascinating area of critical care is urgently required. 


\section{Appendices}

\section{Appendix 1 Systematic Review Protocol}

\section{Review title}

Feeding the Critically III Obese Patient: A Systematic Review Protocol

\section{Reviewers}

Paul Secombe, ${ }^{, 2}$ Simon Harley, ${ }^{, 2}$ Marianne Chapman, ${ }^{, 4}$ Edoardo Aromataris

1 The Joanna Briggs Institute, Faculty of Health Science, University of Adelaide

2 School of Medicine, University of Adelaide

3 Alice Springs Hospital

4 Royal Adelaide Hospital

\section{Review question/objective}

The objective of this review is to identify the effectiveness of enteral nutritional regimens targeting protein and calorie delivery for the critically ill obese patient on morbidity and mortality.

More specifically, the review question is:

In the critically ill obese patient, what is the optimal enteral protein and calorie target that improves mortality and morbidity?

The primary outcome of interest will be a composite measure of mortality measured at either intensive care unit (ICU) discharge or 60 days.

Secondary outcomes of interest include other markers of morbidity and include:

- ICU or hospital length of stay;

- duration of mechanical ventilation or ventilator free days;

- incidence of nosocomial infection;

- renal injury;

- azotemia (blood urea nitrogen);

- nitrogen balance;

- lean muscle loss, and;

- insulin requirement. 


\section{Background}

The World Health Organization (WHO) defines obesity as abnormal or excessive fat accumulation that may impair health, or, empirically, as a body mass index (BMI) $\geq 30 \mathrm{~kg} / \mathrm{m} 2$. (1. 2) Twenty-eight percent of the Australian population is obese with the prevalence rising to $44 \%$ in rural areas, and there is evidence that rates of obesity are increasing. ${ }^{(3.5)}$ The prevalence of obese patients in the intensive care largely mirrors that of the general population. ${ }^{(6,7)}$ There is concern, however, that this may also be rising. A recently published multi-center nutritional study of critically ill patients reported a mean BMI of 29 in their sample, suggesting that just under $50 \%$ of their intensive care population is obese. ${ }^{\left({ }^{8}\right)}$ It is inevitable, therefore, that the intensivist will care for the critically ill obese patient.

Managing the critically ill obese patient is challenging, not least due to the comorbid disease states frequently associated with obesity, including diabetes mellitus, cardiovascular disease, dyslipidaemia, sleep disordered breathing and respiratory insufficiency, hepatic steatohepatitis, chronic kidney disease and hypertension. . $^{(7-94)}$ There is also evidence that metabolic processes differ in the obese patient, particularly in those with underlying insulin resistance, itself a marker of the metabolic syndrome, which may predispose to futile cycling, altered fuel utilization and protein catabolism. ${ }^{(1421)}$ These issues are compounded by altered drug pharmacokinetics, and the additional logistical issues associated with prophylactic, therapeutic and diagnostic interventions.

It is entirely plausible that the altered metabolic processes observed in the obese intensify and compound the metabolic changes that occur during critical illness. The early phases of critical illness are characterized by an increase in energy expenditure, resulting in a catabolic state driven by the stress response. ${ }^{(22-24)}$ Activation of the stress response involves up-regulation of the sympathetic nervous system and the release of pituitary hormones resulting in altered cortisol metabolism and elevated levels of endogenous catecholamines. ${ }^{(2527)}$ These produce a range of metabolic disturbances including stress hyperglycaemia, arising from both peripheral resistance to the effects of anabolic factors (predominantly insulin) and increased hepatic gluconeogenesis. ${ }^{(27,28)}$ Proteolysis is accelerated releasing amino acids that are thought to be important in supporting tissue repair, immune defense and the synthesis of acute phase reactants. ${ }^{(29,30)}$ There is also altered mobilization of fuel stores, futile cycling, and evidence of altered lipoprotein metabolism. $15,20,26,31)$ In the short term this is likely to be an adaptive response, but with time and ongoing inflammation this becomes maladaptive with a concomitant risk of protein-calorie malnutrition, immunosuppression and wasting of functional muscle tissue resulting from protein catabolism and further compounded by disuse atrophy. ${ }^{20,}{ }^{27,32}$ Muscle atrophy and ICU acquired weakness is complex and poorly understood, but it is postulated that the provision of calories and sufficient protein to avoid a negative nitrogen balance mitigates this process. ${ }^{(29)}$ Avoiding lean muscle mass loss in the obese intuitively has substantial implications, given the larger mass that is required to be mobilized during their 
rehabilitation phase.

There is, in addition, evolving evidence that hormones derived from both the gut and adipose tissue are also involved in the response to stress and critical illness, and that adipose tissue in particular is not a benign tissue bed, but rather should be considered an endocrine organ. ${ }^{(18,33-35)}$ Some of these hormones are thought to be pro-inflammatory and some anti-inflammatory, however both the net result and clinical significance of these is yet to be fully elucidated. . $^{(18,27,33)}$

The provision of adequate nutrition has become an integral component of

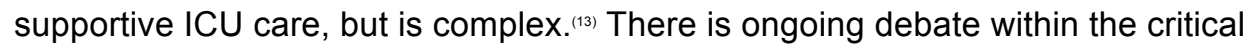
care literature regarding the optimal route of delivery, the target dose, and the macronutrient components (proportion of protein and non-protein calories) of nutritional support. ${ }^{(13,27)} A$ number of studies have associated caloric deficit with morbidity and mortality, with the resultant assumption that prescribing sufficient calories to match energy expenditure will reduce morbidity and mortality, although the evidence base underpinning this assumption is limited to observational studies and small, randomized trials. ${ }^{(13,36-42)}$

There is research available that suggests hyper-caloric feeding or hyperalimentation, particularly of carbohydrates, may result in increased morbidity including hyperglycaemia, liver steatosis, respiratory insufficiency with prolonged duration of mechanical ventilation, re-feeding syndrome and immune suppression. ${ }^{27,43-48)}$ But, the results from studies of hypo-caloric and eucaloric feeding regimens in critically ill patients are conflicting, independent of the added metabolic complexities observed in the critically ill obese patient. ${ }^{(8,13,40,49)}$

Notwithstanding the debate regarding the dose and components of nutritional therapy, there is consensus that nutrition should be provided, preferably via the enteral route, and preferably initiated early in the ICU admission. ${ }^{27,50)}$ The enteral route is preferred for a variety of reasons, not the least of which is cost. In addition there is evidence to suggest the enteral route is associated with the maintenance of gut integrity, a reduction in bacterial translocation and infection rates, a reduction in the incidence of stress ulceration, attenuation of oxidative stress, release of incretins and other entero-hormones, and modulation of systemic immune responses. ${ }^{\left(20,{ }^{27},{ }^{50.55}\right)}$ Yet there is evidence that the initiation of enteral nutritional support for the obese critically ill patient is delayed. ${ }^{(56)}$ The reasons for this remain obscure, but may be associated with the false assumption that every obese patient has nutritional reserves due to their adipose tissues, and can therefore withstand longer periods with no, or reduced nutritional support.(56) In fact obesity does not necessarily protect from malnutrition, particularly protein and micronutrient malnutrition. ${ }^{(7,20,57-61)}$ It has been suggested by some authors that the malnutrition status of critically ill patients is a stronger predictor of mortality than BMI per se, and that, once malnutrition status is controlled for, the apparent protective effects of obesity observed in several epidemiological studies dissipate. ${ }^{(7,6271)}$ This would be consistent with the large body of evidence that associates malnutrition (BMI $<20 \mathrm{~kg} / \mathrm{m} 2$ ) with increased mortality, and has led some authors to postulate that the weightmortality relationship is $\mathrm{U}$-shaped. ${ }^{(13,72: 30)}$ This has proven difficult to demonstrate, 
however, due to recognized confounding influences such as chronic comorbidities, baseline nutritional status and the nature of the presenting critical illness. ${ }^{(13)}$

This has led to interest in nutritional regimens targeting alternative calorie and protein goals to protect the obese critically ill patient from complications arising from critical illness, and particularly protein catabolism. Although, of the three major nutritional organizations, the American Society of Parenteral and Enteral Nutrition (ASPEN) is the only professional organization to make specific recommendations about providing enteral nutritional support to the critically ill obese patient recommending a regimen targeting a hypo-caloric, high-protein goal. ${ }^{20}$ It is thought that this regimen, in which $60-70 \%$ of caloric requirements are provided promotes steady weight loss, while providing sufficient protein to achieve a neutral, or slightly positive, nitrogen balance, mitigating lean muscle mass loss, and allowing for wound healing. ${ }^{(52)}$ Targeting weight loss is proposed to improve insulin sensitivity, improve nursing care and reduce the risk of comorbidities, although how this occurs, and whether it can occur over the relatively short time frame of an intensive care admission (days to weeks) remains unclear. ${ }^{(52)}$

Supporting the critically ill obese patient will become an increasingly important skill in the intensivist's armamentarium, and enteral nutritional therapy forms a cornerstone of this support. Yet, neither the optimal total caloric goal nor the macronutrient components of a feeding regimen for the critically ill obese patient is evident. Although the suggestion that altering the macronutrient goals for this vulnerable group of patients appears to have a sound physiological basis, the level of evidence supporting this remains unclear, and there are no systematic reviews of this topic. The aim of this systematic review is to evaluate the literature to determine the best available evidence describing a nutritional strategy that targets energy and protein delivery to reduce morbidity and mortality for the obese patient who is critically ill.

\section{Inclusion criteria}

\section{Types of participants}

This review will consider studies that include critically ill obese adult patients receiving enteral nutritional support at any stage during their ICU admission for a time period of greater than 72 hours. Studies eligible for retrieval will include intensive care patients in intensive care units or alternatively using a population of patients in which greater than or equal to $50 \%$ of trial participants required mechanical ventilation. In attempting to limit the search to studies involving critically ill patients in this way, it is acknowledged that there are differing criteria that determine ICU admission between countries determined in part by resources, in part by cultural differences and in part by the model of intensive care that predominates (closed versus open intensive care units). This is, however, a universal conundrum of critical care research in which there is often heterogeneity in admission diagnosis, severity of disease, metabolic derangement, therapeutic interventions and has been recognized in other 
publications. ${ }^{(81)}$

Critically ill populations composed of both elective and emergency ICU admissions will be included, as will critically ill populations with a medical or surgical admission diagnosis.

The WHO definition of obesity will be used in this review, this is to say a BMI $\geq$ $30 \mathrm{~kg} / \mathrm{m} 2$, where BMI is body mass in kilograms divided by the square of body height in meters. ${ }^{(2,82)}$

Studies examining a pediatric population, or using parenteral routes of administration will be excluded.

\section{Types of intervention(s)/phenomena of interest}

This review will consider all studies that compare any feeding/nutritional regimens that specify a goal protein and calorie target directed at the obese critically ill patient.

\section{Types of outcomes}

Endpoints of interest in this review are chosen primarily for their importance in patient centered outcomes, while secondary endpoints are chosen as surrogate markers of morbidity.

The primary outcome for this review is a composite mortality outcome (ICU, 60 or 90 day mortality) where they can be identified in studies retrieved.

Secondary outcomes sought that are thought important in patient centred outcomes include ICU and hospital length of stay, duration of mechanical ventilation or it's corollary ventilator free days. Other secondary outcomes will include include nitrogen balance, azotemia (blood urea nitrogen), acute kidney injury, the incidence of nosocomial infection and insulin requirement.

Nitrogen balance has been chosen as a surrogate marker of the adequacy of protein supplementation and is calculated using formulae allowing for protein intake and 24 hour urinary protein excretion. ${ }^{\left({ }^{33)}\right.}$ Azotemia (serum urea) and renal injury using RIFLE criteria as markers of potential harm related to the inability to clear protein metabolites. ${ }^{(84)}$ The incidence of nosocomial infection since an association between nutritional status and nosocomial infection incidence has been identified in a number of studies. ${ }^{(55)}$ Finally, given the experimental findings that indicate high glucose concentrations have a range of negative effects, including increasing the production or expression (or both) of pro-inflammatory mediators, decreased chemotaxis and phagocytosis, alteration in leukocyte adherence, reduced release of reactive oxygen species from neutrophils and alterations in endothelial integrity, insulin requirement has been chosen as a surrogate marker of glycemic control. In addition, given the range of metabolic disturbances seen in the critically ill obese patient, glycemic control is arguably more important in this group than in their lean counterparts. ${ }^{(19,20,27)}$ 


\section{Types of studies}

Studies eligible for retrieval will include, in the first instance, randomized controlled studies. In the absence of randomized controlled trials, any study with a non-randomized control, quasi-experimental, controlled before and after, or cohort study (whether prospective or retrospective) design will be considered for inclusion in order to provide a sufficient evidence base to inform on the effectiveness of different feeding regimes targeting calories and protein in the critically ill obese patient.

\section{Search strategy}

The search strategy will involve a three step process. An initial limited search of PubMed and CINAHL will be undertaken, followed by analysis of keywords contained in the titles and abstracts, and of the index terms used to describe the article. A second search with all identified key words will be undertaken across PubMed, Embase, ProQuest Dissertations and Theses and conference papers index, CINAHL, PyschINFO, Cochrane Central Trials Register, Web of Science, Australian and New Zealand Clinical Trials Register, the EU Clinical Trials Register, WHO Clinical Trials Register and ClinicalTrials.gov. Only studies published in English will be eligible for retrieval, and there will be no date limits applied. Thirdly the reference list of all identified reports and articles will be searched for additional studies.

Initial key words to be used will be; ("critically ill" OR "intensive care") AND (obese OR overweight) AND (nutrition OR diet OR feed*).

\section{Assessment of methodological quality}

Quantitative papers selected for retrieval will be assessed by two independent reviewers for methodological validity prior to inclusion in the review using standardized critical appraisal instruments from the Joanna Briggs Institute Meta Analysis of Statistics Assessment and Review Instrument (JBI-MAStARI) which is found in Appendix I. Any disagreement will be resolved through discussion, or with a third reviewer.

\section{Data collection}

Quantitative data will be extracted from papers included in the review using the standardized data extraction tool from JBI-MAStARI (Appendix II). The data extracted will include specific details about the intervention(s), populations, study methods and outcomes of significance to the review question and specific objectives.

\section{Data synthesis}

Analysis will be conducted on all primary and secondary outcomes where possible. Quantitative data will, where possible, be pooled in a statistical meta- 
analysis using JBI-MAStARI. All results will be subject to double data entry. Effect sizes expressed as odds ratio (for categorical data) and weighted mean differences (for continuous data) and their 95\% confidence intervals will be calculated for analysis. Given the anticipated degree of heterogeneity, it is expected that a random effects model will be used. Heterogeneity will be assessed statistically using the standard chi squared, and, given the expected level of heterogeneity a random effects model will be used. Where statistical pooling is not possible, the findings will be presented in narrative form.

If there is sufficient data, further exploratory synthesis and sensitivity analysis performed on the basis of ICU admission type (medical versus surgical and emergent versus elective) will be carried out to explore anticipated heterogeneity across studies. These subgroups will be considered as there is evidence that admission type effects ICU mortality. ${ }^{\left({ }^{66)}\right.}$ Furthermore, since it is possible that older patients paradoxically require more protein to achieve a neutral nitrogen balance, while having a lower glomerular filtration rate, a comparison of outcomes in a cohort of younger patients ( $<60$ years of age), compared to older patients ( $>60$ years of age) would be appropriate. ${ }^{(33)}$

\section{Conflicts of interest}

There are not conflicts of interest to declare.

\section{Acknowledgements}

The authors would like to acknowledge Dr Adam Deane for contributing ideas and support, and Dr Penny Stewart for support of this project.

\section{Protocol References}

1. World Health Organisation. BMI classification [Web page]. [19/04/2015]. Available from: http://apps.who.int/bmi/index.jsp?introPage=intro_3.html.

2. World Health Organisation. Obesity and overweight: World Health Organisation; 2015 [4 June, 2015]. Available from: http://www.who.int/mediacentre/factsheets/fs311/en/.

3. Australian Institute of Health and Welfare. Overweight and Obesity 2008 [15 March, 2015]. Available from: www.aihw.gov.au/overweight-andobesity/prevalence/\#adults.

4. Australian Bureau of Statistics. Australian Health Survey: Updated Results 2011-2012. Cat no. 4364.0.55.003.2013 2 June 2015. Available from:

http://www.abs.gov.au/ausstats/abs@.nsf/Lookup/034947E844F25207 CA257AA30014BDC7?opendocument.

5. National Heart Foundation. Obesity and Physical Inactivity Australia2015 [cited 201510 May]. Available from: 
http://www.heartfoundation.org.au/SiteCollectionDocuments/HF\%20Ob esity\%20and\%20Physical\%20Inactivity\%20Report\%20overview.pdf.

6. Hogue CW, Jr., Stearns JD, Colantuoni E, Robinson KA, Stierer T, Mitter $\mathrm{N}$, et al. The impact of obesity on outcomes after critical illness: a metaanalysis. Intensive care medicine. 2009 Jul;35(7):1152-70. PubMed PMID: 19189078.

7. Robinson MK, Mogensen KM, Casey JD, McKane CK, Moromizato T, Rawn JD, et al. The relationship among obesity, nutritional status, and mortality in the critically ill. Critical care medicine. 2015 Jan;43(1):87100. PubMed PMID: 25289931.

8. Arabi YM, Aldawood AS, Haddad SH, Al-Dorzi HM, Tamim HM, Jones G, et al. Permissive Underfeeding or Standard Enteral Feeding in Critically III Adults. The New England journal of medicine. 2015 May 20. PubMed PMID: 25992505.

9. Dube DS. Influence of overweight on ICU mortality: a prospective study. Chest. 2005 Feb;127(2):683; author reply 4. PubMed PMID: 15706018.

10. Ejerblad E, Fored CM, Lindblad P, Fryzek J, McLaughlin JK, Nyren O. Obesity and risk for chronic renal failure. Journal of the American Society of Nephrology : JASN. 2006 Jun;17(6):1695-702. PubMed PMID: 16641153

11. Serra A, Romero R, Lopez D, Navarro M, Esteve A, Perez N, et al. Renal injury in the extremely obese patients with normal renal function. Kidney Int. 2008 Apr;73(8):947-55. PubMed PMID: 18216780.

12. Shashaty MG, Stapleton RD. Physiological and management implications of obesity in critical illness. Annals of the American Thoracic Society. 2014 Oct;11(8):1286-97. PubMed PMID: 25172506. Pubmed Central PMCID: 4298999.

13. Chapman M, Peake S, Jones D. Gluttony in the ICU: is it really a deadly sin? Critical care and resuscitation : journal of the Australasian Academy of Critical Care Medicine. 2015 Jun;17(2):63-4. PubMed PMID: 26017120.

14. Fabbrini E, Magkos F. Hepatic Steatosis as a Marker of Metabolic Dysfunction. Nutrients. 2015;7(6):4995-5019. PubMed PMID: 26102213. Pubmed Central PMCID: 4488828.

15. Boiteux A, Hess B. Design of glycolysis. Philos Trans R Soc Lond B Biol Sci. 1981 Jun 26;293(1063):5-22. PubMed PMID: 6115423.

16. Ford ES, Giles WH, Dietz WH. Prevalence of the metabolic syndrome among US adults: findings from the third National Health and Nutrition Examination Survey. JAMA : the journal of the American Medical Association. 2002 Jan 16;287(3):356-9. PubMed PMID: 11790215.

17. Honiden S, McArdle JR. Obesity in the intensive care unit. Clin Chest Med. 2009 Sep;30(3):581-99, x. PubMed PMID: 19700054.

18. Hillenbrand A, Knippschild $U$, Weiss M, Schrezenmeier H, Henne-Bruns $D$, Huber-Lang M, et al. Sepsis induced changes of adipokines and cytokines - septic patients compared to morbidly obese patients. BMC Surg. 2010;10:26. PubMed PMID: 20825686. Pubmed Central PMCID: 2944119. 
19. Port AM, Apovian C. Metabolic support of the obese intensive care unit patient: a current perspective. Current opinion in clinical nutrition and metabolic care. 2010 Mar;13(2):184-91. PubMed PMID: 20040861. Pubmed Central PMCID: 3278904.

20. McClave SA, Kushner R, Van Way CW, 3rd, Cave M, DeLegge M, Dibaise J, et al. Nutrition therapy of the severely obese, critically ill patient: summation of conclusions and recommendations. JPEN Journal of parenteral and enteral nutrition. 2011 Sep;35(5 Suppl):88S96S. PubMed PMID: 21881019.

21. Boutagy NE, McMillan RP, Frisard MI, Hulver MW. Metabolic endotoxemia with obesity: Is it real and is it relevant? Biochimie. 2015 Jun 29. PubMed PMID: 26133659.

22. Desborough JP. The stress response to trauma and surgery. $\mathrm{Br} \mathrm{J}$ Anaesth. 2000 Jul;85(1):109-17. PubMed PMID: 10927999.

23. Cuesta JM, Singer M. The stress response and critical illness: a review. Critical care medicine. 2012 Dec;40(12):3283-9. PubMed PMID: 22975887.

24. Finnerty CC, Mabvuure NT, Ali A, Kozar RA, Herndon DN. The surgically induced stress response. JPEN Journal of parenteral and enteral nutrition. 2013 Sep;37(5 Suppl):21S-9S. PubMed PMID: 24009246. Pubmed Central PMCID: 3920901.

25. Boonen E, Vervenne H, Meersseman P, Andrew R, Mortier L, Declercq $\mathrm{PE}$, et al. Reduced cortisol metabolism during critical illness. The New England journal of medicine. 2013 Apr 18;368(16):1477-88. PubMed PMID: 23506003.

26. Marik PE, Bellomo R. Stress hyperglycemia: an essential survival response! Critical care. 2013;17(2):305. PubMed PMID: 23470218. Pubmed Central PMCID: 3672537.

27. Preiser JC, van Zanten AR, Berger MM, Biolo G, Casaer MP, Doig GS, et al. Metabolic and nutritional support of critically ill patients: consensus and controversies. Critical care. 2015;19(1):35. PubMed PMID: 25886997. Pubmed Central PMCID: 4310041.

28. Marik PE, Bellomo R. Stress hyperglycemia: an essential survival response! Critical care medicine. 2013 Jun;41(6):e93-4. PubMed PMID: 23685597.

29. Hoffer LJ, Bistrian BR. Appropriate protein provision in critical illness: a systematic and narrative review. The American journal of clinical nutrition. 2012 Sep;96(3):591-600. PubMed PMID: 22811443.

30. Plank LD. Protein for the critically ill patient--what and when? Eur J Clin Nutr. 2013 May;67(5):565-8. PubMed PMID: 23403870.

31. Secombe PJ, Brown A, Kruger PS, Stewart PC. Lipid profiles and persisting inflammation following critical illness in a central Australian population: a prospective longitudinal observational study. Internal medicine journal. 2013 Apr;43(4):445-9. PubMed PMID: 23551307.

32. Dickerson RN. Hypocaloric, high-protein nutrition therapy for critically ill patients with obesity. Nutrition in clinical practice : official publication of the American Society for Parenteral and Enteral Nutrition. 2014 
Dec;29(6):786-91. PubMed PMID: 25049263.

33. Fain JN, Madan AK, Hiler ML, Cheema P, Bahouth SW. Comparison of the release of adipokines by adipose tissue, adipose tissue matrix, and adipocytes from visceral and subcutaneous abdominal adipose tissues of obese humans. Endocrinology. 2004 May;145(5):2273-82. PubMed PMID: 14726444.

34. Kershaw EE, Flier JS. Adipose tissue as an endocrine organ. The Journal of clinical endocrinology and metabolism. 2004 Jun;89(6):2548-56. PubMed PMID: 15181022.

35. Marques MB, Langouche L. Endocrine, metabolic, and morphologic alterations of adipose tissue during critical illness. Critical care medicine. 2013 Jan;41(1):317-25. PubMed PMID: 23135416.

36. Rubinson L, Diette GB, Song X, Brower RG, Krishnan JA. Low caloric intake is associated with nosocomial bloodstream infections in patients in the medical intensive care unit. Critical care medicine. 2004 Feb;32(2):350-7. PubMed PMID: 14758147.

37. Villet S, Chiolero RL, Bollmann MD, Revelly JP, Cayeux RNM, Delarue J, et al. Negative impact of hypocaloric feeding and energy balance on clinical outcome in ICU patients. Clinical nutrition. 2005 Aug;24(4):5029. PubMed PMID: 15899538.

38. Dvir D, Cohen J, Singer P. Computerized energy balance and complications in critically ill patients: an observational study. Clinical nutrition. 2006 Feb;25(1):37-44. PubMed PMID: 16321459.

39. Alberda C, Gramlich L, Jones N, Jeejeebhoy K, Day AG, Dhaliwal R, et al. The relationship between nutritional intake and clinical outcomes in critically ill patients: results of an international multicenter observational study. Intensive care medicine. 2009 Oct;35(10):1728-37. PubMed PMID: 19572118.

40. Heyland DK, Cahill N, Day AG. Optimal amount of calories for critically ill patients: depends on how you slice the cake! Critical care medicine. 2011 Dec;39(12):2619-26. PubMed PMID: 21705881.

41. Tsai JR, Chang WT, Sheu CC, Wu YJ, Sheu YH, Liu PL, et al. Inadequate energy delivery during early critical illness correlates with increased risk of mortality in patients who survive at least seven days: a retrospective study. Clinical nutrition. 2011 Apr;30(2):209-14. PubMed PMID: 20943293.

42. Weijs PJ, Stapel SN, de Groot SD, Driessen RH, de Jong E, Girbes AR, et al. Optimal protein and energy nutrition decreases mortality in mechanically ventilated, critically ill patients: a prospective observational cohort study. JPEN Journal of parenteral and enteral nutrition. 2012 Jan;36(1):60-8. PubMed PMID: 22167076.

43. Talpers SS, Romberger DJ, Bunce SB, Pingleton SK. Nutritionally associated increased carbon dioxide production. Excess total calories vs high proportion of carbohydrate calories. Chest. 1992 Aug;102(2):551-5. PubMed PMID: 1643946.

44. Liposky JM, Nelson LD. Ventilatory response to high caloric loads in critically ill patients. Critical care medicine. 1994 May;22(5):796-802. PubMed PMID: 8181288. 
45. Klein CJ, Stanek GS, Wiles CE, 3rd. Overfeeding macronutrients to critically ill adults: metabolic complications. J Am Diet Assoc. 1998 Jul;98(7):795-806. PubMed PMID: 9664922.

46. Barret JP, Jeschke MG, Herndon DN. Fatty infiltration of the liver in severely burned pediatric patients: autopsy findings and clinical implications. The Journal of trauma. 2001 Oct;51(4):736-9. PubMed PMID: 11586168.

47. Reid C. Frequency of under- and overfeeding in mechanically ventilated ICU patients: causes and possible consequences. J Hum Nutr Diet. 2006 Feb;19(1):13-22. PubMed PMID: 16448470.

48. Singer P, Anbar R, Cohen J, Shapiro H, Shalita-Chesner M, Lev S, et al. The tight calorie control study (TICACOS): a prospective, randomized, controlled pilot study of nutritional support in critically ill patients. Intensive care medicine. 2011 Apr;37(4):601-9. PubMed PMID: 21340655.

49. van Zanten AR, Sztark F, Kaisers UX, Zielmann S, Felbinger TW, Sablotzki AR, et al. High-protein enteral nutrition enriched with immunemodulating nutrients vs standard high-protein enteral nutrition and nosocomial infections in the ICU: a randomized clinical trial. JAMA : the journal of the American Medical Association. 2014 Aug 6;312(5):51424. PubMed PMID: 25096691.

50. Shankar B, Daphnee DK, Ramakrishnan N, Venkataraman R. Feasibility, safety, and outcome of very early enteral nutrition in critically ill patients: Results of an observational study. Journal of critical care. 2015 Feb 24. PubMed PMID: 25791768.

51. Raff T, Germann G, Hartmann B. The value of early enteral nutrition in the prophylaxis of stress ulceration in the severely burned patient. Burns : journal of the International Society for Burn Injuries. 1997 Jun;23(4):313-8. PubMed PMID: 9248640.

52. McClave SA, Martindale RG, Vanek VW, McCarthy M, Roberts P, Taylor $B$, et al. Guidelines for the Provision and Assessment of Nutrition Support Therapy in the Adult Critically III Patient: Society of Critical Care Medicine (SCCM) and American Society for Parenteral and Enteral Nutrition (A.S.P.E.N.). JPEN Journal of parenteral and enteral nutrition. 2009 May-Jun;33(3):277-316. PubMed PMID: 19398613.

53. Marik PE, Vasu T, Hirani A, Pachinburavan M. Stress ulcer prophylaxis in the new millennium: a systematic review and meta-analysis. Critical care medicine. 2010 Nov;38(11):2222-8. PubMed PMID: 20711074.

54. McClave SA, Martindale RG, Rice TW, Heyland DK. Feeding the critically ill patient. Critical care medicine. 2014 Dec;42(12):2600-10. PubMed PMID: 25251763.

55. McClave SA, Frazier TH, Vermani SD, Hurt RT. Obesity in Critical Illness: Implications for nutrition therapy. In: Kushner R, Still C, editors. Nutrition and Bariatric Surgery. Florida: Taylor \& Francis Group; 2015.

56. Borel AL, Schwebel C, Planquette B, Vesin A, Garrouste-Orgeas M, Adrie $C$, et al. Initiation of nutritional support is delayed in critically ill obese patients: a multicenter cohort study. The American journal of clinical nutrition. 2014 Sep;100(3):859-66. PubMed PMID: 25080456. 
57. Kaidar-Person O, Person B, Szomstein S, Rosenthal RJ. Nutritional deficiencies in morbidly obese patients: a new form of malnutrition? Part A: vitamins. Obes Surg. 2008 Jul;18(7):870-6. PubMed PMID: 18465178.

58. Kaidar-Person O, Person B, Szomstein S, Rosenthal RJ. Nutritional deficiencies in morbidly obese patients: a new form of malnutrition? Part B: minerals. Obes Surg. 2008 Aug;18(8):1028-34. PubMed PMID: 18461424.

59. Jensen GL, Hsiao PY. Obesity in older adults: relationship to functional limitation. Current opinion in clinical nutrition and metabolic care. 2010 Jan;13(1):46-51. PubMed PMID: 19841579.

60. Via M. The malnutrition of obesity: micronutrient deficiencies that promote diabetes. ISRN endocrinology. 2012;2012:103472. PubMed PMID: 22462011. Pubmed Central PMCID: 3313629.

61. Thibault R, Huber O, Azagury DE, Pichard C. Twelve key nutritional issues in bariatric surgery. Clinical nutrition. 2015 Mar 3. PubMed PMID: 25779332.

62. Corrales-Medina VF, Valayam J, Serpa JA, Rueda AM, Musher DM. The obesity paradox in community-acquired bacterial pneumonia. Int $\mathrm{J}$ Infect Dis. 2011 Jan;15(1):e54-7. PubMed PMID: 21095152.

63. Hutagalung R, Marques J, Kobylka K, Zeidan M, Kabisch B, Brunkhorst $F$, et al. The obesity paradox in surgical intensive care unit patients. Intensive care medicine. 2011 Nov;37(11):1793-9. PubMed PMID: 21818652.

64. Arabi YM, Dara SI, Tamim HM, Rishu AH, Bouchama A, Khedr MK, et al. Clinical characteristics, sepsis interventions and outcomes in the obese patients with septic shock: an international multicenter cohort study. Critical care. 2013;17(2):R72. PubMed PMID: 23594407. Pubmed Central PMCID: 3672731.

65. Pickkers P, de Keizer N, Dusseljee J, Weerheijm D, van der Hoeven JG, Peek N. Body mass index is associated with hospital mortality in critically ill patients: an observational cohort study. Critical care medicine. 2013 Aug;41(8):1878-83. PubMed PMID: 23685638.

66. Wacharasint $P$, Boyd JH, Russell JA, Walley KR. One size does not fit all in severe infection: obesity alters outcome, susceptibility, treatment, and inflammatory response. Critical care. 2013;17(3):R122. PubMed PMID: 23786836. Pubmed Central PMCID: 4057102.

67. Chalkias A, Xanthos $\mathrm{T}$. The obesity paradox in cardiac arrest patients. Int J Cardiol. 2014 Feb 1;171(2):101-2. PubMed PMID: 24360157.

68. Utzolino S, Ditzel CM, Baier PK, Hopt UT, Kaffarnik MF. The obesity paradox in surgical intensive care patients with peritonitis. Journal of critical care. 2014 Oct;29(5):887 e1-5. PubMed PMID: 24997725.

69. Dixon JB, Egger GJ, Finkelstein EA, Kral JG, Lambert GW. 'Obesity paradox' misunderstands the biology of optimal weight throughout the life cycle. Int J Obes (Lond). 2015 Jan;39(1):82-4. PubMed PMID: 24732145.

70. Lasocki S. The true obesity paradox: obese and malnourished? Critical 
care medicine. 2015 Jan;43(1):240-1. PubMed PMID: 25514714.

71. Sasabuchi $Y$, Yasunaga $H$, Matsui $H$, Lefor AT, Horiguchi H, Fushimi K, et al. The Dose-Response Relationship Between Body Mass Index and Mortality in Subjects Admitted to the ICU With and Without Mechanical Ventilation. Respir Care. 2015 Feb 17. PubMed PMID: 25691767.

72. Lee S, Choi M, Kim Y, Lee J, Shin C. Nosocomial infection of malnourished patients in an intensive care unit. Yonsei Med J. 2003 Apr 30;44(2):203-9. PubMed PMID: 12728458.

73. Goiburu ME, Goiburu MM, Bianco H, Diaz JR, Alderete F, Palacios MC, et al. The impact of malnutrition on morbidity, mortality and length of hospital stay in trauma patients. Nutricion hospitalaria. 2006 SepOct;21(5):604-10. PubMed PMID: 17044607.

74. Merli M, Giusto M, Gentili F, Novelli G, Ferretti G, Riggio O, et al. Nutritional status: its influence on the outcome of patients undergoing liver transplantation. Liver Int. 2010 Feb;30(2):208-14. PubMed PMID: 19840246.

75. Kathiresan AS, Brookfield KF, Schuman SI, Lucci JA, 3rd. Malnutrition as a predictor of poor postoperative outcomes in gynecologic cancer patients. Arch Gynecol Obstet. 2011 Aug;284(2):445-51. PubMed PMID: 20803205.

76. Mercadal-Orfila G, Lluch-Taltavull J, Campillo-Artero C, Torrent-Quetglas M. Association between nutritional risk based on the NRS-2002 test and hospital morbidity and mortality. Nutricion hospitalaria. $2012 \mathrm{Jul}-$ Aug;27(4):1248-54. PubMed PMID: 23165569.

77. Fontes D, Generoso Sde V, Toulson Davisson Correia MI. Subjective global assessment: a reliable nutritional assessment tool to predict outcomes in critically ill patients. Clinical nutrition. 2014 Apr;33(2):2915. PubMed PMID: 23755841.

78. Shpata V, Prendushi X, Kreka M, Kola I, Kurti F, Ohri I. Malnutrition at the time of surgery affects negatively the clinical outcome of critically ill patients with gastrointestinal cancer. Med Arch. 2014 Aug;68(4):263-7. PubMed PMID: 25568549. Pubmed Central PMCID: 4240570.

79. Yosry A, Omran D, Said M, Fouad W, Fekry O. Impact of nutritional status of Egyptian patients with end-stage liver disease on their outcomes after living donor liver transplantation. J Dig Dis. 2014 Jun;15(6):321-6. PubMed PMID: 24593282.

80. Shpata V, Ohri I, Nurka T, Prendushi X. The prevalence and consequences of malnutrition risk in elderly Albanian intensive care unit patients. Clin Interv Aging. 2015;10:481-6. PubMed PMID: 25733824. Pubmed Central PMCID: 4337415.

81. Kreymann KG, Berger MM, Deutz NE, Hiesmayr M, Jolliet P, Kazandjiev G, et al. ESPEN Guidelines on Enteral Nutrition: Intensive care. Clinical nutrition. 2006 Apr;25(2):210-23. PubMed PMID: 16697087.

82. World Health Organisation. BMI classification [Web page]. [19/04/2015]. Available from: http://apps.who.int/bmi/index.jsp?introPage=intro_3.html.

83. Dickerson RN, Medling TL, Smith AC, Maish GO, 3rd, Croce MA, Minard 
G, et al. Hypocaloric, high-protein nutrition therapy in older vs younger critically ill patients with obesity. JPEN Journal of parenteral and enteral nutrition. 2013 May-Jun;37(3):342-51. PubMed PMID: 23169899.

84. Bellomo R, Ronco C, Kellum JA, Mehta RL, Palevsky P. Acute renal failure - definition, outcome measures, animal models, fluid therapy and information technology needs: the Second International Consensus Conference of the Acute Dialysis Quality Initiative (ADQI) Group. Critical care. 2004 Aug;8(4):R204-12. PubMed PMID: 15312219. Pubmed Central PMCID: 522841. Epub 2004/08/18. eng.

85. Curtis LT. Prevention of hospital-acquired infections: review of nonpharmacological interventions. J Hosp Infect. 2008 Jul;69(3):204-19. PubMed PMID: 18513830.

86. Bhonagiri D, Pilcher DV, Bailey MJ. Increased mortality associated with after-hours and weekend admission to the intensive care unit: a retrospective analysis. The Medical journal of Australia. $2011 \mathrm{Mar}$ 21;194(6):287-92. PubMed PMID: 21426282. 


\section{PubMed (16 October, 2016)}

\begin{tabular}{|c|c|c|}
\hline \multicolumn{3}{|l|}{ PubMED obesity logic grid } \\
\hline Obese & critically ill & $\begin{array}{l}\text { nutrition } \\
\text { OR } \\
\text { hypocaloric feeding }\end{array}$ \\
\hline $\begin{array}{l}\text { obese [tiab] OR obesity [tiab] OR } \\
\text { overweight [tiab] OR bariatric*} \\
\text { [tiab] OR adipos }{ }^{\star} \text { [tiab] OR body } \\
\text { composition [mh] OR body } \\
\text { composition [tiab] OR body mass } \\
\text { index [tiab] OR BMI [tiab] OR body } \\
\text { weights and measures [mh] }\end{array}$ & $\begin{array}{l}\text { critically ill [tiab] OR critical } \\
\text { illness [mh] OR critical ill* } \\
\text { [tiab] OR critically unwell } \\
\text { [tiab] OR critical care [mh] } \\
\text { OR intensive care [tiab] } \\
\text { OR ICU [tiab] OR intensive } \\
\text { care unit [mh] }\end{array}$ & $\begin{array}{l}\text { nutritional sciences [mh] OR nutritional physiological } \\
\text { phenomena [mh] OR nutrition requirements [mh] OR } \\
\text { nutritional requirements [mh] OR nutritional therapy } \\
\text { [mh] OR enteral nutrition [mh] OR feeding method [mh] } \\
\text { OR dietary proteins [mh] OR diet [mh] OR caloric } \\
\text { restriction [mh] OR energy intake [mh] OR diet, } \\
\text { carbohydrate-restricted [mh] OR diet, reducing [mh] } \\
\text { OR food [mh] OR feeding [tiab] OR nutrition [tiab] OR } \\
\text { hypo-caloric [tiab] OR hypocaloric [tiab] OR high } \\
\text { protein [tiab] OR permissive underfeeding [tiab] OR } \\
\text { normocaloric [tiab] or normo-caloric [tiab] OR eucaloric } \\
\text { [tiab] }\end{array}$ \\
\hline
\end{tabular}

(obese [tiab] OR obesity [tiab] OR overweight [tiab] OR bariatric* [tiab] OR adipos* [tiab] OR body composition [mh] OR body composition [tiab] OR body mass index [tiab] OR BMI [tiab] OR body weights and measures [mh]) AND (critically ill [tiab] OR critical illness [mh] OR critical ill $^{\star}$ [tiab] OR critically unwell [tiab] OR critical care [mh] OR intensive care [tiab] OR ICU [tiab] OR intensive care unit [mh]) AND (nutritional sciences [mh] OR nutritional physiological phenomena [mh] OR nutrition requirements [mh] OR nutritional requirements [mh] OR nutritional therapy [mh] OR enteral nutrition [mh] OR feeding method [mh] OR dietary proteins [mh] OR diet [mh] OR caloric restriction [mh] OR energy intake [mh] OR diet, carbohydrate-restricted [mh] OR diet, reducing [mh] OR food [mh] OR feeding [tiab] OR nutrition [tiab] OR hypo-caloric [tiab] OR hypocaloric [tiab] OR high protein [tiab] OR permissive underfeeding [tiab] OR normocaloric [tiab] or normo-caloric [tiab] OR eucaloric [tiab])

\section{Filters}

human studies

exclude paediatric 


\section{Embase (16 October, 2016)}

\begin{tabular}{|c|c|c|}
\hline \multicolumn{3}{|l|}{ Embase obesity logic grid } \\
\hline obese & critically ill & $\begin{array}{l}\text { nutrition } \\
\text { OR } \\
\text { hypocaloric feeding }\end{array}$ \\
\hline $\begin{array}{l}\text { obesity/exp OR adipos*:ab,ti OR "body weight, } \\
\text { excess":ab,ti OR bariatrics/exp OR obes*:ab,ti OR } \\
\text { "body mass"/exp OR BMl:ab,ti OR obese:ab,ti OR } \\
\text { "body weight disorder"/exp OR "overnutrition"/exp } \\
\text { OR "nutritional disorder"/exp OR bariatric*:ti,ab OR } \\
\text { "body composition":ab,ti }\end{array}$ & $\begin{array}{l}\text { "critically ill patient"/exp OR } \\
\text { "intensive care"/exp OR } \\
\text { "critically ill":ti,ab OR "critical } \\
\text { illness":ti,ab OR critically } \\
\text { unwell:it,ab OR "intensive } \\
\text { care":ti,ab OR ICU:ti,ab }\end{array}$ & $\begin{array}{l}\text { "artificial feeding"/exp OR } \\
\text { "nutrition"/exp OR "diet therapy"/exp } \\
\text { OR "diet"/exp OR "dietary intake"/exp } \\
\text { or "diet restriction"/exp OR } \\
\text { nutrition:ti,ab OR hypocaloric:ti,ab } \\
\text { OR "high protein":ti,ab OR } \\
\text { normocaloric:ti,ab }\end{array}$ \\
\hline
\end{tabular}

(obesity/exp OR adipos*:ab,ti OR "body weight, excess":ab,ti OR bariatrics/exp OR obes*:ab,ti OR "body mass"/exp OR BMI:ab,ti OR obese:ab,ti OR "body weight disorder"/exp OR "overnutrition"/exp OR "nutritional disorder"/exp OR bariatric*:ti,ab OR "body composition":ab,ti) AND ("critically ill patient"/exp OR "intensive care"/exp OR "critically ill”:ti,ab OR “critical illness":ti,ab OR critically unwell:it,ab OR "intensive care":ti,ab OR ICU:ti,ab) AND ("artificial feeding"/exp OR "nutrition"/exp OR "diet therapy"/exp OR "diet"/exp OR "dietary intake"/exp or "diet restriction"/exp OR nutrition:ti,ab OR hypocaloric:ti,ab OR "high protein":ti,ab OR normocaloric:ti,ab)

\section{Filters}

Human studies

Young, adult, middle aged, aged, very elderly 
ProQuest Dissertations and Theses (16 October, 2016)

\begin{tabular}{|c|c|c|}
\hline \multicolumn{3}{|c|}{ ProQuest dissertations and theses obesity logic grid } \\
\hline obese & critically ill & $\begin{array}{l}\text { nutrition } \\
\text { OR } \\
\text { hypocaloric feeding }\end{array}$ \\
\hline $\begin{array}{l}\text { TI(obese) OR AB(obese) OR TI(overweight) } \\
\text { OR AB(overweight) OR TI("body mass index") } \\
\text { OR AB("body mass index") OR TI(bariatric) OR } \\
\text { AB(bariatric) OR DISKW(obesity) OR } \\
\text { DISKW(overweight) OR DISKW("body mass } \\
\text { index") OR DISKW("weight loss") OR } \\
\text { DISKW(obese) OR DISKW(weight) OR } \\
\text { DISKW(BMI) OR DISKW(adiposity) OR } \\
\text { DISKW("body weight") OR DISKW(adipose } \\
\text { tissue) OR DISKW("weight status") OR } \\
\text { DISKW("body composition") }\end{array}$ & $\begin{array}{l}\text { DISKW(“intensive care units") } \\
\text { OR DISKW(“critical care") OR } \\
\text { DISKW(sepsis) OR } \\
\text { DISKW("intensive care") OR } \\
\text { DISKW("critically ill") OR } \\
\text { TI("critically ill") OR AB("critically } \\
\text { ill") OR TI("intensive care") OR } \\
\text { AB("intensive care") OR TI(ICU) } \\
\text { OR AB(ICU) }\end{array}$ & $\begin{array}{l}\text { DISKW(nutrition) OR DISKW(diet) OR } \\
\text { DISKW(metabolism) OR } \\
\text { DISKW(“dietary intake") OR } \\
\text { DISKW(“enteral nutrition") OR } \\
\text { DISKW(nutritional) OR TI(nutrition*) } \\
\text { OR AB(nutrition*) OR TI(protein) OR } \\
\text { AB(protein) OR TI(feed*) OR } \\
\text { AB(feed*) OR TI(calor*) OR AB(calor*) } \\
\text { OR TI(underfeeding) OR } \\
\text { AB(underfeeding) }\end{array}$ \\
\hline
\end{tabular}

(TI(obese) OR AB(obese) OR TI(overweight) OR AB(overweight) OR $\mathrm{Tl}$ ("body mass index") OR AB("body mass index") OR TI(bariatric) OR AB(bariatric) OR DISKW(obesity) OR DISKW(overweight) OR DISKW("body mass index") OR DISKW("weight loss") OR DISKW(obese) OR DISKW(weight) OR DISKW(BMI) OR DISKW(adiposity) OR DISKW(“body weight”) OR DISKW(adipose tissue) OR DISKW(“weight status") OR DISKW(“body composition")) AND (DISKW(“intensive care units") OR DISKW(“critical care”) OR DISKW(sepsis) OR DISKW(“intensive care") OR DISKW(“critically ill”) OR TI(“critically ill”) OR AB(“critically ill”) OR TI(“intensive care”) OR $A B$ (“intensive care") OR TI(ICU) OR AB(ICU)) AND (DISKW(nutrition) OR DISKW(diet) OR DISKW(metabolism) OR DISKW(“dietary intake") OR DISKW(“enteral nutrition”) OR DISKW(nutritional) OR TI(nutrition*) OR AB(nutrition*) OR TI(protein) OR AB(protein) OR TI(feed*) OR AB (feed $\left.{ }^{\star}\right)$ OR TI(calor $\left.{ }^{\star}\right)$ OR AB(calor*) OR TI(underfeeding) OR $\mathrm{AB}$ (underfeeding))

\section{Filters}

Exclude paediatric 
CINAHL (16 October, 2016)

\begin{tabular}{|c|c|c|}
\hline \multicolumn{3}{|l|}{ CINAHL obesity logic grid } \\
\hline obese & critically ill & $\begin{array}{l}\text { nutrition } \\
\text { OR } \\
\text { hypocaloric feeding }\end{array}$ \\
\hline $\begin{array}{l}\text { MH obesity OR MH "body weight } \\
\text { changes" OR MH "bariatric patients" OR } \\
\text { MH "body weights and measures" OR MH } \\
\text { "fat free mass" OR TI obes* OR AB obes* } \\
\text { OR TI bariatric OR AB bariatric OR TI BMI } \\
\text { OR AB BMI OR TI adipos* OR AB adipos* }\end{array}$ & $\begin{array}{l}\text { MH "critically ill patients" OR MH } \\
\text { "critical illness" OR MH "critical care" } \\
\text { OR MH "intensive care units" OR TI } \\
\text { ICU OR AB ICU OR TI "intensive } \\
\text { care" OR AB "intensive care" OR TI } \\
\text { "critical ill" OR AB "critical ill"” }\end{array}$ & $\begin{array}{l}\text { MH "nutritional support" OR MH } \\
\text { "enteral nutrition" OR MH "nutritional } \\
\text { physiology" OR MH nutrition OR TI } \\
\text { hypo-caloric OR AB hypo-caloric OR } \\
\text { TI hypocaloric OR AB hypocaloric OR } \\
\text { TI protein OR AB protein }\end{array}$ \\
\hline
\end{tabular}

(MH obesity OR MH "body weight changes" OR MH "bariatric patients" OR MH "body weights and measures" OR MH "fat free mass" OR TI obes* OR AB obes* OR TI bariatric OR AB bariatric OR TI BMI OR AB BMI OR TI adipos* OR AB adipos*) AND (MH "critically ill patients" OR $\mathrm{MH}$ "critical illness" OR MH "critical care" OR MH "intensive care units" OR TI ICU OR AB ICU OR TI "intensive care" OR AB "intensive care" OR TI "critical ill”” OR AB "critical ill*”) AND (MH "nutritional support" OR $\mathrm{MH}$ "enteral nutrition" OR MH "nutritional physiology" OR MH nutrition OR TI hypo-caloric OR AB hypo-caloric OR TI hypocaloric OR AB hypocaloric OR TI protein OR AB protein)

Filters

All adult 
Cochrane Central Trials Register (16 October, 2016)

obese AND intensive care OR obesity AND intensive care OR obese AND critical care OR obesity AND critical care OR bariatric AND intensive care OR bariatric AND critical care OR BMI AND intensive care OR BMI AND critical care OR body mass index AND intensive care OR body mass index AND critical care

\section{WHO Clinical Trials (16 October, 2016)}

obese AND intensive care OR obesity AND intensive care OR obese AND critical care OR obesity AND critical care OR bariatric AND intensive care OR bariatric AND critical care OR BMI AND intensive care OR BMI AND critical care OR body mass index AND intensive care OR body mass index AND critical care 


\section{Appendix 3 MAStARI Critical Appraisal Tool}

\subsection{Randomised Control / Pseudo-randomised Trial}

Reviewer:

Date:

Title:

Author:

Year:

1. Was the assignment to treatment groups truly random?

\begin{tabular}{|l|l|}
\hline Yes & $\begin{array}{l}\text { Method by which randomisation to treatment or control group was } \\
\text { clearly described by the author(s), and the method is likely to } \\
\text { produce true randomisation (ie: each patient has an equal } \\
\text { probability of allocation to each arm). }\end{array}$ \\
\hline No & $\begin{array}{l}\text { Methods other than randomisation used to allocate patients to a } \\
\text { nutritional regimen. }\end{array}$ \\
\hline Unclear & $\begin{array}{l}\text { General terms like "random" and "randomisation" used but the } \\
\text { method by which this was achieved is not clearly defined or was } \\
\text { vague. }\end{array}$ \\
\hline
\end{tabular}

Response:

Comments: 
2. Were participants blinded to treatment allocation?

\begin{tabular}{|l|l|}
\hline Yes & $\begin{array}{l}\text { Appropriate methods were employed to ensure that patients were } \\
\text { blinded to which arm (control or experimental) that they had been } \\
\text { allocated (subject blinding). }\end{array}$ \\
\hline No & $\begin{array}{l}\text { Patients were aware of which arm they had been allocated even } \\
\text { though blinding may have been possible. }\end{array}$ \\
\hline Unclear & Description of blinding method was unclear. \\
\hline
\end{tabular}

Response:

Comments: 
3. Was allocation to treatment groups concealed from the allocator?

\begin{tabular}{|l|l|}
\hline Yes & $\begin{array}{l}\text { Appropriate method used to ensure that the allocator was unaware } \\
\text { of the arm to which patients were being allocated (allocator } \\
\text { blinding) AND a method employed to ensure that the allocator was } \\
\text { likely to be unaware of the order in which patients were allocated to } \\
\text { a study arm (allocation concealment). }\end{array}$ \\
No & $\begin{array}{l}\text { The allocator was aware of which group patients were being } \\
\text { assigned, or was likely to be able to determine which group a } \\
\text { patient was likely to be allocated. }\end{array}$ \\
\hline Unclear & $\begin{array}{l}\text { Insufficient information to determine whether allocation blinding } \\
\text { and allocation concealment had occurred satisfactorily. }\end{array}$ \\
\hline
\end{tabular}

Response:

Comments: 
4. Were the outcomes of people who withdrew described \& included in the analysis?

\begin{tabular}{|l|l|}
\hline Yes & $\begin{array}{l}\text { The withdrawal of patients reported and the reasons for the } \\
\text { withdrawal described. } \\
\text { Patients who withdrew from the study were analysed in the group } \\
\text { to which they were originally allocated (intention to treat analysis), } \\
\text { preferably with the inclusion of a Consort diagram. } \\
\text { All patients were included in the final calculations including those } \\
\text { patients who had withdrawn from the study regardless of whether } \\
\text { their final outcomes were measured. }\end{array}$ \\
\hline No & $\begin{array}{l}\text { No explanation of patient withdrawals or the significance of these } \\
\text { withdrawals. } \\
\text { Patients had had withdrawn from the study group were not } \\
\text { analysed in the groups to which they were originally allocated. }\end{array}$ \\
\hline Unclear & $\begin{array}{l}\text { Incomplete description of patient withdrawals. } \\
\text { Numbers of withdrawn patients fail to match result figures. } \\
\text { Description of withdrawn patients unclear. }\end{array}$ \\
\hline
\end{tabular}

Response:

\section{Comments:}


5. Were those assessing outcomes blind to the treatment allocation?

\begin{tabular}{|l|l|}
\hline Yes & $\begin{array}{l}\text { Researchers collecting data on outcome measure(s) were unaware } \\
\text { of the treatment allocation (assessor blinding). }\end{array}$ \\
\hline No & $\begin{array}{l}\text { Researchers collecting data on outcome measure(s) were aware, } \\
\text { or likely to be aware, the treatment allocation. }\end{array}$ \\
\hline Unclear & Insufficient information provided to assess for assessor blinding. \\
\hline
\end{tabular}

Response:

Comments: 
6. Were the control and treatment groups comparable at entry?

\begin{tabular}{|l|l|} 
Yes & $\begin{array}{l}\text { At a minimum the following baseline data for the patients was } \\
\text { reported, and groups were reasonably matched for these. } \\
\text { - age. } \\
\text { - sex. } \\
\text { - reason for admission to ICU (medical, surgical, trauma, } \\
\text { elective, emergent). } \\
\text { - weight. } \\
\text { - BMI. } \\
\text { No severity of illness (APACHE or SOFA score). } \\
\text { No co-morbid disease states (particularly diabetes mellitus). } \\
\text { No or minimal reporting of baseline data. }\end{array}$ \\
\hline Unclear & $\begin{array}{l}\text { Insufficient information provided to allow assessment of baseline } \\
\text { data. }\end{array}$ \\
\hline
\end{tabular}

\section{Response:}

\section{Comments:}


7. Were groups treated identically other than for the named interventions?

\begin{tabular}{|l|l|}
\hline Yes & $\begin{array}{l}\text { Patients in each arm of the study were treated identically for all } \\
\text { other aspects of their intensive care admission. }\end{array}$ \\
\hline No & $\begin{array}{l}\text { Patients in each arm of the study were (or were likely to have } \\
\text { been) treated substantially differently as a result of the arm to } \\
\text { which they were allocated. }\end{array}$ \\
\hline Unclear & $\begin{array}{l}\text { Insufficient information provided to allow assessment of treatment } \\
\text { confounding. }\end{array}$ \\
\hline
\end{tabular}

Response:

Comments: 
8. Were outcomes measured in the same way for all groups?

\begin{tabular}{|c|c|}
\hline Yes & $\begin{array}{l}\text { A clear description and definition of the outcome(s) was provided. } \\
\text { A description of how the outcome(s) were measured or proposed } \\
\text { to be measured spefically; } \\
\text { - mortality: deaths at a pre-specific time point or days alive at a } \\
\text { time point; } \\
\text { - ICU length of stay: the time from admission to the ICU till ICU } \\
\text { discharge; } \\
\text { - hospital length of stay: the time from ICU discharge until } \\
\text { hospital discharge; } \\
\text { - duration of mechanical ventilation: days requiring invasive } \\
\text { ventilation or days free of ventilation at a pre-specified time } \\
\text { point; } \\
\text { - nitrogen balance: urinary analysis of nitrogen excretion to } \\
\text { allow calculation of nitrogen balance; } \\
\text { - azotaemia: measures of serum urea in either } \mu \text { mol/L or mg/dL } \\
\text { - acute kidney injury: measured by RIFLE criteria;(Bellomo, } \\
2004) \\
\text { - nosocomial infection: standardised definition such as that } \\
\text { proposed by the Centre for Disease Control (CDC) and } \\
\text { confirmed by a blinded third party such as a radiologist or } \\
\text { microbiologist. } \\
\text { - weight change: measured in kilograms or pounds from ICU } \\
\text { admission to a pre-determined time point following ICU } \\
\text { discharge. } \\
\text { - gastro-intestinal intolerance: measured by high gastric } \\
\text { residual volumes ( }>250 \text { ml), or diarrhoea ( } 4 \text { loose } \\
\text { stools/day). } \\
\text { - insulin requirement: in international units (IU) per hour or daily } \\
\text { requirement (IU/day). } \\
\text { The timing of outcome measure(s) is clearly articulated. }\end{array}$ \\
\hline No & $\begin{array}{l}\text { The description of what was measured, how it was measured or } \\
\text { when it was measured is different in each group. }\end{array}$ \\
\hline Unclear & $\begin{array}{l}\text { Insufficient information provided to assess how outcome were } \\
\text { measured. }\end{array}$ \\
\hline
\end{tabular}

Response:

\section{Comments:}


9. Were outcomes measured in a reliable way?

\begin{tabular}{|l|l|}
\hline Yes & $\begin{array}{l}\text { All outcomes were measured using standard methods or } \\
\text { instruments. } \\
\text { Outcome measure(s) supported in the literature. } \\
\text { Where instruments were used they have been validated } \\
\text { independently. }\end{array}$ \\
No & $\begin{array}{l}\text { Estimates or self reported outcomes reported. } \\
\text { Incorrect, inappropriate or non-standard methods or instruments } \\
\text { were used. } \\
\text { The reliability and/or variability and/or validity of the method(s) } \\
\text { used for measuring outcome were no reported. } \\
\text { No training provided to data collectors. }\end{array}$ \\
\hline Unclear & $\begin{array}{l}\text { Insufficient information provided to assess for the reliability of the } \\
\text { outcome measure. }\end{array}$ \\
\hline
\end{tabular}

Response:

Comments: 
10. Was appropriate statistical analysis used?

\begin{tabular}{|l|l|}
\hline Yes & $\begin{array}{l}\text { Appropriate statistical methods were used, described and reported. } \\
\text { Numbers of patients with missing data were reported and there } \\
\text { was an adequate description of how this was dealt with in } \\
\text { reporting. }\end{array}$ \\
\hline No & $\begin{array}{l}\text { Statistical methods were either not described or inappropriate } \\
\text { methods were used. } \\
\text { Missing patient data was either not reported or not accounted for. }\end{array}$ \\
\hline Unclear & $\begin{array}{l}\text { Insufficient information provided to assess the appropriateness of } \\
\text { statistical analysis. }\end{array}$ \\
\hline
\end{tabular}

Response:

\section{Comments:}




\section{Overall Appraisal}

\begin{tabular}{|l|l|l|l|}
\hline Include & Exclude & Seek further information & $\begin{array}{l}\text { Possibly contains } \\
\text { subgroup data }\end{array}$
\end{tabular}

Comments (including reasons for exclusion) 


\subsection{Cohort (with control)/Case-Controlled Series}

Reviewer:

Date:

Title:

Author:

Year:

1. Is the sample representative of patients in the population as a whole?

\begin{tabular}{|l|l|}
\hline Yes & $\begin{array}{l}\text { The sample described is representative of obese intensive care } \\
\text { populations, particularly with regard to } \\
\text { - age } \\
\text { severity of illness (as measured by APACHE II, APACHE III } \\
\text { or SOFA or similar scoring system) } \\
\text { - mix of medical, surgical, trauma critically ill patients. }\end{array}$ \\
\hline No & $\begin{array}{l}\text { The sample is clearly not representative of a critically ill population. } \\
\text { Or } \\
\text { Is limited in its selection to a subspecialty of intensive care } \\
\text { medicine (for example largely trauma, surgical, burns or medical } \\
\text { patients). }\end{array}$ \\
\hline Unclear & $\begin{array}{l}\text { Insufficient information provided to assess the representativeness } \\
\text { of the sample. }\end{array}$ \\
\hline
\end{tabular}

Response:

Comments: 
2. Are the patients at a similar point in the course of their critical illness.

\begin{tabular}{|l|l|}
\hline Yes & $\begin{array}{l}\text { Inclusion in the study has occurred during the patient's ICU } \\
\text { admission. } \\
\text { No }\end{array}$ \\
\hline Unclear & $\begin{array}{l}\text { Insufficient information provided to assess the time point in the } \\
\text { trajectory of the patient's illness. }\end{array}$
\end{tabular}

\section{Response:}

Comments: 
3. Has bias been minimised in relation to selection of cases and controls?

\begin{tabular}{|l|l|}
\hline Yes & $\begin{array}{l}\text { There is a clear description of how the groups were selected (such } \\
\text { as a pre-defined cohort with clear follow up period and clear points } \\
\text { of measurement). } \\
\text { Sample sizes are articulated. }\end{array}$ \\
\hline No & $\begin{array}{l}\text { No description of how the groups were selected. } \\
\text { The methodology introduces an unreasonable risk of systematic } \\
\text { bias including that is not acknowledged and/or has had no attempt } \\
\text { at controlling. }\end{array}$ \\
\hline Unclear & $\begin{array}{l}\text { Insufficient information provided to assess whether the risk of bias } \\
\text { has been minimised. }\end{array}$ \\
\hline
\end{tabular}

Response:

Comments: 
4. Are confounding factors identified and strategies to deal with them stated?

\begin{tabular}{|c|c|}
\hline Yes & $\begin{array}{l}\text { Potential confounding factor(s) have been identified, measured and } \\
\text { a description provided of the possible impact of the compounding } \\
\text { factor(s). } \\
\text { Potential confounding factors include: } \\
\text { - the use of supplement parenteral nutrition. } \\
\text { - co-morbid disease states. } \\
\text { - impact of malnutrition. } \\
\text { - samples in which there is an over represented subtype of } \\
\text { critically ill patient (eg: trauma, surgical, medical, burns). }\end{array}$ \\
\hline No & No measurement of potential confounding factor(s). \\
\hline Unclear & $\begin{array}{l}\text { Insufficient information provided to assess for the identification and } \\
\text { management of confounding factors. }\end{array}$ \\
\hline
\end{tabular}

Response:

Comments: 
5. Were outcomes assessed using objective criteria?

\begin{tabular}{|l|l|}
\hline Yes & $\begin{array}{l}\text { All outcomes were measured using standard methods or } \\
\text { instruments. } \\
\text { Outcome measure(s) supported in the literature. } \\
\text { Where instruments were used they have been validated } \\
\text { independently. }\end{array}$ \\
No & $\begin{array}{l}\text { Estimates or self reported outcomes reported. } \\
\text { Incorrect, inappropriate or non-standard methods or instruments } \\
\text { were used. } \\
\text { The reliability and/or variability and/or validity of the method(s) } \\
\text { used for measuring outcome were no reported. } \\
\text { No training provided to data collectors. }\end{array}$ \\
\hline Unclear & $\begin{array}{l}\text { Insufficient information provided to assess for the reliability of the } \\
\text { outcome measure. }\end{array}$ \\
\hline
\end{tabular}

Response:

Comments: 
6. Was followup carried over a sufficient time period?

\begin{tabular}{|l|l|}
\hline Yes & $\begin{array}{l}\text { Follow up has occurred until at least hospital discharge or death, } \\
\text { whichever is earlier. } \\
\text { No }\end{array}$ \\
\hline Enclear & $\begin{array}{l}\text { Insufficient information provided to allow assessment of followup } \\
\text { time. }\end{array}$
\end{tabular}

Response:

Comments: 
7. Were the outcomes of people who withdrew described and included in the analysis?

\begin{tabular}{|l|l|}
\hline Yes & $\begin{array}{l}\text { Withdrawal of patients reported and the reasons for the withdrawal } \\
\text { described. } \\
\text { Patients who withdrew from the study were analysed in the group } \\
\text { to which they were originally allocated (intention to treat analysis), } \\
\text { preferably with the inclusion of a Consort diagram. } \\
\text { All patients were included in the final calculations including those } \\
\text { patients who had withdrawn from the study regardless of whether } \\
\text { their final outcomes were measured. }\end{array}$ \\
\hline No & $\begin{array}{l}\text { No explanation of patient withdrawals or the significance of these } \\
\text { withdrawals. } \\
\text { Patients had had withdrawn from the study group were not } \\
\text { analysed in the groups to which they were originally allocated. }\end{array}$ \\
\hline Unclear & $\begin{array}{l}\text { Incomplete description of patient withdrawals. } \\
\text { Numbers of withdrawn patients fail to match result figures. } \\
\text { Description of withdrawn patients unclear. }\end{array}$ \\
\hline
\end{tabular}

Response:

\section{Comments:}


8. Were outcomes measured in a reliable way?

\begin{tabular}{|c|c|}
\hline Yes & $\begin{array}{l}\text { A clear description and definition of the outcome(s) was provided. } \\
\text { A description of how the outcome(s) were measured or proposed } \\
\text { to be measured spefically; } \\
\text { - mortality: deaths at a pre-specific time point or days alive at a } \\
\text { time point; } \\
\text { - ICU length of stay: the time from admission to the ICU till ICU } \\
\text { discharge; } \\
\text { - hospital length of stay: the time from ICU discharge until } \\
\text { hospital discharge; } \\
\text { - duration of mechanical ventilation: days requiring invasive } \\
\text { ventilation or days free of ventilation at a pre-specified time } \\
\text { point; } \\
\text { - nitrogen balance: urinary analysis of nitrogen excretion to } \\
\text { allow calculation of nitrogen balance; } \\
\text { - azotaemia: measures of serum urea in either } \mu \text { mol/L or mg/dL } \\
\text { - acute kidney injury: measured by RIFLE criteria;(Bellomo, } \\
\text { 2004) } \\
\text { - nosocomial infection: standardised definition such as that } \\
\text { proposed by the Centre for Disease Control (CDC) and } \\
\text { confirmed by a blinded third party such as a radiologist or } \\
\text { microbiologist. } \\
\text { - weight change: measured in kilograms or pounds from ICU } \\
\text { admission to a pre-determined time point following ICU } \\
\text { discharge. } \\
\text { - gastro-intestinal intolerance: measured by high gastric } \\
\text { residual volumes (> } 250 \text { ml), or diarrhoea ( } 4 \text { loose } \\
\text { stools/day). } \\
\text { - insulin requirement: in international units (IU) per hour or daily } \\
\text { requirement (IU/day). } \\
\text { The timing of outcome measure(s) is clearly articulated. }\end{array}$ \\
\hline No & $\begin{array}{l}\text { Estimates reported. } \\
\text { Incorrect, inappropriate or non-standard methods or instruments } \\
\text { were used. } \\
\text { The reliability and/or variability and/or validity of the method(s) } \\
\text { used for measuring outcome were not reported. }\end{array}$ \\
\hline Unclear & $\begin{array}{l}\text { Insufficient information provided to assess for the reliability of the } \\
\text { outcome measure. }\end{array}$ \\
\hline
\end{tabular}

Response: 
Comments:

p. 160 of 216 
9. Was appropriate statistical analysis used?

\begin{tabular}{|l|l|}
\hline Yes & $\begin{array}{l}\text { Appropriate statistical methods were used, described and reported. } \\
\text { Numbers of patients with missing data were reported and there } \\
\text { was an adequate description of how this was dealt with in } \\
\text { reporting. }\end{array}$ \\
\hline No & $\begin{array}{l}\text { Statistical methods were either not described or inappropriate } \\
\text { methods were used. } \\
\text { Missing patient data was either not reported or not accounted for. }\end{array}$ \\
\hline Unclear & $\begin{array}{l}\text { Insufficient information provided to assess the appropriateness of } \\
\text { statistical analysis. }\end{array}$ \\
\hline
\end{tabular}

Response:

Comments:

\section{Overall Appraisal}

\begin{tabular}{|l|l|l|l|}
\hline Include & Exclude & Seek further information & $\begin{array}{l}\text { Possibly contains } \\
\text { subgroup data }\end{array}$ \\
\hline \multicolumn{2}{|l|}{ Comments (including reasons for exclusion) } \\
\hline
\end{tabular}




\subsection{Data Extraction Template}

Reviewer:

Date:

Title:

Author:

Year:

\section{Study Method}

$\begin{array}{lll}\text { RCT } & \text { Quasi-RCT } & \text { Longitudinal } \\ \text { Retrospective } & \text { Observational } & \text { Other }\end{array}$

\section{Participants}

Setting

Population

\section{Sample Size}

Group A

Group B

\section{Interventions}

Intervention A

Intervention B 


\section{Conclusions}

Author's

Conclusions:

Reviewer's

conclusions:

Study Results

Dichotomous Data

\begin{tabular}{|l|c|c|}
\hline Outcome & $\begin{array}{c}\text { Intervention ( ) } \\
\text { number / total number }\end{array}$ & $\begin{array}{c}\text { Intervention ( ) } \\
\text { number / total number }\end{array}$ \\
\hline & & \\
\hline & & \\
\hline & & \\
\hline & & \\
\hline
\end{tabular}

Continuous Data

\begin{tabular}{|l|c|c|}
\hline Outcome & $\begin{array}{c}\text { Intervention ( ) } \\
\text { number/total number }\end{array}$ & $\begin{array}{c}\text { Intervention ( ) } \\
\text { number / total number }\end{array}$ \\
\hline & & \\
\hline & & \\
\hline & & \\
\hline & & \\
\hline
\end{tabular}




\section{Appendix 4 Correspondence}

\subsection{Included Studies}

Peake SL, Davies AR, Deane AM, Lange K, Moran JL, O'Connor SN, et al. Use of a concentrated enteral nutrition solution to increase calorie delivery to critically ill patients: a randomized, double-blind, clinical trial. America Journal of Clinical Nutrition. 2014 Aug;100(2):616-25.

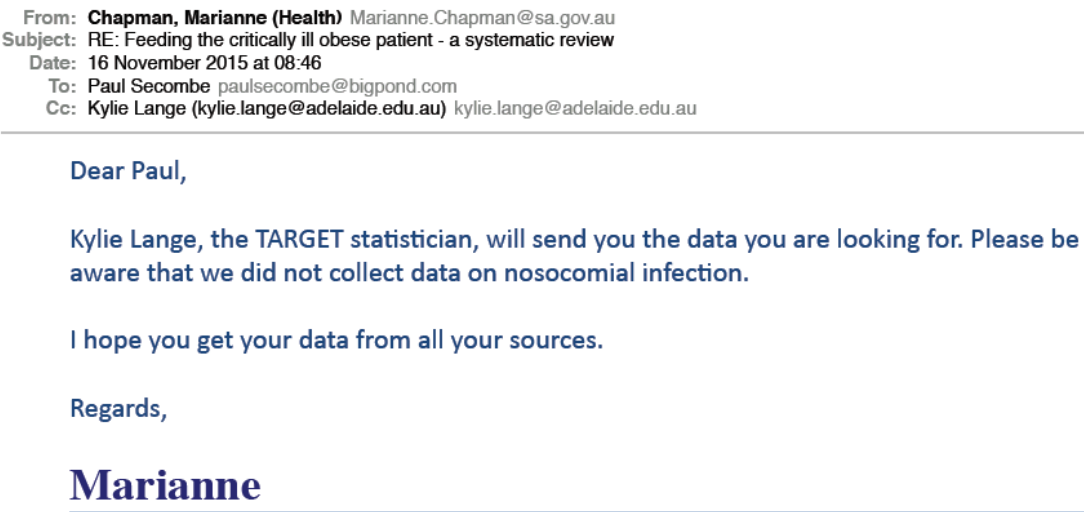

Petros S, Horbach M, Seidel F, Weidhase L. Hypocaloric vs Normocaloric Nutrition in Critically III Patients: A Prospective Randomized Pilot Trial. JPEN Journal of parenteral and enteral nutrition. 2016 Apr 3;40(2):242-9.

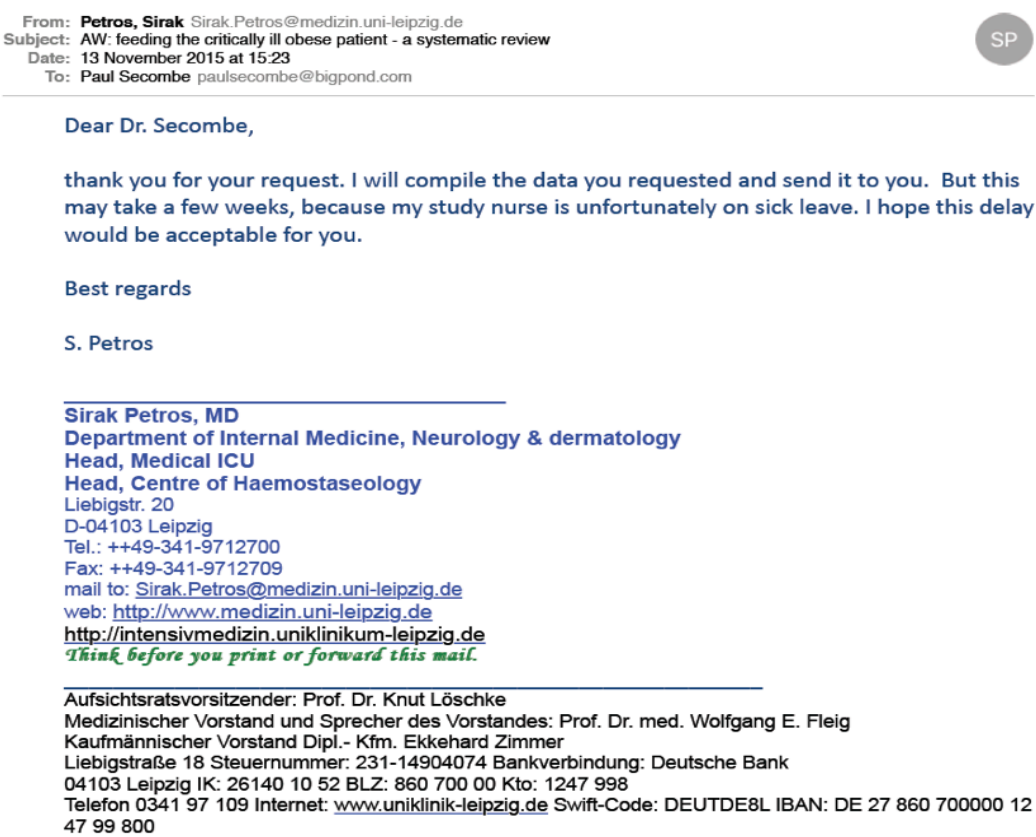


Dickerson RN, Boschert KJ, Kudsk KA, Brown RO. Hypocaloric enteral tube feeding in critically ill obese patients. Nutrition. 2002

Mar;18(3):241-6.

From: Dickerson, Roland N rdicker1@uthsc.edu

Subject: RE: feeding the critically ill obese patient - systematic review

Date: 26 November 2015 at 23:02

To: Paul Secombe paulsecombe@bigpond.com

Sorry, I do not have the time to try to do this. Additionally, I am not certain if I have the raw data anymore as we are only required by the University to keep the raw data collection forms for a period of 10 years beyond its publication date.

Roland N. Dickerson, Pharm.D., BCNSP, FCCP, FASHP, FCCM, FASPEN

Professor of Clinical Pharmacy

University of Tennessee Health Science Center

881 Madison Avenue, Room 333

Memphis, TN 38163

Phone: $901-448-6420$

Fax: 901-448-174

E-mail: rdickerson@uthsc.edu

Komjathy CM. Aggressive versus traditional enteral nutrition prescription in medical intensive care unit patients [M.S.]. Ann Arbor: Rush University; 2010.

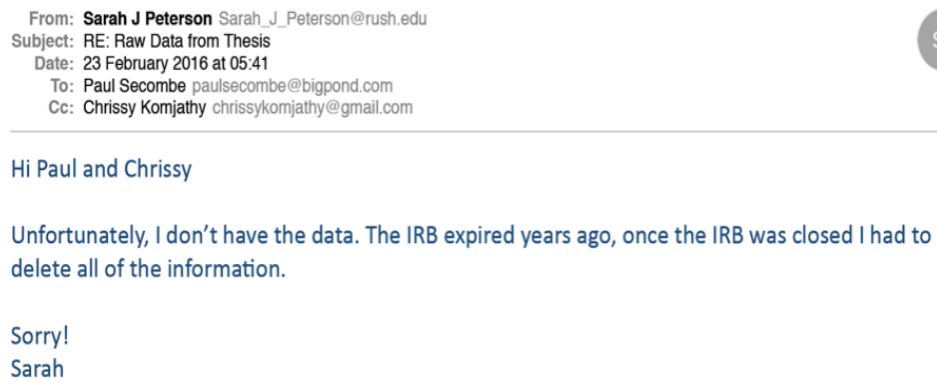

Unfortunately, I don't have the data. The IRB expired years ago, once the IRB was closed I had to delete all of the information.

Sorry!

Sarah

Arabi YM, Tamim HM, Dhar GS, Al-Dawood A, Al-Sultan M, Sakkijha $\mathrm{MH}$, et al. Permissive underfeeding and intensive insulin therapy in critically ill patients: a randomized controlled trial. Am J Clin Nutr. 2011 Mar;93(3):569-77.

and

Arabi YM, Aldawood AS, Haddad SH, Al-Dorzi HM, Tamim HM, Jones

G, et al. Permissive Underfeeding or Standard Enteral Feeding in Critically III Adults. N Engl J Med. 2015 Jun 18;372(25):2398-408.

PubMed PMID: 25992505. 
From: Yaseen Arabi Arabi@NGHA.MED.SA

Subject: RE: Feeding the critically ill obese patient - a systematic review

To: Paul Secombe paulsecombe@ bigpond.com

Dear Paul,

Very sorry for the delay. We are finalizing a manuscript that addresses this issue, therefore it will be difficult to provide the data before the manuscript is published.

Yaseen

Yaseen Arabi, MD, FCCP, FCCM

Chairman, Intensive Care Departmen

Professor. College of Medicine King Saud Bin Abdulaziz University for Health Sciences

King Abdulaziz Medical City ICU 1425 PO Box 22490 Riyadh, 11426, Kingdom of Saudi Arabia

+966(1)252-0088 Ext 18855/18877

arabi@ngha.med.sa

National Heart L, Blood Institute Acute Respiratory Distress Syndrome

Clinical Trials N, Rice TW, Wheeler AP, Thompson BT, Steingrub J,

et al. Initial trophic vs full enteral feeding in patients with acute lung

injury: the EDEN randomized trial. JAMA. 2012 Feb 22;307(8):795-

803.

No response despite multiple email attempts

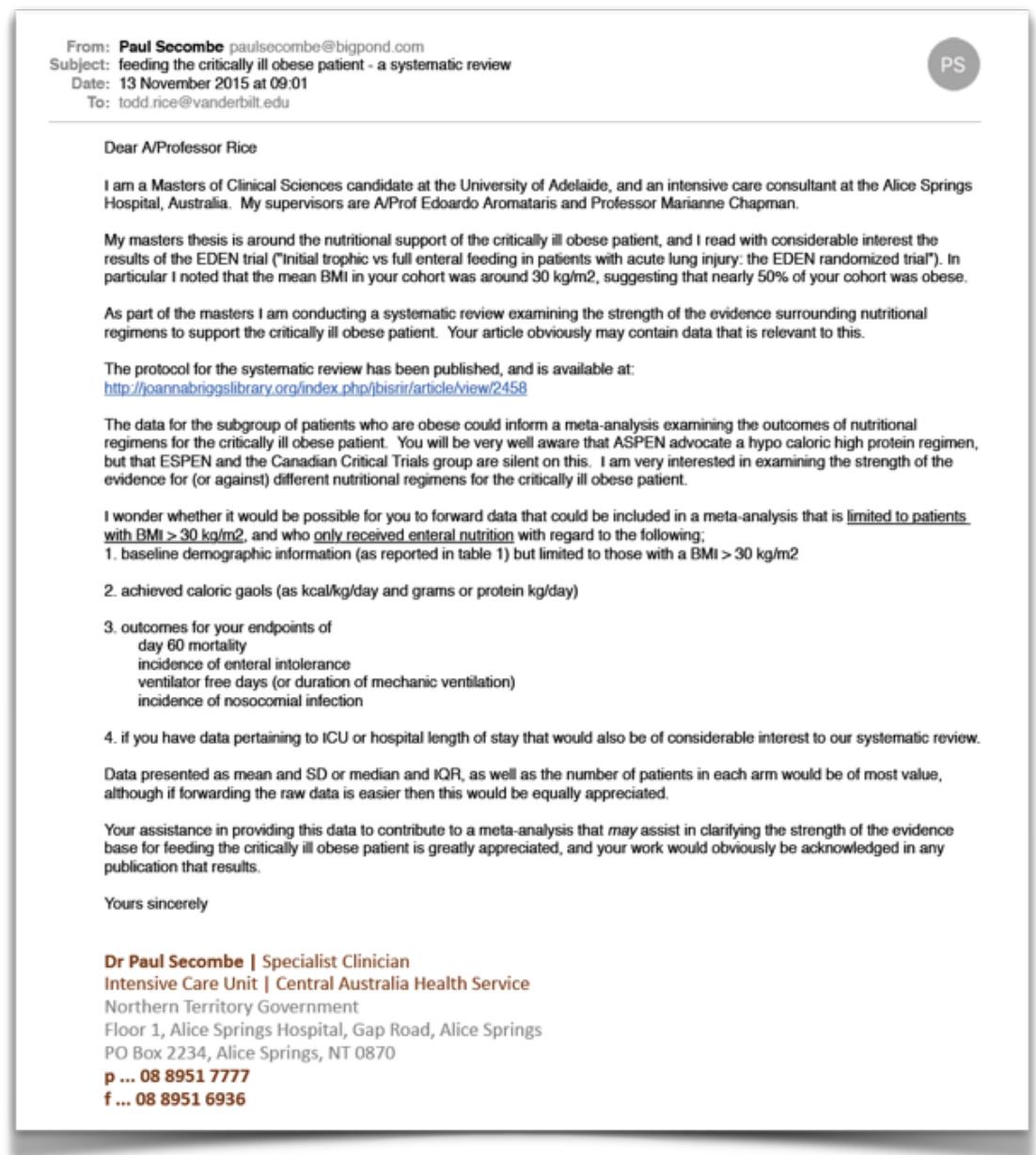


Charles EJ, Petroze RT, Metzger R, Hranjec T, Rosenberger LH, Riccio LM, et al. Hypocaloric compared with eucaloric nutritional support and its effect on infection rates in a surgical intensive care unit: a randomized controlled trial. American Journal of Clinical Nutrition. 2014 Nov;100(5):1337-43.

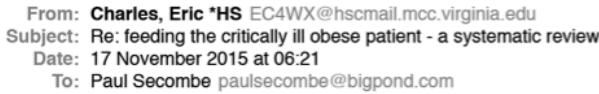

I very much enjoyed receiving your email. I am glad that you are working to answer a very important question regarding optimal nutrition strategies for the critically ill obese patient. Your email couldn't have been more timely as we are currently in the process of publishing

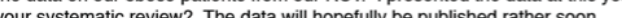

Eric

Eric J. Charles, MD University of Virginia

Doig GS, Simpson F, Heighes PT, Bellomo R, Chesher D, Caterson ID, et al. Restricted versus continued standard caloric intake during the management of refeeding syndrome in critically ill adults: a randomised, parallel-group, multicentre, single-blind controlled trial. The Lancet Respiratory medicine. 2015 Dec;3(12):943-52.

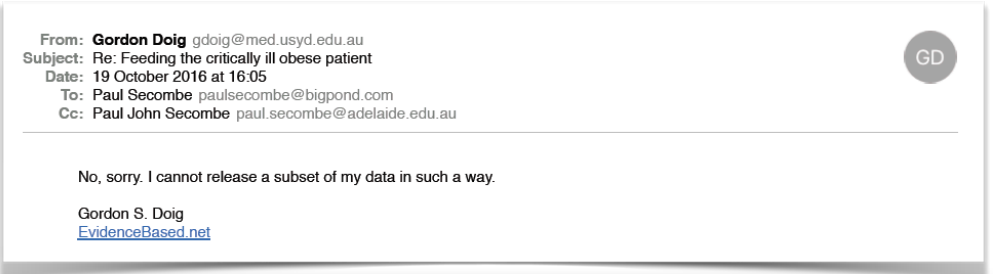

Rugeles SJ, Rueda JD, Diaz CE, Rosselli D. Hyperproteic hypocaloric enteral nutrition in the critically ill patient: A randomized controlled clinical trial. Indian Journal of Critical Care Medicine. 2013 Nov;17(6):343-9. and

Rugeles S, Villarraga-Angulo LG, Ariza-Gutierrez A, Chaverra-Kornerup S, Lasalvia P, Rosselli D. High-protein hypocaloric vs normocaloric enteral nutrition in critically ill patients: A randomized clinical trial. Journal of critical care. 2016 Oct;35:110-4. 
From: Saul Rugeles saul.rugeles@ gmail.com
Subject: Re: Feeding the critically ill obese patient

Date: 19 October 2016 at 08:09

To: Paul Secombe paulsecombe@bigpond.con

Dear Paul:

We reviewed our master data of both studies. Unfortunately we did not find any patient with BMI over 30 .

I am sorry we can not contribute to your project

Best regards

Saludos

Saúl Rugeles 


\section{Appendix 5 Excluded Studies}

\subsection{Following Review of Full Text}

Genton L, Dupertuis YM, Romand JA, Simonet ML, Jolliet P, Huber O, et al. Higher calorie prescription improves nutrient delivery during the first 5 days of enteral nutrition. Clinical Nutrition. 2004,;23(3):307-15.

Reason for exclusion: Ineligible population - did not include ICU patients. Recruited hospitalised patients only.

Alberda C, Gramlich L, Jones N, Jeejeebhoy K, Day AG, Dhaliwal R, et al. The relationship between nutritional intake and clinical outcomes in critically ill patients: results of an international multicenter observational study. Intensive Care Medicine. 2009 Oct;35(10):172837.

Reason for exclusion: Ineligible design - no intervention. Observational study with no intervention arm designed to describe current practice.

Arabi YM, Haddad SH, Aldawood AS, Al-Dorzi HM, Tamim HM, Sakkijha $\mathrm{M}$, et al. Permissive underfeeding versus target enteral feeding in adult critically ill patients (PermiT Trial): a study protocol of a multicenter randomized controlled trial. Trials. 2012;13:191,

Reason for exclusion: Ineligible design - no intervention. A priori study protocol only.

Dickerson RN, Medling TL, Smith AC, Maish GO, 3rd, Croce MA, Minard $G$, et al. Hypocaloric, high-protein nutrition therapy in older vs younger critically ill patients with obesity. Journal of Parenteral and Enteral Nutrition. 2013 May-Jun;37(3):342-51.

Reason for exclusion: Ineligible design - no intervention.

Compared older and younger patients on same nutritional regimen 
Charles EJ, Petroze RT, Hranjec T, Metzger R, Rosenberger LH,

Swenson B, et al. Hypocaloric versus eucaloric nutrition support and its effect on infection rates in a single-institution surgical ICU. Surgical Infections. 2013;14:S1.

Reason for exclusion: Ineligible - duplicate study. Conference abstract containing no data. Subsequently published in 2014 and included for possible subgroup analysis.

\subsection{Following Correspondence with Author (Figure 5)}

Dickerson RN, Boschert KJ, Kudsk KA, Brown RO. Hypocaloric enteral tube feeding in critically ill obese patients. Nutrition. 2002 Mar;18(3):241-6.

Reason for exclusion: Author contacted, but declined to provide clarification about details of study and declined to provide subgroup data. There were, in addition, substantial methodological issues including retrospective design with very high risk of selection bias, non-blinded, non-randomised sample that was almost exclusively trauma patients and further complicated by the use of an outdated definition of obesity (>125\% IBW).

\begin{tabular}{|l|c|c|c|c|c|c|c|c|c|c|c|}
\hline Question Number & $\mathbf{1}$ & $\mathbf{2}$ & $\mathbf{3}$ & $\mathbf{4}$ & $\mathbf{5}$ & $\mathbf{6}$ & $\mathbf{7}$ & $\mathbf{8}$ & $\mathbf{9}$ & Total & Include \\
\hline Dickerson, 2002 & $\mathrm{N}$ & $\mathrm{Y}$ & $\mathrm{N}$ & $\mathrm{N}$ & $\mathrm{Y}$ & $\mathrm{Y}^{\#}$ & $\mathrm{U}$ & $\mathrm{Y}$ & $\mathrm{N}^{\wedge}$ & 4 & $\mathrm{~N}$ \\
\hline
\end{tabular}

* JBI MAStARI Critical Appraisal Tool for Cohort (with control)/ Case Controlled Studies (Appendix 3.1) $\mathrm{Y}-$ yes, meets criterion.

$\mathrm{N}$ - no, does not meet criterion.

$U-$ unknown, unclear from text whether criterion met.

$\mathrm{N} / \mathrm{A}^{\wedge}$ - retrospective cohort controlled study, no withdrawals.

\# Follow up was of appropriate length in the context of the time at which the study was undertaken.

In the current climate of critical care research ICU mortality would no longer be an appropriate time frame.

$\wedge$ given small numbers and high likelihood of non-normal distribution, median (and IQR)

complemented by non-parametric statistical tests should have been used rather than mean (and

$\mathrm{SD}$ ) and parametric statistical tests. 
Komjathy CM. Aggressive versus traditional enteral nutrition prescription in medical intensive care unit patients [M.S.]. Ann Arbor: Rush

University; 2010.

Reason for exclusion: No longer had access to raw data. Deleted five years after data collection as per local Institutional Review Board requirements.

\begin{tabular}{|l|c|c|c|c|c|c|c|c|c|c|c|c|}
\hline Question Number & 1 & 2 & 3 & 4 & 5 & 6 & 7 & 8 & 9 & 10 & Total & Include \\
\hline Komjathy, 2010 & Y & Y & N & Y & Y & Y & U & Y & Y & N/A & 6 & N \\
\hline
\end{tabular}

* JBI MAStARI Critical Appraisal Tool for Cohort (with control)/ Case Controlled Studies (Appendix 3.2)

$\mathrm{Y}-$ yes, meets criterion.

$\mathrm{N}-\mathrm{no}$, does not meet criterion.

$\mathrm{U}$ - unknown, unclear from text whether criterion met.

N/A^ retrospective cohort controlled study, no withdrawals.

Arabi YM, Tamim HM, Dhar GS, AI-Dawood A, Al-Sultan M, Sakkijha $\mathrm{MH}$, et al. Permissive underfeeding and intensive insulin therapy in critically ill patients: a randomized controlled trial. Am J Clin Nutr. 2011 Mar;93(3):569-77.

Reason for exclusion: Author declined to provide subgroup data. Following email correspondence the author declined to provide subgroup data on the basis that subgroups from their trial were currently being analysed and prepared for publication. As such they were not prepared to provide access to any raw or additional subgroup data until such time as this had occurred.

\begin{tabular}{|l|c|c|c|c|c|c|c|c|c|c|c|c|}
\hline $\begin{array}{l}\text { Question } \\
\text { Number* }\end{array}$ & $\mathbf{1}$ & $\mathbf{2}$ & $\mathbf{3}$ & $\mathbf{4}$ & $\mathbf{5}$ & $\mathbf{6}$ & $\mathbf{7}$ & $\mathbf{8}$ & $\mathbf{9}$ & $\mathbf{1 0}$ & Total & Include \\
\hline Arabi, 2011 & $\mathrm{Y}$ & $\mathrm{N}$ & $\mathrm{Y}$ & $\mathrm{Y}$ & $\mathrm{U}$ & $\mathrm{Y}$ & $\mathrm{N}$ & $\mathrm{Y}$ & $\mathrm{Y}$ & $\mathrm{Y}$ & 7 & Subgroup \\
\hline
\end{tabular}

* JBI MAStARI Critical Appraisal Tool for Randomised Control / Pseudo-randomised Trial (Appendix

3.1)

$\mathrm{Y}$ - yes, meets criterion

$\mathrm{N}-$ no, does not meet criterion

$\mathrm{U}$ - unknown, unclear from text whether criterion met

National Heart L, Blood Institute Acute Respiratory Distress Syndrome 
Clinical Trials N, Rice TW, Wheeler AP, Thompson BT, Steingrub J, et al. Initial trophic vs full enteral feeding in patients with acute lung injury: the EDEN randomized trial. JAMA. 2012 Feb 22;307(8):795803.

Reason for exclusion: No response from author despite multiple attempts (email, fax, phone call).

\begin{tabular}{|l|c|c|c|c|c|c|c|c|c|c|c|c|}
\hline $\begin{array}{l}\text { Question } \\
\text { Number* }\end{array}$ & $\mathbf{1}$ & $\mathbf{2}$ & $\mathbf{3}$ & $\mathbf{4}$ & $\mathbf{5}$ & $\mathbf{6}$ & $\mathbf{7}$ & $\mathbf{8}$ & $\mathbf{9}$ & $\mathbf{1 0}$ & Total & Include \\
\hline Rice, 2013 & 1 & U & U & 1 & U & 1 & 0 & U & 0 & 1 & 4 & Subgroup \\
\hline
\end{tabular}

* JBI MAStARI Critical Appraisal Tool for Randomised Control / Pseudo-randomised Trial (Appendix 3.1)

$\mathrm{Y}-$ yes, meets criterion

$\mathrm{N}-$ no, does not meet criterion

$\mathrm{U}$ - unknown, unclear from text whether criterion met

Rugeles SJ, Rueda JD, Diaz CE, Rosselli D. Hyperproteic hypocaloric enteral nutrition in the critically ill patient: A randomized controlled clinical trial. Indian Journal of Critical Care Medicine. 2013

Nov;17(6):343-9.

Reason for exclusion: Recruited no obese patients into trial (Appendix 4).

\begin{tabular}{|l|c|c|c|c|c|c|c|c|c|c|c|c|}
\hline $\begin{array}{l}\text { Question } \\
\text { Number* }\end{array}$ & 1 & 2 & 3 & 4 & 5 & 6 & 7 & 8 & 9 & 10 & Total & Included \\
\hline Rugeles, 2016 & Y & U & Y & N & U & Y & Y & Y & Y & Y & 7 & Subgroup \\
\hline
\end{tabular}

* JBI MAStARI Critical Appraisal Tool for Randomised Control / Pseudo-randomised Trial (Appendix 3.1)

$\mathrm{Y}$ - yes, meets criterion

$\mathrm{N}-$ no, does not meet criterion

$\mathrm{U}-$ unknown, unclear from text whether criterion met

Ulusoy H, Ozkan AR, Kucuk AO, Besir A. The effects of hypocaloric underfeeding in adult ICU patients. Clinical Nutrition. 2014;33:S29.

Reason for exclusion: Conference abstract - unable to contact 
author for further details.

\begin{tabular}{|l|c|c|c|c|c|c|c|c|c|c|c|}
\hline $\begin{array}{l}\text { Question } \\
\text { Number }\end{array}$ & $\mathbf{1}$ & $\mathbf{2}$ & $\mathbf{3}$ & $\mathbf{4}$ & $\mathbf{5}$ & $\mathbf{6}$ & $\mathbf{7}$ & $\mathbf{8}$ & $\mathbf{9}$ & Total & Include \\
\hline Ulusoy, 2014 & U & U & Y & U & Y & Y & N/A^ & N & U & 3 & Subgroup \\
\hline
\end{tabular}

* JBI MAStARI Critical Appraisal Tool for Cohort (with control)/ Case Controlled Studies (Appendix 3.2)

$\mathrm{Y}-$ yes, meets criterion.

$\mathrm{N}-$ no, does not meet criterion.

$\mathrm{U}$ - unknown, unclear from text whether criterion met.

$\mathrm{N} / \mathrm{A}^{\wedge}$ retrospective cohort controlled study, no withdrawals.

Charles EJ, Petroze RT, Metzger R, Hranjec T, Rosenberger LH, Riccio

LM, et al. Hypocaloric compared with eucaloric nutritional support and its effect on infection rates in a surgical intensive care unit: a randomized controlled trial. American Journal of Clinical Nutrition. 2014 Nov;100(5):1337-43.

Reason for exclusion: Author declined to provide subgroup data. Following email correspondence the author declined to provide subgroup data on the basis that subgroups from their trial were being analysed and prepared for publication. As such they were not prepared to provide access to any raw or additional subgroup data until such time as this had occurred. Data in the public domain (a conference presentation) was provided; however this contained insufficient demographic and outcome data to allow data synthesis.

\begin{tabular}{|l|c|c|c|c|c|c|c|c|c|c|c|c|}
\hline $\begin{array}{l}\text { Question } \\
\text { Number }\end{array}$ & $\mathbf{1}$ & $\mathbf{2}$ & $\mathbf{3}$ & $\mathbf{4}$ & $\mathbf{5}$ & $\mathbf{6}$ & $\mathbf{7}$ & $\mathbf{8}$ & $\mathbf{9}$ & $\mathbf{1 0}$ & Total & Include \\
\hline Charles 2014 & Y & U & Y & Y & U & Y & Y & U & N & Y & 6 & Subgroup \\
\hline
\end{tabular}

* JBI MAStARI Critical Appraisal Tool for Randomised Control / Pseudo-randomised Trial (Appendix 3.1)

$\mathrm{Y}-$ yes, meets criterion

$\mathrm{N}-$ no, does not meet criterion

$\mathrm{U}$ - unknown, unclear from text whether criterion met

Arabi YM, Aldawood AS, Haddad SH, Al-Dorzi HM, Tamim HM, Jones

$\mathrm{G}$, et al. Permissive Underfeeding or Standard Enteral Feeding in

Critically III Adults. N Engl J Med. 2015 Jun 18;372(25):2398-408. 
Reason for exclusion: Author declined to provide subgroup data.

Following email correspondence the author declined to provide subgroup data on the basis that subgroups from their trial were being analysed and prepared for publication. As such they were not prepared to provide access to any raw or additional subgroup data until such time as this had occurred.

\begin{tabular}{|l|c|c|c|c|c|c|c|c|c|c|c|c|}
\hline $\begin{array}{l}\text { Question } \\
\text { Number* }\end{array}$ & $\mathbf{1}$ & $\mathbf{2}$ & $\mathbf{3}$ & $\mathbf{4}$ & $\mathbf{5}$ & $\mathbf{6}$ & $\mathbf{7}$ & $\mathbf{8}$ & $\mathbf{9}$ & $\mathbf{1 0}$ & TOTAL & Included \\
\hline Arabi, 2015 & $\mathrm{Y}$ & $\mathrm{N}$ & $\mathrm{Y}$ & $\mathrm{Y}$ & $\mathrm{U}$ & $\mathrm{Y}$ & $\mathrm{Y}$ & $\mathrm{Y}$ & $\mathrm{Y}$ & $\mathrm{Y}$ & 8 & Subgroup \\
\hline
\end{tabular}

* JBI MAStARI Critical Appraisal Tool for Randomised Control / Pseudo-randomised Trial (Appendix 3.1)

$\mathrm{Y}-$ yes, meets criterion

$\mathrm{N}-$ no, does not meet criterion

$\mathrm{U}$ - unknown, unclear from text whether criterion met

Rugeles S, Villarraga-Angulo LG, Ariza-Gutierrez A, Chaverra-Kornerup S, Lasalvia P, Rosselli D. High-protein hypocaloric vs normocaloric enteral nutrition in critically ill patients: A randomized clinical trial. Journal of critical care. 2016 Oct;35:110-4.

Reason for exclusion: Recruited no obese patients into trial (Appendix 4).

\begin{tabular}{|c|c|c|c|c|c|c|c|c|c|c|c|c|}
\hline $\begin{array}{c}\text { Question } \\
\text { Number* }\end{array}$ & 1 & 2 & 3 & 4 & 5 & 6 & 7 & 8 & 9 & 10 & Total & Included \\
\hline Rugeles, 2016 & $\mathrm{Y}$ & $\mathrm{U}$ & $\mathrm{Y}$ & $\mathrm{N}$ & $\mathrm{U}$ & $\mathrm{Y}$ & $\mathrm{Y}$ & $\mathrm{Y}$ & $\mathrm{Y}$ & $\mathrm{Y}$ & 7 & Subgroup \\
\hline
\end{tabular}

* JBI MAStARI Critical Appraisal Tool for Randomised Control / Pseudo-randomised Trial (Appendix 3.1)

$\mathrm{Y}$ - yes, meets criterion

$\mathrm{N}-\mathrm{no}$, does not meet criterion

$\mathrm{U}-$ unknown, unclear from text whether criterion met

Doig GS, Simpson F, Heighes PT, Bellomo R, Chesher D, Caterson ID, et al. Restricted versus continued standard caloric intake during the management of refeeding syndrome in critically ill adults: a randomised, parallel-group, multicentre, single-blind controlled trial. Lancet Respir Med. 2015 Dec;3(12):943-52. 
Reason for exclusion: Declined (Appendix 4).

\begin{tabular}{|c|c|c|c|c|c|c|c|c|c|c|c|c|}
\hline $\begin{array}{c}\text { Question } \\
\text { Number* }\end{array}$ & 1 & 2 & 3 & 4 & 5 & 6 & 7 & 8 & 9 & 10 & Total & Included \\
\hline Doig et al, 2015 & $\mathrm{Y}$ & $\mathrm{N}$ & $\mathrm{Y}$ & $\mathrm{Y}$ & $\mathrm{Y}$ & $\mathrm{Y}$ & $\mathrm{Y}$ & $\mathrm{Y}$ & $\mathrm{Y}$ & $\mathrm{Y}$ & 9 & Subgroup \\
\hline
\end{tabular}

* JBI MAStARI Critical Appraisal Tool for Randomised Control / Pseudo-randomised Trial (Appendix 3.1)

$\mathrm{Y}$ - yes, meets criterion

$\mathrm{N}$ - no, does not meet criterion

$\mathrm{U}$ - unknown, unclear from text whether criterion met 


\section{References}

1. Eknoyan G. Adolphe Quetelet (1796-1874) - the average man and indices of obesity. Nephrology Dialysis and Transplant. 2008;23(1):47-51.

2. Gluckman PD, Lillycrop KA, Vickers MH, Pleasants AB, Phillips ES, Beedle AS, et al. Metabolic plasticity during mammalian development is directionally dependent on early nutritional status. Proceeding of the Natlonal Academy of Sciences U S A. 2007;104(31):12796-800.

3. Swinburn BA, Sacks G, Hall KD, McPherson K, Finegood DT, Moodie ML, et al. The global obesity pandemic: shaped by global drivers and local environments. Lancet. 2011;378(9793):804-14.

4. Slomko H, Heo HJ, Einstein FH. Minireview: Epigenetics of obesity and diabetes in humans. Endocrinology. 2012;153(3):1025-30.

5. Dalgaard K, Landgraf K, Heyne S, Lempradl A, Longinotto J, Gossens K, et al. Trim28 Haploinsufficiency Triggers Bi-stable Epigenetic Obesity. Cell. 2016;164(3):353-64.

6. Smith KB, Smith MS. Obesity Statistics. Primary Care. 2016;43(1):121-35. 
7. Johnson J. Highlights of the New Build and Blood Pressure Study. Transactions of the Association of Life Insurance Medical Directors America. 1959;43:34 - 42.

8. Society of Actuaries. Build and Blood Pressure Study. Chicago, USA: Society of Actuaries; 1959.

9. Keys A, Fidanza F, Karvonen MJ, Kimura N, Taylor HL. Indices of relative weight and obesity. Journal of Chronic Diseases. 1972;25(6):329-43.

10. Quetelet LA. A treatise on man and the development of his faculties. 1842. Obesity Research. 1994;2(1):72-85.

11. Dickerson RN, Boschert KJ, Kudsk KA, Brown RO. Hypocaloric enteral tube feeding in critically ill obese patients. Nutrition. 2002;18(3):241-6.

12. Devine B. Case Number 25: Gentamicin Therapy. Drug Intelligency and Clinical Pharmacy. 1974;8:650 - 55.

13. Robinson JD, Lupkiewicz SM, Palenik L, Lopez LM, Ariet M. Determination of ideal body weight for drug dosage calculations. American Journal of Hospital Pharmacy. 1983;40(6):1016-9.

14. Hamwi G. Therapy: Changing dietary concepts. In: Danowski T, editor. Diabetes Mellitus: Diagnosis and Treatment. 1st ed. New York: American Diabetes Association; 1964. p. pp 73 - 8.

15. The Acute Respiratory Distress Syndrome Network. Ventilation with lower tidal volumes as compared with traditional tidal volumes for acute lung injury and the acute 
respiratory distress syndrome. The Acute Respiratory

Distress Syndrome Network. New England Journal of Medicine. 2000;342(18):1301-8.

16. Dankel SJ, Loenneke JP, Loprinzi PD. Does the fat-but-fit paradigm hold true for all-cause mortality when considering the duration of overweight/obesity? Analyzing the WATCH (Weight, Activity and Time Contributes to Health) paradigm. Preventive Medicine. 2016;83:37-40.

17. Hogstrom G, Nordstrom A, Nordstrom P. Aerobic fitness in late adolescence and the risk of early death: a prospective cohort study of 1.3 million Swedish men. International Journal of Epidemiology. 2015.

18. Jackson AS, Stanforth PR, Gagnon J, Rankinen T, Leon AS, Rao DC, et al. The effect of sex, age and race on estimating percentage body fat from body mass index: The Heritage Family Study. International Journal of Obesity and Related Metabolic Disorders. 2002;26(6):789-96.

19. Stoner L, Cornwall J. Did the American Medical Association make the correct decision classifying obesity as a disease? The Australasian Medical Journal. 2014;7(11):462-4.

20. Fox CS, Massaro JM, Hoffmann U, Pou KM, Maurovich-Horvat P, Liu CY, et al. Abdominal visceral and subcutaneous adipose tissue compartments: association with metabolic risk factors in the Framingham Heart Study. Circulation. 2007;116(1):3948. 
21. Rothman KJ. BMI-related errors in the measurement of obesity. International Journal of Obesity (Lond). 2008;32 Suppl 3:S56-9.

22. The Prospective Studies Collaboration, Whitlock G, Lewington S, Sherliker P, Clarke R, Emberson J, et al. Body-mass index and cause-specific mortality in 900000 adults: collaborative analyses of 57 prospective studies. Lancet. 2009;373(9669):1083-96.

23. Flicker L, McCaul KA, Hankey GJ, Jamrozik K, Brown WJ, Byles JE, et al. Body mass index and survival in men and women aged 70 to 75 . Journal of the American Geriatric Society. 2010;58(2):234-41.

24. Afzal S, Tybjaerg-Hansen A, Jensen GB, Nordestgaard BG. Change in Body Mass Index Associated With Lowest Mortality in Denmark, 1976-2013. JAMA: Journal of the American Medical Association. 2016;315(18):1989-96.

25. Thomson CA, Garcia DO, Wertheim BC, Hingle MD, Bea JW, Zaslavsky 0, et al. Body shape, adiposity index, and mortality in postmenopausal women: Findings from the Women's Health Initiative. Obesity (Silver Spring). 2016;24(5):1061-9.

26. Allison DB, Zhu SK, Plankey M, Faith MS, Heo M. Differential associations of body mass index and adiposity with all-cause mortality among men in the first and second National Health and Nutrition Examination Surveys (NHANES I and NHANES 
II) follow-up studies. International Journal of Obesity and Related Metabolic Disorders. 2002;26(3):410-6.

27. Oreopoulos A, Kalantar-Zadeh K, Sharma AM, Fonarow GC. The obesity paradox in the elderly: potential mechanisms and clinical implications. Clinics in Geriatric Medicine. 2009;25(4):643-59, viii.

28. Rahman M, Berenson AB. Accuracy of current body mass index obesity classification for white, black, and Hispanic reproductive-age women. Obstetrics and Gynecology. 2010;115(5):982-8.

29. Pan WH, Flegal KM, Chang HY, Yeh WT, Yeh CJ, Lee WC. Body mass index and obesity-related metabolic disorders in Taiwanese and US whites and blacks: implications for definitions of overweight and obesity for Asians. American Journal of Clinical Nutrition. 2004;79(1):31-9.

30. American Medical Association. AMA Adopts New Policies on Second Day of Voting at Annual Meeting. American Medical Association; 2013.

31. The Committee of Presidents of Medical Colleges. Specialist Medical Colleges call for action to tackle obesity crisis in Australia. 2016.

32. Taylor BE, McClave SA, Martindale RG, Warren MM, Johnson DR, Braunschweig C, et al. Guidelines for the Provision and Assessment of Nutrition Support Therapy in the Adult Critically Ill Patient: Society of Critical Care Medicine (SCCM) 
and American Society for Parenteral and Enteral Nutrition (A.S.P.E.N.). Critical Care Medicine. 2016;44(2):390-438.

33. World Health Organisation. Obesity and overweight. World Health Organisation; 2015 [4 June, 2015]. Available from: http://www.who.int/mediacentre/factsheets/fs311/en/

34. Port AM, Apovian C. Metabolic support of the obese intensive care unit patient: a current perspective. Current Opinion in Clinical Nutrition and Metabolic Care. 2010;13(2):184-91.

35. Ng M, Fleming T, Robinson M, Thomson B, Graetz N, Margono C, et al. Global, regional, and national prevalence of overweight and obesity in children and adults during 19802013: a systematic analysis for the Global Burden of Disease Study 2013. Lancet. 2014;384(9945):766-81.

36. Ogden CL, Carroll MD, Kit BK, Flegal KM. Prevalence of childhood and adult obesity in the United States, 2011-2012. JAMA: Journal of the American Medical Association. 2014;311(8):806-14.

37. Ogden CL, Carroll MD, Lawman HG, et al. Trends in obesity prevalence among children and adolescents in the united states, 1988-1994 through 2013-2014. JAMA: Journal of the American Medical Association. 2016;315(21):2292-9.

38. Flegal KM, Kruszon-Moran D, Carroll MD, Fryar CD, Ogden CL. Trends in obesity among adults in the united states, 2005 to 2014. JAMA: Journal of the American Medical Association. 2016;315(21):2284-91. 
39. Twig G, Yaniv G, Levine H, Leiba A, Goldberger N, Derazne E, et al. Body-Mass Index in 2.3 Million Adolescents and Cardiovascular Death in Adulthood. New England Journal of Medicine. 2016;374(25):2430 - 40.

40. Cawley J, Meyerhoefer C. The medical care costs of obesity: an instrumental variables approach. Journal of Health Economics. 2012;31(1):219-30.

41. Finkelstein EA, Trogdon JG, Cohen JW, Dietz W. Annual medical spending attributable to obesity: payer-and servicespecific estimates. Health Affairs. 2009;28(5):w822-31.

42. Australian Institute of Health and Welfare. Overweight and Obesity. 2008 [15 March, 2015]. Available from:

www.aihw.gov.au/overweight-andobesity/prevalence/\#adults.

43. Australian Bureau of Statistics. Australian Health Survey: Updated Results 2011-2012. Cat no. 4364.0.55.003.2013 [cited 2 June 2015]. Available from: http://www.abs.gov.au/ausstats/abs@.nsf/Lookup/034947E 844F25207CA257AA30014BDC7?opendocument

44. National Heart Foundation. Obesity and Physical Inactivity. Australia 2015 [cited 201510 May]. Available from: http://www.heartfoundation.org.au/SiteCollectionDocument s/HF\%200besity\%20and\%20Physical\%20Inactivity\%20Rep ort\%20overview.pdf 
45. Australian Institute of Health and Welfare 2014. Australia's health 2014. In: AIHW, editor. Australia's health series no. 14. Cat. no. AUS178. Canberra: AIHW; 2014.

46. Shashaty MG, Stapleton RD. Physiological and management implications of obesity in critical illness. Ann Am Thorac Soc. 2014;11(8):1286-97.

47. Backman L, Freyschuss U, Hallberg D, Melcher A. Cardiovascular function in extreme obesity. Acta Medica Scandinavica. 1973;193(5):437-46.

48. de Divitiis O, Fazio S, Petitto M, Maddalena G, Contaldo F, Mancini M. Obesity and cardiac function. Circulation. 1981;64(3):477-82.

49. Lemmens HJ, Bernstein DP, Brodsky JB. Estimating blood volume in obese and morbidly obese patients. Obesity Surgery. 2006;16(6):773-6.

50. Stelfox HT, Ahmed SB, Ribeiro RA, Gettings EM, Pomerantsev E, Schmidt U. Hemodynamic monitoring in obese patients: the impact of body mass index on cardiac output and stroke volume. Critical Care Medicine. 2006;34(4):1243-6.

51. Marik P, Varon J. The obese patient in the ICU. Chest. 1998;113(2):492-8.

52. Rugeles S, Villarraga-Angulo LG, Ariza-Gutierrez A, ChaverraKornerup S, Lasalvia P, Rosselli D. High-protein hypocaloric vs normocaloric enteral nutrition in critically ill patients: A 
randomized clinical trial. Journal of Critical Care. 2016;35:110-4.

53. Rugeles SJ, Rueda JD, Diaz CE, Rosselli D. Hyperproteic hypocaloric enteral nutrition in the critically ill patient: A randomized controlled clinical trial. Indian Journal of Critical Care Medicine. 2013;17(6):343-9.

54. Arabi YM, Aldawood AS, Haddad SH, Al-Dorzi HM, Tamim HM, Jones G, et al. Permissive Underfeeding or Standard Enteral Feeding in Critically Ill Adults. New England Journal of Medicine. 2015;372(25):2398-408.

55. Dennis DM, Bharat C, Paterson T. Prevalence of obesity and the effect on length of mechanical ventilation and length of stay in intensive care patients: A single site observational study. Australian Critical Care. 2016.

56. Dennis DM, Trevenen M. Prevalence of obesity in an intensive care unit patient population. Intensive Critical Care Nursing. 2016;35:52-6.

57. Alberda C, Gramlich L, Jones N, Jeejeebhoy K, Day AG, Dhaliwal R, et al. The relationship between nutritional intake and clinical outcomes in critically ill patients: results of an international multicenter observational study. Intensive Care Medicine. 2009;35(10):1728-37.

58. Peake SL, Moran JL, Ghelani DR, Lloyd AJ, Walker MJ. The effect of obesity on 12-month survival following admission to 
intensive care: a prospective study. Critical Care Medicine. 2006;34(12):2929-39.

59. Hogue CW, Jr., Stearns JD, Colantuoni E, Robinson KA, Stierer T, Mitter N, et al. The impact of obesity on outcomes after critical illness: a meta-analysis. Intensive Care Medicine. 2009;35(7):1152-70.

60. Robinson MK, Mogensen KM, Casey JD, McKane CK, Moromizato T, Rawn JD, et al. The relationship among obesity, nutritional status, and mortality in the critically ill. Critical Care Medicine. 2015;43(1):87-100.

61. Bercault N, Boulain T, Kuteifan K, Wolf M, Runge I, Fleury JC. Obesity-related excess mortality rate in an adult intensive care unit: A risk-adjusted matched cohort study. Critical Care Medicine. 2004;32(4):998-1003.

62. Neville AL, Brown CV, Weng J, Demetriades D, Velmahos GC. Obesity is an independent risk factor of mortality in severely injured blunt trauma patients. Archives of Surgery. 2004;139(9):983-7.

63. Yaegashi M, Jean R, Zuriqat M, Noack S, Homel P. Outcome of morbid obesity in the intensive care unit. Journal of Intensive Care Medicine. 2005;20(3):147-54.

64. Dossett LA, Dageforde LA, Swenson BR, Metzger R, Bonatti H, Sawyer RG, et al. Obesity and site-specific nosocomial infection risk in the intensive care unit. Surgical Infections. 2009;10(2):137-42. 
65. Smith RL, Chong TW, Hedrick TL, Hughes MG, Evans HL, McElearney ST, et al. Does body mass index affect infectionrelated outcomes in the intensive care unit? Surgical Infections. 2007;8(6):581-8.

66. Akinnusi ME, Pineda LA, El Solh AA. Effect of obesity on intensive care morbidity and mortality: a meta-analysis. Critical Care Medicine. 2008;36(1):151-8.

67. Dossett LA, Heffernan D, Lightfoot M, Collier B, Diaz JJ, Sawyer RG, et al. Obesity and pulmonary complications in critically injured adults. Chest. 2008;134(5):974-80.

68. Oliveros H, Villamor E. Obesity and mortality in critically ill adults: a systematic review and meta-analysis. Obesity (Silver Spring). 2008;16(3):515-21.

69. Ciesla DJ, Moore EE, Johnson JL, Burch JM, Cothren CC, Sauaia A. Obesity increases risk of organ failure after severe trauma. Journal of the American College of Surgeons. 2006;203(4):539-45.

70. Martino JL, Stapleton RD, Wang M, Day AG, Cahill NE, Dixon AE, et al. Extreme obesity and outcomes in critically ill patients. Chest. 2011;140(5):1198-206.

71. Chapman M, Peake S, Jones D. Gluttony in the ICU: is it really a deadly sin? Critical Care and Resuscitation. 2015;17(2):63-4.

72. Ridley E, Gantner D, Pellegrino V. Nutrition therapy in critically ill patients- a review of current evidence for clinicians. Clinical Nutrition. 2015. 
73. Rubinson L, Diette GB, Song X, Brower RG, Krishnan JA. Low caloric intake is associated with nosocomial bloodstream infections in patients in the medical intensive care unit. Critical Care Medicine. 2004;32(2):350-7.

74. Villet S, Chiolero RL, Bollmann MD, Revelly JP, Cayeux RNM, Delarue J, et al. Negative impact of hypocaloric feeding and energy balance on clinical outcome in ICU patients. Clinical Nutrition. 2005;24(4):502-9.

75. Dvir D, Cohen J, Singer P. Computerized energy balance and complications in critically ill patients: an observational study. Clinical Nutrition. 2006;25(1):37-44.

76. Heyland DK, Cahill N, Day AG. Optimal amount of calories for critically ill patients: depends on how you slice the cake! Critical Care Medicine. 2011;39(12):2619-26.

77. Tsai JR, Chang WT, Sheu CC, Wu YJ, Sheu YH, Liu PL, et al. Inadequate energy delivery during early critical illness correlates with increased risk of mortality in patients who survive at least seven days: a retrospective study. Clinical Nutrition 2011;30(2):209-14.

78. Weijs PJ, Stapel SN, de Groot SD, Driessen RH, de Jong E, Girbes AR, et al. Optimal protein and energy nutrition decreases mortality in mechanically ventilated, critically ill patients: a prospective observational cohort study. Journal of Parenteral and Enteral Nutrition. 2012;36(1):60-8. 
79. Wei X, Day AG, Ouellette-Kuntz H, Heyland DK. The Association Between Nutritional Adequacy and Long-Term Outcomes in Critically Ill Patients Requiring Prolonged Mechanical Ventilation: A Multicenter Cohort Study. Critical Care Medicine. 2015;43(8):1569-79.

80. Patel JJ, Codner P. Controversies in Critical Care Nutrition Support. Critical Care Clinics. 2016;32(2):173-89.

81. Elke G, Wang M, Weiler N, Day AG, Heyland DK. Close to recommended caloric and protein intake by enteral nutrition is associated with better clinical outcome of critically ill septic patients: secondary analysis of a large international nutrition database. Critical Care. 2014;18(1):R29.

82. Martindale RG, Warren M, Diamond S, Kiraly L. Nutritional Therapy for Critically Ill Patients. Nestle Nutrition Workshop Series. 2015;82:103-16.

83. Kreymann KG, Berger MM, Deutz NE, Hiesmayr M, Jolliet P, Kazandjiev G, et al. ESPEN Guidelines on Enteral Nutrition: Intensive care. Clinical Nutrition. 2006;25(2):210-23.

84. Canadian Critical Care Nutrition Clinical Practice Guidelines. 1.0 The Use of Enteral Nutrition vs. Parental Nutrition. 2013 [updated 2013; cited 20168 February]. Available from: http://criticalcarenutrition.com/docs/cpgs2012/1.0.pdf

85. Casaer MP, Van den Berghe G. Nutrition in the acute phase of critical illness. New England Journal of Medicine. 2014;370(25):2450-1. 
86. Cuthbertson DP. Observations On The Disturbance Of Metabolism Produced By Injury To The Limbs. QJM: An International Journal of Medicine. 1932;1(2):233-46.

87. Desborough JP. The stress response to trauma and surgery. British Journal of Anaesthesia. 2000;85(1):109-17.

88. Cuesta JM, Singer M. The stress response and critical illness: a review. Critical Care Medicine. 2012;40(12):3283-9.

89. Finnerty CC, Mabvuure NT, Ali A, Kozar RA, Herndon DN. The surgically induced stress response. Journal of Parenteral and Enteral Nutrition. 2013;37(5 Suppl):21S-9S.

90. Boonen E, Vervenne H, Meersseman P, Andrew R, Mortier L, Declercq PE, et al. Reduced cortisol metabolism during critical illness. New England Journal of Medicine. 2013;368(16):1477-88.

91. Marik PE, Bellomo R. Stress hyperglycemia: an essential survival response! Critical Care. 2013;17(2):305.

92. Preiser JC, van Zanten AR, Berger MM, Biolo G, Casaer MP, Doig GS, et al. Metabolic and nutritional support of critically ill patients: consensus and controversies. Critical Care. 2015;19(1):35.

93. Preiser JC, Ichai C, Orban JC, Groeneveld AB. Metabolic response to the stress of critical illness. British Journal of Anaesthesia. 2014;113(6):945-54. 
94. Boiteux A, Hess B. Design of glycolysis. Philosophical Transactions of the Royal Society of London B Biological Sciences. 1981;293(1063):5-22.

95. McClave SA, Kushner R, Van Way CW, 3rd, Cave M, DeLegge M, Dibaise J, et al. Nutrition therapy of the severely obese, critically ill patient: summation of conclusions and recommendations. Journal of Parenteral and Enteral Nutrition. 2011;35(5 Suppl):88S-96S.

96. Secombe PJ, Brown A, Kruger PS, Stewart PC. Lipid profiles and persisting inflammation following critical illness in a central Australian population: a prospective longitudinal observational study. Internal Medicine Journal. 2013;43(4):445-9.

97. Ishibashi N, Plank LD, Sando K, Hill GL. Optimal protein requirements during the first 2 weeks after the onset of critical illness. Critical Care Medicine. 1998;26(9):1529-35.

98. Allingstrup MJ, Esmailzadeh N, Wilkens Knudsen A, Espersen K, Hartvig Jensen T, Wiis J, et al. Provision of protein and energy in relation to measured requirements in intensive care patients. Clinical Nutrition. 2012;31(4):462-8.

99. Hoffer LJ, Bistrian BR. Appropriate protein provision in critical illness: a systematic and narrative review. American Journal of Clinical Nutrition. 2012;96(3):591-600.

100. Plank LD. Protein for the critically ill patient--what and when? European Journal of Clinical Nutrition. 2013;67(5):565-8. 
101. Li P, Yin YL, Li D, Kim SW, Wu G. Amino acids and immune function. British Journal of Nutrition. 2007;98(2):237-52.

102. Dickerson RN. Hypocaloric, high-protein nutrition therapy for critically ill patients with obesity. Nutrition in Clinical Practice. 2014;29(6):786-91.

103. Schetz M, Casaer MP, Van den Berghe G. Does artificial nutrition improve outcome of critical illness? Critical Care. 2013;17(1):302.

104. McClave SA, Weijs PJ. Preservation of autophagy should not direct nutritional therapy. Current Opinion in Clinical and Nutritional Metabolic Care. 2015;18(2):155-61.

105. Cuervo AM, Macian F. Autophagy, nutrition and immunology. Molecular Aspects of Medicine. 2012;33(1):2-13.

106. Taylor S, Dumont N, Clemente R, Allan K, Downer C, Mitchell A. Critical care: Meeting protein requirements without overfeeding energy. Clinical Nutrition ESPEN. 2016;11:e55e62.

107. Marik PE, Hooper MH. Normocaloric versus hypocaloric feeding on the outcomes of ICU patients: a systematic review and meta-analysis. Intensive Care Medicine. 2015.

108. Parikh HG, Miller A, Chapman M, Moran JL, Peake SL. Calorie delivery and clinical outcomes in the critically ill: a systematic review and meta-analysis. Critical Care and Resuscitation. 2016;18(1):17-24. 
109. Walker RN, Heuberger RA. Predictive equations for energy needs for the critically ill. Respiratory Care. 2009;54(4):50921.

110. Peake SL, Chapman MJ, Davies AR, Moran JL, O'Connor S, Ridley E, et al. Enteral nutrition in Australian and New Zealand intensive care units: a point-prevalence study of prescription practices. Critical Care and Resuscitation. 2012;14(2):148-53.

111. Singer P, Anbar R, Cohen J, Shapiro H, Shalita-Chesner M, Lev S, et al. The tight calorie control study (TICACOS): a prospective, randomized, controlled pilot study of nutritional support in critically ill patients. Intensive Care Medicine. 2011;37(4):601-9.

112. Canadian Critical Care Nutrition Clinical Practice Guidelines. 3.1 Nutritional Prescription: Use of Indirect Calorimetry vs. Predictive Equations. 2015 [cited 20163 March]. Available from:

http://www.criticalcarenutrition.com/docs/CPGs\%202015/ 3.1\%202015.pdf

113. Singer P. TICACOS International (P2 -RMCS).

ClinicalTrials.gov; 2011 [cited 20174 January]. Available from:

https://clinicaltrials.gov/ct2/show/NCT01479673?term=indi $\underline{\text { rect }+ \text { calorimetry\&rank }=6}$ 
114. Rehal MS, Fiskaare E, Tjader I, Norberg A, Rooyackers O, Wernerman J. Measuring energy expenditure in the intensive care unit: a comparison of indirect calorimetry by E-sCOVX and Quark RMR with Deltatrac II in mechanically ventilated critically ill patients. Critical Care. 2016;20(1):54.

115. Talpers SS, Romberger DJ, Bunce SB, Pingleton SK. Nutritionally associated increased carbon dioxide production. Excess total calories vs high proportion of carbohydrate calories. Chest. 1992;102(2):551-5.

116. Cade JF, Jones DA, Bellomo R. Nutrition in the intensive care unit - you must breathe what you eat. Crit Care Resusc. 2016;18(4):224-7.

117. Zusman O, Theilla M, Cohen J, Kagan I, Bendavid I, Singer P. Resting energy expenditure, calorie and protein consumption in critically ill patients: a retrospective cohort study. Crit Care. 2016;20(1):367.

118. Cohen HY, Miller C, Bitterman KJ, Wall NR, Hekking B, Kessler B, et al. Calorie restriction promotes mammalian cell survival by inducing the SIRT1 deacetylase. Science. 2004;305(5682):390-2.

119. Lin SJ, Kaeberlein M, Andalis AA, Sturtz LA, Defossez PA, Culotta VC, et al. Calorie restriction extends Saccharomyces cerevisiae lifespan by increasing respiration. Nature. 2002;418(6895):344-8. 
120. Colman RJ, Beasley TM, Kemnitz JW, Johnson SC, Weindruch R, Anderson RM. Caloric restriction reduces age-related and all-cause mortality in rhesus monkeys. Nature Communications. 2014;5:3557.

121. Heilbronn LK, Ravussin E. Calorie restriction and aging: review of the literature and implications for studies in humans. American Journal of Clinical Nutrition. 2003;78(3):361-9.

122. National Heart LaBIARDSCTN, Rice TW, Wheeler AP, Thompson BT, Steingrub J, Hite RD, et al. Initial trophic vs full enteral feeding in patients with acute lung injury: the EDEN randomized trial. JAMA: Journal of the American Medical Association. 2012;307(8):795-803.

123. Arabi YM, Tamim HM, Dhar GS, Al-Dawood A, Al-Sultan M, Sakkijha MH, et al. Permissive underfeeding and intensive insulin therapy in critically ill patients: a randomized controlled trial. American Journal of Clinical Nutrition. 2011;93(3):569-77.

124. Charles EJ, Petroze RT, Metzger R, Hranjec T, Rosenberger LH, Riccio LM, et al. Hypocaloric compared with eucaloric nutritional support and its effect on infection rates in a surgical intensive care unit: a randomized controlled trial. Americal Journal of Clinical Nutrition. 2014;100(5):1337-43.

125. Choi EY, Park DA, Park J. Calorie intake of enteral nutrition and clinical outcomes in acutely critically ill patients: a meta- 
analysis of randomized controlled trials. Journal of Parenteral and Enteral Nutrition. 2015;39(3):291-300.

126. Peake SL, Davies AR, Deane AM, Lange K, Moran JL, O'Connor SN, et al. Use of a concentrated enteral nutrition solution to increase calorie delivery to critically ill patients: a randomized, double-blind, clinical trial. America Journal of Clinical Nutrition. 2014;100(2):616-25.

127. Young P, Hodgson C, Dulhunty J, Saxena M, Bailey M, Bellomo $\mathrm{R}$, et al. End points for phase II trials in intensive care: recommendations from the Australian and New Zealand Clinical Trials Group consensus panel meeting. Critical Care and Resuscitation. 2012;14(3):211-5.

128. Ali Abdelhamid Y, Cousins CE, Sim JA, Bellon MS, Nguyen NQ, Horowitz M, et al. Effect of Critical Illness on Triglyceride Absorption. Journal of Parenteral and Enteral Nutrition. 2015;39(8):966-72.

129. Deane AM, Rayner CK, Keeshan A, Cvijanovic N, Marino Z, Nguyen NQ, et al. The effects of critical illness on intestinal glucose sensing, transporters, and absorption. Critical Care Medicine. 2014;42(1):57-65.

130. Nordenstrom J, Carpentier YA, Askanazi J, Robin AP, Elwyn DH, Hensle TW, et al. Free fatty acid mobilization and oxidation during total parenteral nutrition in trauma and infection. Annals of Surgery. 1983;198(6):725-35. 
131. Seres D. Nutrition Support in Critically Ill Patients: An Overview2015 [cited 24/02/2016]. Available from: http://www.uptodate.com/contents/nutrition-support-incritically-ill-patients-anoverview?source=search result\&search=nutrition + support $+\mathrm{i}$ $\underline{\mathrm{n}+\mathrm{critical}+\mathrm{illness} \& \text { selectedTitle }=1 \% 7 \mathrm{E} 150}$

132. Nicolo M, Heyland DK, Chittams J, Sammarco T, Compher C. Clinical Outcomes Related to Protein Delivery in a Critically Ill Population: A Multicenter, Multinational Observation Study. Journal of Parenteral and Enteral Nutrition. 2015.

133. Rooyackers O, Kouchek-Zadeh R, Tjader I, Norberg A, Klaude M, Wernerman J. Whole body protein turnover in critically ill patients with multiple organ failure. Clinical Nutrition. 2015;34(1):95-100.

134. Wischmeyer PE. Are we creating survivors[horizontal ellipsis]or victims in critical care? Delivering targeted nutrition to improve outcomes. Current Opinion in Critical Care. . [Editorial]. 2016.

135. Furst P. Protein and Amino Acid Metabolism: Composition of stresses and non-stressed states. In: Cresci G, editor. Nutrition Support for the Critically Ill Patient. Boca Raton, Florida: Taylor and Francis; 2005. p. 29.

136. Tomlin G. Nutritional Requirements of the Critically Ill. UK: Royal College of Anaesthetists; 2007 [updated 21/05/2007; 
cited 201622 Mar]. Available from:

http://www.frca.co.uk/article.aspx?articleid=100869

137. Macdonald K, Page K, Brown L, Bryden D. Parenteral nutrition in critical care. Continuing Education in Anaesthesia, Critical Care \& Pain. 2013;13(1):1-5.

138. Bier DM, Brosnan JT, Flatt JP, Hanson RW, Heird W, Hellerstein MK, et al. Report of the IDECG Working Group on lower and upper limits of carbohydrate and fat intake. International Dietary Energy Consultative Group. European Journal of Clinical Nutrition. 1999;53 Suppl 1:S177-8.

139. Hodges BaM, J. Nutrition Management in the Intensive Care Unit. Pharmacotherapy Self-Assessment Program [Internet]. 2009 [cited 23 Mar 2016]. Available from:

https://www.accp.com/docs/bookstore/psap/p5b7sample0 3.pdf

140. Leonard R. Enteral and Parenteral Nutrition. In: Bersten A, Soni, N, editor. Oh's Intensive Care Manual: Butterworth Heineman Elsevier; 2009.

141. Casaer MP, Wilmer A, Hermans G, Wouters PJ, Mesotten D, Van den Berghe G. Role of disease and macronutrient dose in the randomized controlled EPaNIC trial: a post hoc analysis. American Journal of Respiratory and Critical Care Medicine. 2013;187(3):247-55. 
142. Preiser JC, Fraipont V, Quilliot D. Trial of the route of early nutritional support in critically ill adults. New England Journal of Medicine. 2015;372(5):487-8.

143. Doig GS, Heighes PT, Simpson F, Sweetman EA, Davies AR. Early enteral nutrition, provided within $24 \mathrm{~h}$ of injury or intensive care unit admission, significantly reduces mortality in critically ill patients: a meta-analysis of randomised controlled trials. Intensive Care Medicine. 2009;35(12):201827.

144. Marik PE, Zaloga GP. Early enteral nutrition in acutely ill patients: a systematic review. Critical Care Medicine. 2001;29(12):2264-70.

145. Shankar B, Daphnee DK, Ramakrishnan N, Venkataraman R. Feasibility, safety, and outcome of very early enteral nutrition in critically ill patients: Results of an observational study. J Crit Care. 2015.

146. Nice-Sugar Study Investigators., Finfer S, Chittock DR, Su SY, Blair D, Foster D, et al. Intensive versus conventional glucose control in critically ill patients. New England Journal of Medicine. 2009;360(13):1283-97.

147. Doig GS, Simpson F, Finfer S, Delaney A, Davies AR, Mitchell I, et al. Effect of evidence-based feeding guidelines on mortality of critically ill adults: a cluster randomized controlled trial. JAMA: Journal of the American Medical Association. 2008;300(23):2731-41. 
148. Passier RH, Davies AR, Ridley E, McClure J, Murphy D,

Scheinkestel CD. Periprocedural cessation of nutrition in the intensive care unit: opportunities for improvement. Intensive Care Medicine. 2013;39(7):1221-6.

149. Cahill NE, Dhaliwal R, Day AG, Jiang X, Heyland DK. Nutrition therapy in the critical care setting: what is "best achievable" practice? An international multicenter observational study. Critical Care Medicine. 2010;38(2):395-401.

150. Caddell KA, Martindale R, McClave SA, Miller K. Can the intestinal dysmotility of critical illness be differentiated from postoperative ileus? Current gastroenterology reports. 2011;13(4):358-67.

151. Kudsk KA. Importance of enteral feeding in maintaining gut integrity. Techniques in Gastrointestinal Endoscopy. 2001;3(1):2 - 8.

152. Kudsk KA. Current aspects of mucosal immunology and its influence by nutrition. American Journal of Surgery. 2002;183(4):390-8.

153. Alverdy J, Zaborina O, Wu L. The impact of stress and nutrition on bacterial-host interactions at the intestinal epithelial surface. Current Opinion in Clinical Nutrition and Metabolic Care. 2005;8(2):205-9.

154. Marik PE, Vasu T, Hirani A, Pachinburavan M. Stress ulcer prophylaxis in the new millennium: a systematic review and meta-analysis. Critical Care Medicine. 2010;38(11):2222-8. 
155. Jabbar A, Chang WK, Dryden GW, McClave SA. Gut immunology and the differential response to feeding and starvation. Nutrition in Clinical Practice. 2003;18(6):461-82.

156. Fukatsu K, Zarzaur BL, Johnson CD, Lundberg AH, Wilcox HG, Kudsk KA. Enteral nutrition prevents remote organ injury and death after a gut ischemic insult. Annals of Surgery. 2001;233(5):660-8.

157. Kudsk KA. Effect of route and type of nutrition on intestinederived inflammatory responses. American Journal of Surgery. 2003;185(1):16-21.

158. Ikeda S, Kudsk KA, Fukatsu K, Johnson CD, Le T, Reese S, et al. Enteral feeding preserves mucosal immunity despite in vivo MAdCAM-1 blockade of lymphocyte homing. Annals of Surgery. 2003;237(5):677-85; discussion 85.

159. Johnson CD, Kudsk KA, Fukatsu K, Renegar KB, Zarzaur BL. Route of nutrition influences generation of antibody-forming cells and initial defense to an active viral infection in the upper respiratory tract. Annals of Surgery. 2003;237(4):56573.

160. Genton L, Kudsk KA, Reese SR, Ikeda S. Enteral feeding preserves gut Th-2 cytokines despite mucosal cellular adhesion molecule- 1 blockade. Journal of Parenteral and Enteral Nutrition 2005;29(1):44-7.

161. Kang W, Gomez FE, Lan J, Sano Y, Ueno C, Kudsk KA. Parenteral nutrition impairs gut-associated lymphoid tissue 
and mucosal immunity by reducing lymphotoxin Beta receptor expression. Annals of Surgery. 2006;244(3):392-9.

162. Bayliss WM, Starling EH. The mechanism of pancreatic secretion. Journal of Physiology. 1902;28(5):325-53.

163. Plummer MP, Chapman MJ, Horowitz M, Deane AM. Incretins and the intensivist: what are they and what does an intensivist need to know about them? Critical Care. 2014;18(2):205.

164. Ford ES, Giles WH, Dietz WH. Prevalence of the metabolic syndrome among US adults: findings from the third National Health and Nutrition Examination Survey. JAMA: Journal of the American Medical Association. 2002;287(3):356-9.

165. Honiden S, McArdle JR. Obesity in the intensive care unit. Clinics in Chest Medicine. 2009;30(3):581-99, x.

166. Hillenbrand A, Knippschild U, Weiss M, Schrezenmeier H, Henne-Bruns D, Huber-Lang M, et al. Sepsis induced changes of adipokines and cytokines - septic patients compared to morbidly obese patients. BMC Surgery. 2010;10:26.

167. Boutagy NE, McMillan RP, Frisard MI, Hulver MW. Metabolic endotoxemia with obesity: Is it real and is it relevant? Biochimie. 2015.

168. Fabbrini E, Magkos F. Hepatic Steatosis as a Marker of Metabolic Dysfunction. Nutrients. 2015;7(6):4995-5019. 
169. Jeevanandam M, Young DH, Schiller WR. Obesity and the metabolic response to severe multiple trauma in man. The Journal of Clinical Investigation. 1991;87(1):262-9.

170. Fain JN, Madan AK, Hiler ML, Cheema P, Bahouth SW. Comparison of the release of adipokines by adipose tissue, adipose tissue matrix, and adipocytes from visceral and subcutaneous abdominal adipose tissues of obese humans. Endocrinology. 2004;145(5):2273-82.

171. Kershaw EE, Flier JS. Adipose tissue as an endocrine organ. Journal of Clinical Endocrinology and Metabolism. 2004;89(6):2548-56.

172. Marques MB, Langouche L. Endocrine, metabolic, and morphologic alterations of adipose tissue during critical illness. Critical Care Medicine. 2013;41(1):317-25.

173. Borel AL, Schwebel C, Planquette B, Vesin A, Garrouste-Orgeas M, Adrie C, et al. Initiation of nutritional support is delayed in critically ill obese patients: a multicenter cohort study. American Journal Clinical Nutrition. 2014;100(3):859-66.

174. Kee AL, Isenring E, Hickman I, Vivanti A. Resting energy expenditure of morbidly obese patients using indirect calorimetry: a systematic review. Obesity Reviews. 2012;13(9):753-65.

175. Australian and New Zealand Intensive Care Research Centre. The Augmented Versus Routine Approach to Giving Energery Trial (TARGET). ClinicalTrials.gov [Internet]. Bethesda (MD): 
National Library of Medicine (US); 2014 [cited 201528 April].

Available from:

https://clinicaltrials.gov/ct2/show/NCT02306746?term=tar get\&rank=13

176. Choban PS, Burge JC, Scales D, Flancbaum L. Hypoenergetic nutrition support in hospitalized obese patients: a simplified method for clinical application. American Journal of Clinical Nutrition. 1997;66(3):546-50.

177. Yerrakalva D, Mullis R, Mant J. The associations of "fatness," "fitness," and physical activity with all-cause mortality in older adults: A systematic review. Obesity (Silver Spring). 2015;23(10):1944-56.

178. Andersen KK, Olsen TS. The obesity paradox in stroke: lower mortality and lower risk of readmission for recurrent stroke in obese stroke patients. International journal of stroke. 2015;10(1):99-104.

179. Konigstein M, Havakuk O, Arbel Y, Finkelstein A, Ben-Assa E, Leshem Rubinow E, et al. The obesity paradox in patients undergoing transcatheter aortic valve implantation. Clinical Cardiology. 2015;38(2):76-81.

180. Littnerova S, Parenica J, Spinar J, Vitovec J, Linhart A, Widimsky $\mathrm{P}$, et al. Positive influence of being overweight/obese on long term survival in patients hospitalised due to acute heart failure. PLoS One. 2015;10(2):e0117142. 
181. Numasawa Y, Kohsaka S, Miyata H, Kawamura A, Noma S, Suzuki M, et al. Impact of body mass index on in-hospital complications in patients undergoing percutaneous coronary intervention in a Japanese real-world multicenter registry. PLoS One. 2015;10(4):e0124399.

182. Wohlfahrt P, Lopez-Jimenez F, Krajcoviechova A, Jozifova M, Mayer 0, Vanek J, et al. The Obesity Paradox and Survivors of Ischemic Stroke. Journal of Stroke and Cerebrovascular Diseases. 2015.

183. Garrouste-Orgeas M, Troche G, Azoulay E, Caubel A, de Lassence A, Cheval C, et al. Body mass index. An additional prognostic factor in ICU patients. Intensive Care Medicine. 2004;30(3):437-43.

184. Corrales-Medina VF, Valayam J, Serpa JA, Rueda AM, Musher DM. The obesity paradox in community-acquired bacterial pneumonia. International Journal of Infectious Diseases. 2011;15(1):e54-7.

185. Hutagalung R, Marques J, Kobylka K, Zeidan M, Kabisch B, Brunkhorst F, et al. The obesity paradox in surgical intensive care unit patients. Intensive Care Medicine. 2011;37(11):1793-9.

186. Arabi YM, Dara SI, Tamim HM, Rishu AH, Bouchama A, Khedr MK, et al. Clinical characteristics, sepsis interventions and outcomes in the obese patients with septic shock: an 
international multicenter cohort study. Critical Care. 2013;17(2):R72.

187. Pickkers P, de Keizer N, Dusseljee J, Weerheijm D, van der Hoeven JG, Peek N. Body mass index is associated with hospital mortality in critically ill patients: an observational cohort study. Critical Care Medicine. 2013;41(8):1878-83.

188. Wacharasint P, Boyd JH, Russell JA, Walley KR. One size does not fit all in severe infection: obesity alters outcome, susceptibility, treatment, and inflammatory response. Critical Care. 2013;17(3):R122.

189. Chalkias A, Xanthos T. The obesity paradox in cardiac arrest patients. International Journal of Cardiology. 2014;171(2):101-2.

190. Utzolino S, Ditzel CM, Baier PK, Hopt UT, Kaffarnik MF. The obesity paradox in surgical intensive care patients with peritonitis. Journal of Critical Care. 2014;29(5):887 e1-5.

191. Sasabuchi Y, Yasunaga H, Matsui H, Lefor AT, Horiguchi H, Fushimi K, et al. The Dose-Response Relationship Between Body Mass Index and Mortality in Subjects Admitted to the ICU With and Without Mechanical Ventilation. Respiratory Care. 2015.

192. Goulenok C, Monchi M, Chiche JD, Mira JP, Dhainaut JF, Cariou A. Influence of overweight on ICU mortality: a prospective study. Chest. 2004;125(4):1441-5. 
193. Frat JP, Gissot V, Ragot S, Desachy A, Runge I, Lebert C, et al. Impact of obesity in mechanically ventilated patients: a prospective study. Intensive Care Medicine. 2008;34(11):1991-8.

194. Dube DS. Influence of overweight on ICU mortality: a prospective study. Chest. 2005;127(2):683; author reply 4.

195. Ferreira I, Stehouwer CD. Obesity paradox or inappropriate study designs? Time for life-course epidemiology. Journal of Hypertension. 2012;30(12):2271-5.

196. Standl E, Erbach M, Schnell O. Defending the con side: obesity paradox does not exist. Diabetes Care. 2013;36 Suppl 2:S2826.

197. Bozorgmanesh M, Arshi B, Sheikholeslami F, Azizi F, Hadaegh F. No Obesity Paradox-BMI Incapable of Adequately Capturing the Relation of Obesity with All-Cause Mortality: An Inception Diabetes Cohort Study. International Journal of Endocrinology. 2014;2014:282089.

198. Robinson WR, Furberg H, Banack HR. Selection bias: a missing factor in the obesity paradox debate. Obesity (Silver Spring). 2014;22(3):625.

199. Banack HR, Kaufman JS. Does selection bias explain the obesity paradox among individuals with cardiovascular disease? Annals of Epidemiology. 2015;25(5):342-9.

200. Dixon JB, Egger GJ, Finkelstein EA, Kral JG, Lambert GW. 'Obesity paradox' misunderstands the biology of optimal 
weight throughout the life cycle. International Journal of Obesity. 2015;39(1):82-4.

201. Paolini JB, Mancini J, Genestal M, Gonzalez H, McKay RE, Samii $\mathrm{K}$, et al. Predictive value of abdominal obesity vs. body mass index for determining risk of intensive care unit mortality. Critical Care Medicine. 2010;38(5):1308-14.

202. Dickerson RN, Kumpf VJ, Rollins CJ, Frankel EH, Kraft MD, Canada TW, et al. Significant publications for pharmacy nutrition support practice in 2013. Hospital Pharmacy. 2014;49(8):717-30.

203. Hanson CW, 3rd, Deutschman CS, Anderson HL, 3rd, Reilly PM, Behringer EC, Schwab CW, et al. Effects of an organized critical care service on outcomes and resource utilization: a cohort study. Critical Care Medicine. 1999;27(2):270-4.

204. Pronovost PJ, Angus DC, Dorman T, Robinson KA, Dremsizov TT, Young TL. Physician staffing patterns and clinical outcomes in critically ill patients: a systematic review. JAMA: Journal of the American Medical Association. 2002;288(17):2151-62.

205. Guidelines CCCNCP. 7.1 Combination Parental Nutrition and Enteral Nutrition. 2015 [cited 20162 March]. Available from: http://www.criticalcarenutrition.com/docs/CPGs\%202015/ 7.1\%202015.pdf 
206. Lev S, Cohen J, Singer P. Indirect calorimetry measurements in the ventilated critically ill patient: facts and controversies-the heat is on. Critical Care Clinics. 2010;26(4):e1-9.

207. Kondrup J, Rasmussen HH, Hamberg O, Stanga Z, Ad Hoc EWG. Nutritional risk screening (NRS 2002): a new method based on an analysis of controlled clinical trials. Clinical Nutrition. 2003;22(3):321-36.

208. Heyland DK, Dhaliwal R, Jiang X, Day AG. Identifying critically ill patients who benefit the most from nutrition therapy: the development and initial validation of a novel risk assessment tool. Critiical Care. 2011;15(6):R268.

209. Kondrup J. Nutritional-risk scoring systems in the intensive care unit. Current Opinion in Clinical Nutrition and Metabolic Care. 2014;17(2):177-82.

210. Rahman A, Hasan RM, Agarwala R, Martin C, Day AG, Heyland DK. Identifying critically-ill patients who will benefit most from nutritional therapy: Further validation of the "modified NUTRIC" nutritional risk assessment tool. Clinical Nutrition. 2015.

211. Hawker F. Design and organisation of intensive care units. In: Bersten A, Soni, N, editor. Oh's Intensive Care Manual. Sixth ed: Butterworth Heinemann Elsevier; 2009.

212. National Health and Medical Research Council. NHMRC Additional Levels of Evidence and Grades for 
Recommendations for Developers of Guidlines. Canberra, Australia.

213. National Health and Medical Research Council. How to Review the Evidence: Systematic Identification and Review of the Scientific Literature. Canberra, Austrlia: Commonwealth Government of Australia; 1999.

214. Aromataris E, Riitano D. Constructing a search strategy and searching for evidence. A guide to the literature search for a systematic review. American Journal of Nursing. $2014 ; 114(5): 49-56$.

215. Higgins J, Green, S. (editors). Cochrane Handbook for Systematic Reviews of Interventions Version 5.1.0 [updated March 2011]. Version 5.1.0 ed: The Cochrane Collaboration; 2011.

216. The Joanna Briggs Institute Joanna Briggs Institute Reviewers' Manual: 2014 edition. Adelaide, SA: The Joanna Briggs Institute; 2014.

217. Secombe P, Harley S, Chapman M, Aromataris E. Feeding the critically ill obese patient: a systematic review protocol. JBI Database Systematic Reviews and Implementation Reports. 2015;13(10):95-109.

218. Angus DC, Carlet J, Brussels Roundtable P. Surviving intensive care: a report from the 2002 Brussels Roundtable. Intensive Care Medicine. 2003;29(3):368-77. 
219. National Health and Hospitals Reform Commission. A Healthier Future For All Australians - Final Report of the National Health and Hospitals Reform Comission - June 2009. Canberra: Commonwealth of Australia; 2009.

220. Dickerson RN, Medling TL, Smith AC, Maish G0, 3rd, Croce MA, Minard G, et al. Hypocaloric, high-protein nutrition therapy in older vs younger critically ill patients with obesity. Journal of Parenteral and Enteral Nutrition. 2013;37(3):34251.

221. Bellomo R, Ronco C, Kellum JA, Mehta RL, Palevsky P. Acute renal failure - definition, outcome measures, animal models, fluid therapy and information technology needs: the Second International Consensus Conference of the Acute Dialysis Quality Initiative (ADQI) Group. Critical Care. 2004;8(4):R204-12.

222. Lee S, Choi M, Kim Y, Lee J, Shin C. Nosocomial infection of malnourished patients in an intensive care unit. Yonsei Medical Journal. 2003;44(2):203-9.

223. Curtis LT. Prevention of hospital-acquired infections: review of non-pharmacological interventions. Journal of Hospital Infection. 2008;69(3):204-19.

224. Andersen SK, Gjedsted J, Christiansen C, Tonnesen E. The roles of insulin and hyperglycemia in sepsis pathogenesis. Journal of Leukocyte Biology. 2004;75(3):413-21. 
225. Turina M, Fry DE, Polk HC, Jr. Acute hyperglycemia and the innate immune system: clinical, cellular, and molecular aspects. Critical Care Medicine. 2005;33(7):1624-33.

226. BMJ Cinical Evidence. What is GRADE? : British Medical Journal; [cited 201620 Mar]. Available from: http://clinicalevidence.bmj.com/x/set/static/ebm/learn/665 $\underline{072 . h t m l}$

227. Guyatt GH, Oxman AD, Vist GE, Kunz R, Falck-Ytter Y, AlonsoCoello P, et al. GRADE: an emerging consensus on rating quality of evidence and strength of recommendations. British Medical Journal. 2008;336(7650):924-6.

228. Genton L, Dupertuis YM, Romand JA, Simonet ML, Jolliet P, Huber 0, et al. Higher calorie prescription improves nutrient delivery during the first 5 days of enteral nutrition. Clinical Nutrition. 2004;23(3):307-15.

229. Charles EJ, Petroze RT, Hranjec T, Metzger R, Rosenberger LH, Swenson B, et al. Hypocaloric versus eucaloric nutrition support and its effect on infection rates in a single-institution surgical ICU. Surgical Infections. 2013;14:S10.

230. Arabi YM, Haddad SH, Aldawood AS, Al-Dorzi HM, Tamim HM, Sakkijha M, et al. Permissive underfeeding versus target enteral feeding in adult critically ill patients (PermiT Trial): a study protocol of a multicenter randomized controlled trial. Trials. 2012;13:191. 
231. NCT01357200. Feeding Trial in the Obese Critical Care Population. 2011.

232. Ulusoy H, Ozkan AR, Kucuk AO, Besir A. The effects of hypocaloric underfeeding in adult ICU patients. Clinical Nutrition. 2014;33:S29.

233. Petros S, Horbach M, Seidel F, Weidhase L. Hypocaloric vs Normocaloric Nutrition in Critically Ill Patients: A Prospective Randomized Pilot Trial. Journal of Parenteral and Enteral Nutrition. 2016;40(2):242-9.

234. Komjathy CM. Aggressive versus traditional enteral nutrition prescription in medical intensive care unit patients [M.S.]. Ann Arbor: Rush University; 2010.

235. Doig GS, Simpson F, Heighes PT, Bellomo R, Chesher D, Caterson ID, et al. Restricted versus continued standard caloric intake during the management of refeeding syndrome in critically ill adults: a randomised, parallel-group, multicentre, single-blind controlled trial. Lancet Respiratory Medicine. 2015;3(12):943-52.

236. Horan TC, Andrus M, Dudeck MA. CDC/NHSN surveillance definition of health care-associated infection and criteria for specific types of infections in the acute care setting. American Journal of Infection Control. 2008;36(5):309-32.

237. Ireton-Jones CS, Turner WW, Jr. Actual or ideal body weight: which should be used to predict energy expenditure? Journal of the American Dietetic Association. 1991;91(2):193-5. 
238. Ireton-Jones CS, Turner WW, Jr., Liepa GU, Baxter CR.

Equations for the estimation of energy expenditures in patients with burns with special reference to ventilatory status. Journal of Burn Care and Rehabilitation. 1992;13(3):330-3.

239. Nielsen N, Wetterslev J, Cronberg T, Erlinge D, Gasche Y, Hassager C, et al. Targeted temperature management at 33 degrees $C$ versus 36 degrees $C$ after cardiac arrest. New England Journal of Medicine. 2013;369(23):2197-206.

240. Arise Investigators., Anzics Clinical Trials Group., Peake SL, Delaney A, Bailey M, Bellomo R, et al. Goal-directed resuscitation for patients with early septic shock. New England Journal of Medicine. 2014;371(16):1496-506.

241. Rivers E, Nguyen B, Havstad S, Ressler J, Muzzin A, Knoblich B, et al. Early goal-directed therapy in the treatment of severe sepsis and septic shock. New England Journal of Medicine. 2001;345(19):1368-77.

242. van den Berghe $G$, Wouters $P$, Weekers F, Verwaest $C$, Bruyninckx F, Schetz M, et al. Intensive insulin therapy in critically ill patients. New England Journal of Medicine. 2001;345(19):1359-67.

243. Bernard SA, Gray TW, Buist MD, Jones BM, Silvester W, Gutteridge G, et al. Treatment of comatose survivors of out-ofhospital cardiac arrest with induced hypothermia. New England Journal of Medicine. 2002;346(8):557-63. 
244. Hypothermia after Cardiac Arrest Study Group. Mild therapeutic hypothermia to improve the neurologic outcome after cardiac arrest. New England Journal of Medicine. 2002;346(8):549-56.

245. Bhonagiri D, Pilcher DV, Bailey MJ. Increased mortality associated with after-hours and weekend admission to the intensive care unit: a retrospective analysis. Medical Journal of Australia. 2011;194(6):287-92.

246. Medlock RM, Pandit JJ. Intravenous anaesthetic agents. Anaesthesia \& Intensive Care Medicine. 2016;17(3):155-62.

247. Lowrey TS, Dunlap AW, Brown RO, Dickerson RN, Kudsk KA. Pharmacologic influence on nutrition support therapy: use of propofol in a patient receiving combined enteral and parenteral nutrition support. Nutrition in Clinical Practice. 1996;11(4):147-9.

248. Uehara M, Plank LD, Hill GL. Components of energy expenditure in patients with severe sepsis and major trauma: a basis for clinical care. Critical Care Medicine. 1999;27(7):1295-302.

249. Kaukonen KM, Bailey M, Suzuki S, Pilcher D, Bellomo R. Mortality related to severe sepsis and septic shock among critically ill patients in Australia and New Zealand, 20002012. JAMA: Journal of the American Medical Association. 2014;311(13):1308-16. 
250. van Heerden PV, Blott JA, Pinder M, Cameron PD, Roberts BL, Brinkworth A, et al. Intensive care unit occupancy after introduction of the emergency department 4-hour discharge rule at a tertiary referral hospital in Western Australia. Critical Care and Resuscitation. 2013;15(4):318-21.

251. Taichman DB, Backus J, Baethge C, Bauchner H, de Leeuw PW, Drazen JM, et al. Sharing Clinical Trial Data--A Proposal from the International Committee of Medical Journal Editors. New England Journal of Medicine. 2016;374(4):384-6.

252. ANZICS Centre for Outcome and Resource Evaluation. Annual Report 2014 - 2015 [Internet]. Melboure: ANZICS; 2016. Available from:

http://www.anzics.com.au/Downloads/ANZICS\%20CORE\%2 0Annual\%20Report\%202015.pdf

253. StatSoft Inc. Statistica (data analysis software system). version 10. www.statsoft.com. 2011. 